\title{
Full-Scale Experiments to Demonstrate Flammability Risk of Residential Upholstered Furniture and Mitigation Using Barrier Fabric
}

Mauro Zammarano Matthew S. Hoehler John Randy Shields Andre L. Thompson Ickchan Kim Isaac T. Leventon Matthew F. Bundy

This publication is available free of charge from:

https://doi.org/10.6028/NIST.TN.2129

National Institute of Standards and Technology U.S. Department of Commerce 
NIST Technical Note 2129

\section{Full-Scale Experiments to Demonstrate Flammability Risk of Residential Upholstered Furniture and Mitigation Using Barrier Fabric}

Mauro Zammarano Matthew S. Hoehler John Randy Shields Andre L. Thompson Ickchan Kim

Isaac T. Leventon Matthew F. Bundy

Fire Research Division Engineering Laboratory

This publication is available free of charge from: https://doi.org/10.6028/NIST.TN.2129

December 2020

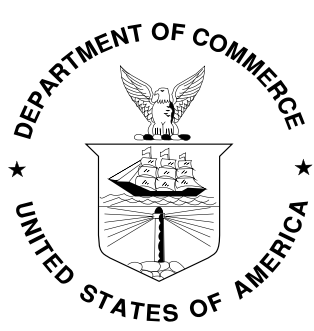

U.S. Department of Commerce Wilbur L. Ross, Jr., Secretary

National Institute of Standards and Technology Walter Copan, NIST Director and Undersecretary of Commerce for Standards and Technology 
This report is dedicated to the memory of our friend and colleague John Randy Shields who sadly passed away while this report was being prepared. 
Certain commercial entities, equipment, or materials may be identified in this document to describe an experimental procedure or concept adequately. Such identification is not intended to imply recommendation or endorsement by the National Institute of Standards and Technology, nor is it intended to imply that the entities, materials, or equipment are necessarily the best available for the purpose.

National Institute of Standards and Technology Technical Note 2129

Natl. Inst. Stand. Technol. Tech. Note 2129, 72 pages (December 2020)

CODEN: NTNOEF

This publication is available free of charge from: https://doi.org/10.6028/NIST.TN.2129 


\begin{abstract}
Residential upholstered furniture (RUF) remains the main contributor to fire growth in fatal home fires despite widespread RUF compliance with smoldering ignition resistance tests (e.g., California Technical Bulletin TB-117-2013), which limit the likelihood of RUF fires initiated by cigarettes. Over $50 \%$ of the RUF fire deaths are due to fires that started due to smoldering ignition (mainly smoking material) but, independently of the ignition source, over two thirds of RUF fire deaths occur when flaming is present and the fire spreads beyond the room of origin. Despite the leading role flaming combustion plays in fire deaths, RUF flaming, fire growth and heat release rate are not currently regulated in the United States.

In this work, we investigated fire growth in a furnished compartment intended to mimic a living room where a couch was the main fuel load. Three TB-117-2013 compliant and commercially available couches were procured. The couches were identical except for the type of cover fabric: two couches used a cotton blend cover and one used a thermoplastic polyester cover. One of the two couches with the cotton blend cover fabric was modified by adding a barrier fabric as a liner between the cover fabric and the couch padding material. The barrier contained only intrinsically fire-resistant fibers without additional, chemically active fire retardants. Three fire tests, one per couch type, were conducted. A throw pillow on the arm of the couch, ignited with a propane flame, acted as an ignition source. Measurements included heat release rate, gas species $\left(\mathrm{O}_{2}, \mathrm{CO}, \mathrm{CO}_{2}\right)$, video, heat flux, and temperature.

The results showed that these cover fabric types on the couch had only a marginal effect on heat release rate, but the addition of the barrier fabric significantly decreased the fire hazard by reducing the fire growth and delaying room flashover from about $6 \mathrm{~min}$ to $21 \mathrm{~min}$. When no barrier fabric was present, flashover conditions could be reached without involvement of the bottom of the couch; whereas, the flow and ignition of liquid pyrolyzates underneath the couch played a key role in the fire growth when barrier fabric was included.
\end{abstract}

\title{
Key words
}

Barrier fabric; Residential upholstered furniture; Compartment fire; Flashover; Flexible polyurethane foam

\section{Acknowledgments}

This work was funded by the National Institute of Standards and Technology (NIST). The authors thank NIST Fire Research Division staff including Anthony Putorti, Ryan FalkensteinSmith, Laurean DeLauter, Anthony Chakalis, Philip Deardorff, Marco Fernandez, Michael Selepak, Artur Chernovsky and Andrew Mundy whose efforts and expertise made these experiments possible. Special thanks are given to the NIST Fire Department for their support for each burn. 


\section{Table of Contents}

1. Introduction ....................................................................................................................................... 1

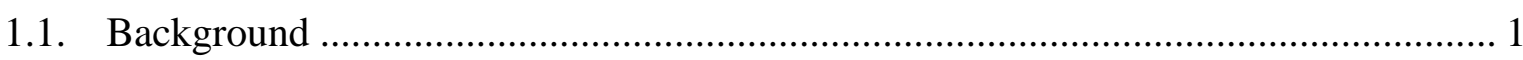

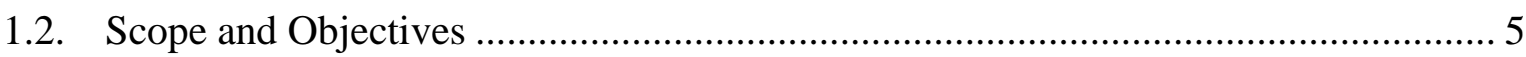

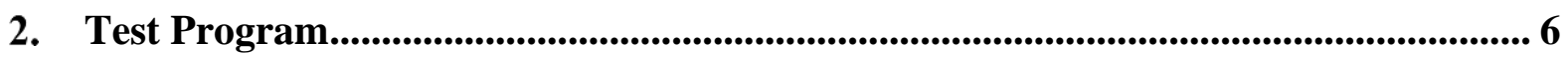

3. Test Setup and Procedure .................................................................................... 7

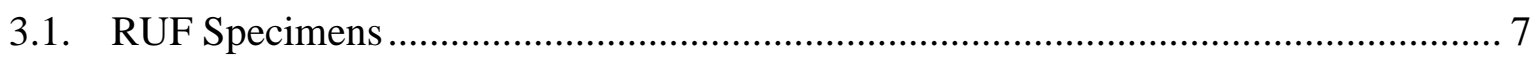

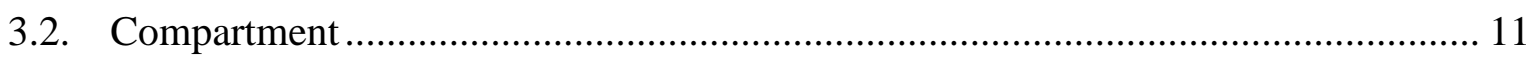

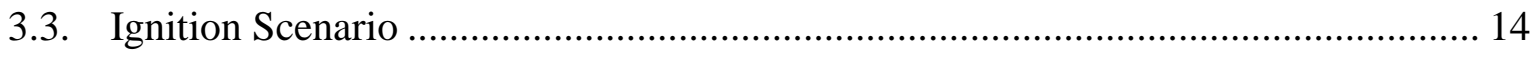

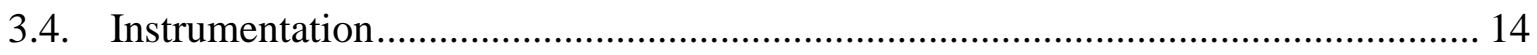

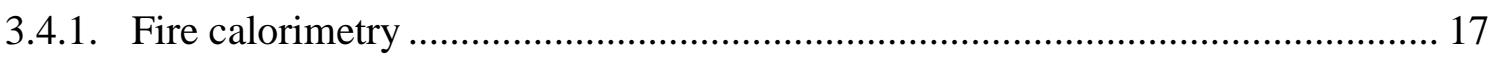

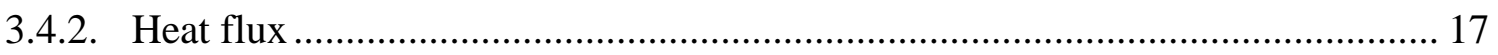

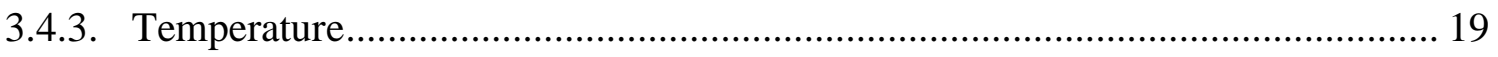

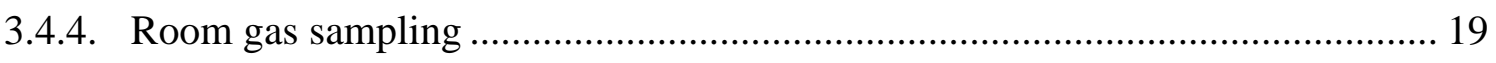

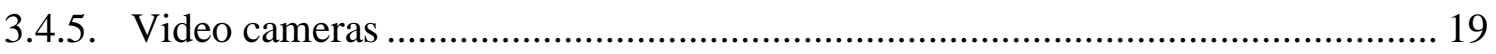

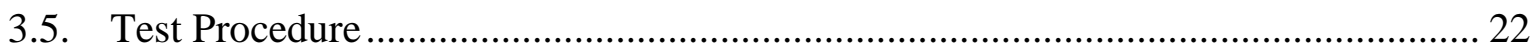

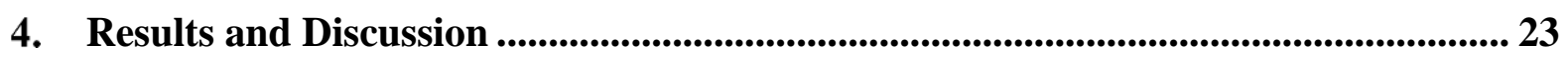

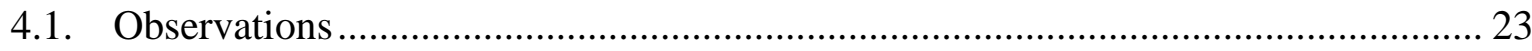

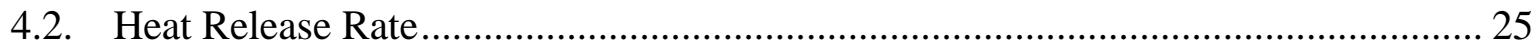

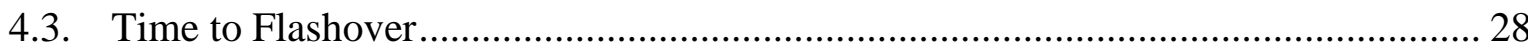

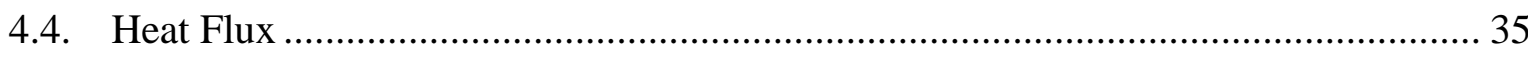

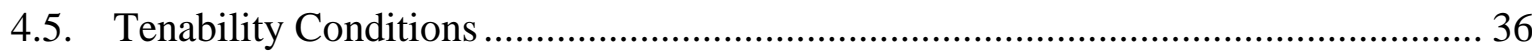

5. Summary and Conclusions ..................................................................................................... 38

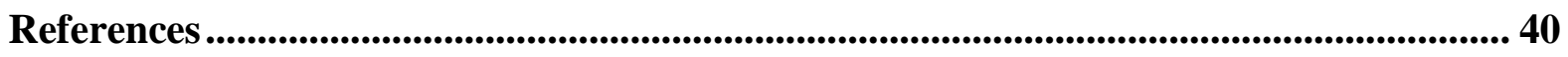

Appendix A: Uncertainty of Measurements......................................................................... 44

Appendix B: Data for Test 1 ................................................................................................. 46

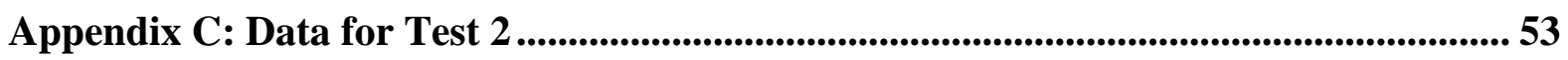

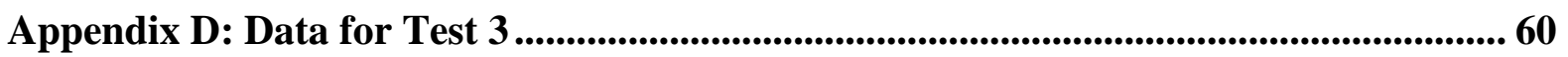




\section{Introduction}

\subsection{Background}

Residential upholstered furniture (RUF) persists as a leading cause of residential fire deaths in the United States (U.S.) [1]. Fire statistics data released by the National Fire Protection Association (NFPA) for the period between 2013 and 2017 indicated that residential fires in which a RUF item was first ignited caused an estimated annual average of $\$ 243$ million in direct property damage, 660 civilian injuries and 450 civilian deaths, i.e., about $17 \%$ of civilian deaths in home fires [2]. The RUF death toll increases to about $22 \%$ (570 civilian deaths) when fires, in which RUF was the primary item contributing to fire growth but not the first item ignited, were also accounted for $[2,3]$.

The most common ignition sources in RUF deadly fires are (1) smoking products, (2) open flame from other item, (3) operating equipment, (4) small open flame and (5) hot or smoldering objects; they account for $45 \%, 21 \%, 12 \%, 10 \%$ and $10 \%$, respectively, of RUF fire deaths [3]. Smoldering ignition sources, i.e., sources (1) and (5), cause a total of about $55 \%$ of the RUF fire deaths; flaming ignition sources, i.e., sources (2) and (4), cause a total of about $31 \%$. Thus, deadly RUF fires are more likely to start with a smoldering source rather than a flaming source. Smoldering poses a severe fire hazard due to the potentially lethal amount of toxic carbon monoxide released and the possible transition from smoldering to flaming [4].

NFPA data indicate that the large majority of RUF fire deaths (about $95 \%$ ) occurred in fires spreading beyond the first item ignited (presumably due to open flames) and about $68 \%$ in fires spreading beyond the room of origin (presumably due to intense flaming leading to flashover) [5]; hence, open flames are most likely present in a deadly RUF fire scenario. This suggests that even if deadly fires are more likely to start with a smoldering source rather than a flaming source, independent of the ignition source, most of the RUF fire deaths occur as a result of flaming, often after transition from smoldering to flaming.

Due to the central role of flaming, a reduction in RUF flammability is expected to have a major impact on residential fires losses. There are two alternative ways to decrease RUF flammability risk: (1) by flame prevention (i.e., reducing the probability that flaming will occur by increasing the flaming or smoldering ignition resistance of the item, and by decreasing the likelihood of smoldering to flaming transition), or (2) by flame mitigation (i.e., limiting the consequences of a burning item by reducing fire growth) [6]. RUF compliance with small-flame ignition tests could at most reduce fire deaths by about $10 \%$ of RUF fire deaths (see above), but could not guarantee fire prevention in ignition scenarios that involve a much larger flame size, like second item ignition and smoldering-to-flaming transition, which largely contribute to the death toll [3]. Ignition resistance with these flame sizes is unlikely, hence, flame mitigation rather than flame prevention appears to be a more robust approach to decrease RUF flammability risk [3].

In the United States, only cigarette smoldering ignition tests have been adopted by the NFPA, the American Society of Testing and Materials (ASTM), the Upholstered Furniture Action Council (UFAC), and the State of California [7-11]. At a Federal level, there is no mandated regulation for RUF fire resistance, and at State level, the only mandatory standard is California Technical Bulletin TB-117-2013. 
In 2019, the U.S. House of Representatives passed a bill (the Safer Occupancy Furniture Flammability Act) to extend TB-117-2013 to the entire United States [3]. To meet the standard, RUF must pass a test of the materials' ability to resist cigarette smoldering ignition; however, there are limited data that relate TB-117-2013 to the smoldering ignition resistance of the upholstered furniture item, and there is evidence to suggest that the standard test can underestimate smoldering in RUF due to a reduction in oxygen supply [12]. Additionally, the standard does not require the RUF to resist flaming ignition nor guarantee a reduced burning rate after ignition such that the fire hazard is mitigated.

Fire retardant chemicals have been used for decades to reduce the propensity for flaming ignition and fire growth after ignition in RUF. However, several States have adopted or are discussing the introduction of regulations (e.g., California AB 2998) that ban the use of most chemical flame retardants in RUF [13]. As a result, the use of chemical flame retardants has been restricted or, in certain applications, completely banned, and the market has been forced to look for non-chemical approaches to improve fire safety worldwide [13-16]. In this regard, barrier fabrics offer a potential solution.

In soft furnishing, padding materials like flexible polyurethane foam and polyester fiber fill are often the main fuel source [17]. Fire barriers are protective layers designed to prevent or delay ignition of this padding material and, therefore, reduce the growth rate and size (heat release rate) of a fire after flaming ignition [18]. A fire barrier is typically a fabric liner placed between the cover fabric and the padding material. Fire barriers can achieve a reduction in fire hazard by (a) limiting heat transfer (e.g., from a flame or an external heat source) to the padding material, thus limiting the rate at which combustible volatiles are generated, and by (b) controlling the rate and location at which combustible volatiles and liquids (produced by melting or thermal degradation of the padding material) are released and able to burn. These two mechanisms of action are physically-based (i.e., no chemical fire retardants are needed) and can be referred to as heat and mass transfer effects, respectively. Fire barriers often rely on inherently fire-resistant materials (e.g., glass, carbon and polysilicic acid/rayon fibers) [19, 20]. Certain inherently fire resistant materials like polysilicic acid combine heat and mass transfer mechanisms to other physical mechanisms of fire retardancy like heat-sink effects (associated with the endothermic decomposition of the material) and dilution effects (associated with the release of non-flammable gases during the decomposition of the material, e.g., water vapor, that decrease the concentration of combustible gases) [21].

Previously, the National Institute of Standards and Technology (NIST) conducted flammability tests of full-scale chair mock-ups exposed to a $18 \mathrm{~kW}$ square burner (Fig. 1) [22] under a furniture calorimeter. The main takeaways from that research are as follows.

- Flash-over conditions can be achieved within 5 min from flaming ignition of TB-1172013 compliant chair mock-ups.

- Barrier fabrics, which do not rely on chemical flame retardants and are compliant with California AB 2998, can significantly reduce the fire hazard of chair mock-ups by decreasing the burning rate and delaying flashover conditions by up to $20 \mathrm{~min}$.

- The failure of the barrier fabric was triggered by the percolation of liquid pyrolyzates through the bottom of the RUF. 
NIST has developed a bench scale test, the Cube Test, which captures this failure mechanism observed in full-scale chair mock-ups (as well, other type of cored composites) [23]. In fact, the Cube test has been designed to mimic mass/heat transfer phenomena through an ideal cross section of the seat cushion, including percolation of liquid pyrolyzates through the bottom of the RUF. Once validated, the Cube Test could be adopted as a standardized bench-scale test, which would minimize the number of full-scale tests needed to assess RUF flammability; this is a key factor in the RUF market, where the almost limitless number of combinations of upholstery materials, shapes and dimensions, make full-scale testing of all items economically infeasible.

One of the goals of this study is to determine if the failure mechanism of barrier fabrics previously observed in the chair mock-up experiment also applies to commercial RUF in furnished compartments, so that the use of the Cube test might be possibly extended to predict the performance of barrier fabric in realistic fire scenarios. 


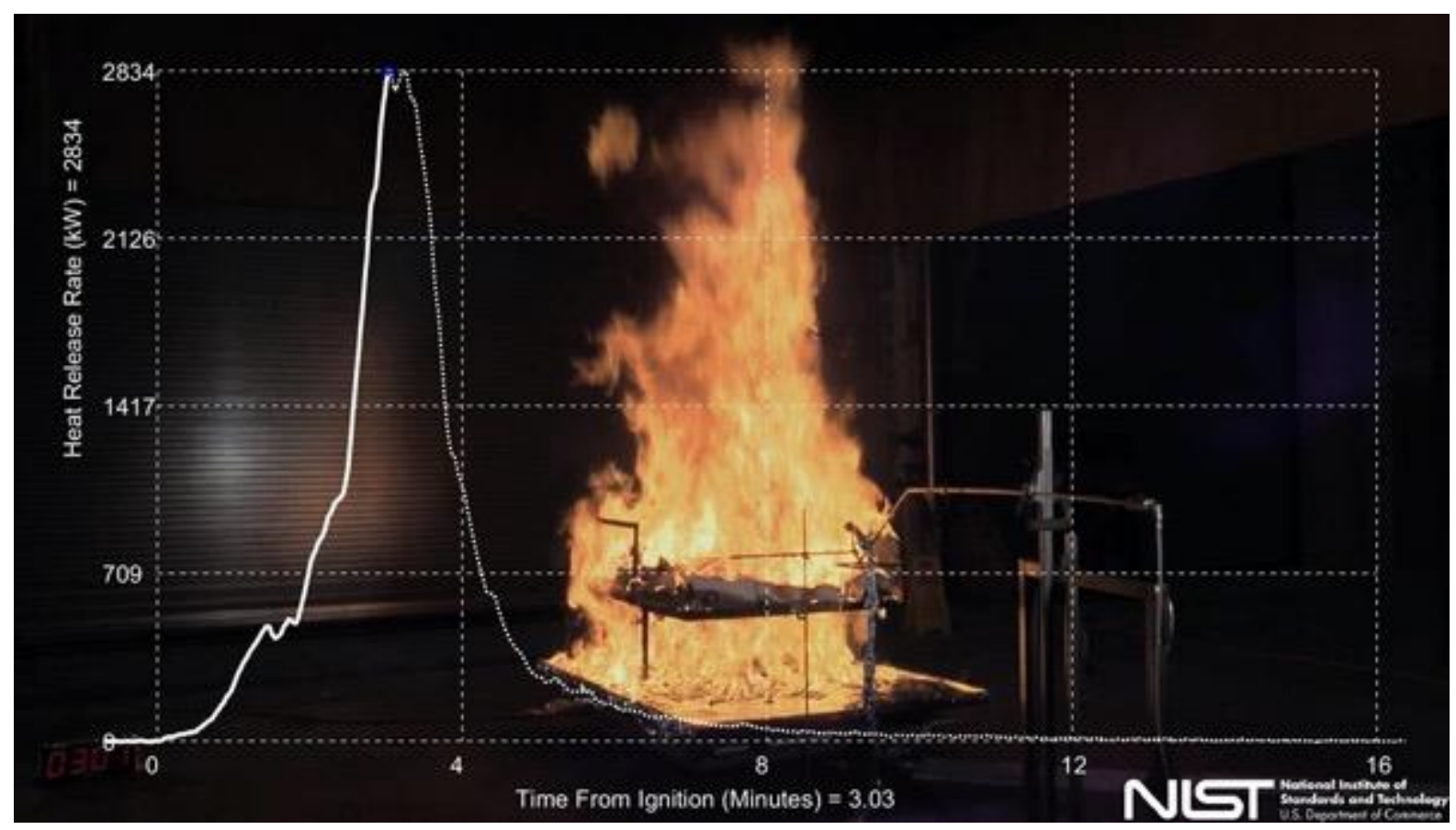

(a)

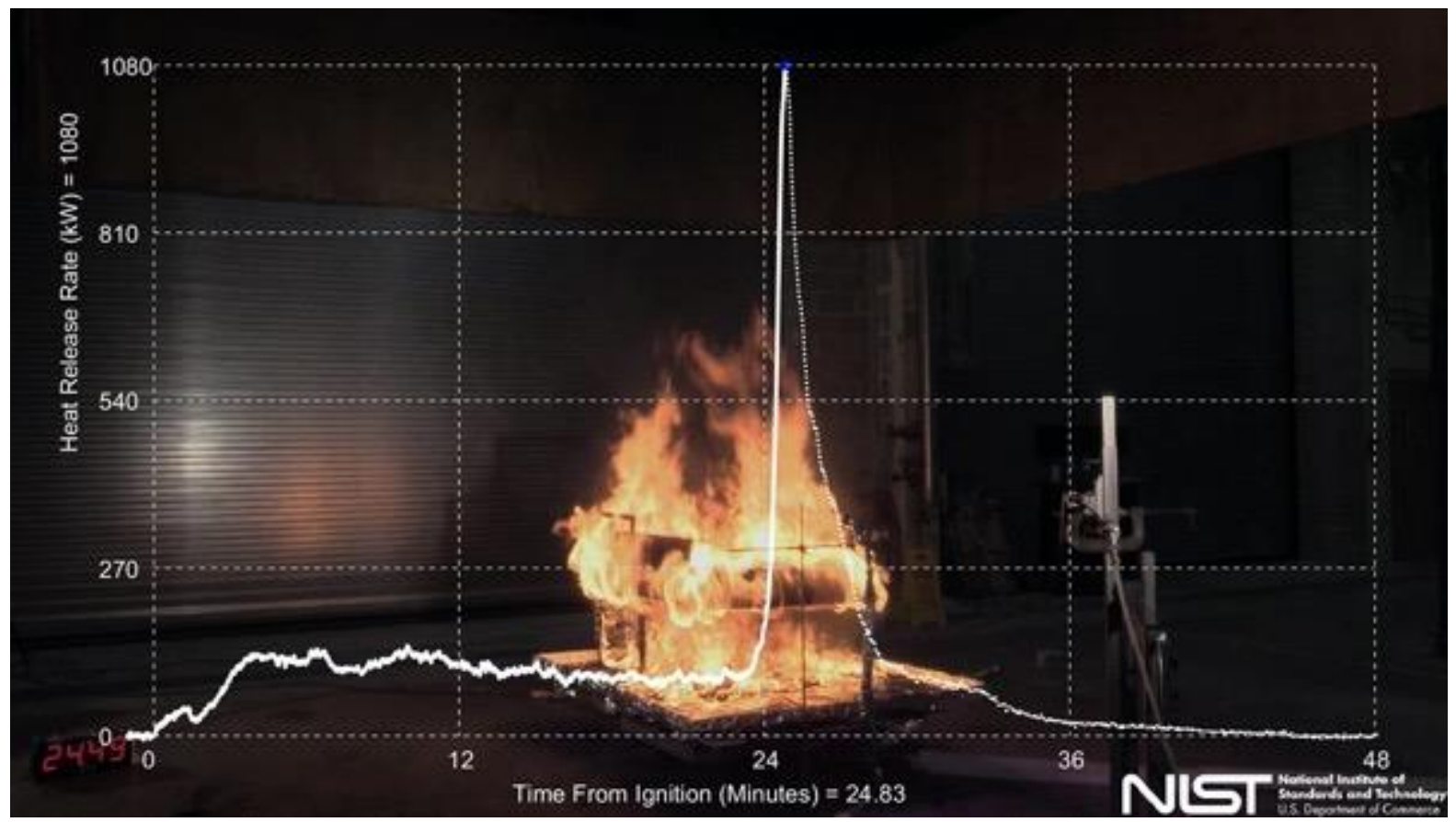

(b)

Fig. 1. Digital images at the time of peak of heat release rate from video of chair mock-ups with: (a) polypropylene covering without barrier fabric, and (b) polypropylene covering with barrier fabric. Data overlay shows the heat release rate for both tests. 


\subsection{Scope and Objectives}

Herein, the best performing barrier fabric identified in the chair mock-up study (barrier fabric B6 [22]) has been used in a commercial couch for full-scale compartment tests in a realistic fire scenario. Each compartment is designed to mimic a typical living room including RUF items, tables, a shelf, decorative items and reading material. The study is not intended to encompass all room fire scenarios; e.g., ventilation, room geometry. Early fire development is typically governed by flame spread over the first objects ignited and will be more generally applicable than fire behavior immediately before and after transition to flashover, which is strongly influenced by the compartment configuration.

The objectives of this study include:

- Quantifying the effect of barrier fabrics on the fire hazard (e.g., tenability conditions, heat release rate, time to flashover and smoke generation) of RUF ignited by a flamingignition source in a realistic living room scenario.

- Show that barrier fabrics, which can remarkably reduce the fire hazard without using chemically active fire retardants, not only exist but are commercially available.

- Determine if the failure mechanism of barrier fabrics previously observed in the chair mock-up experiment also applies to commercial RUF in a realistic scenario [22].

Video content has been generated for each test to promote public awareness about the hazards that RUF items can pose, even when TB-117-2013 compliant, and the potential benefits which barrier fabrics offer without the potential risk associated to the use of certain chemical flame retardants [24-26]. 


\section{Test Program}

Table 1 shows the test matrix for this study. Three full-scale compartment fires were conducted and allowed to continue until complete burnout of furnishings in purpose-built rooms located under the $10 \mathrm{MW}$ exhaust hood at the National Fire Research Laboratory (NFRL) at NIST in Gaithersburg, Maryland (Fig. 2). The geometry and contents of each room was the same except for the investigated item of residential upholstered furniture, i.e., the couch.

Three TB-117-2013 compliant and commercially available couches were procured. The couches were identical except for the type of cover fabric: two couches used a cotton blend cover, and one used a thermoplastic polyester cover. One of the two couches with the cotton blend cover fabric was modified by adding a barrier fabric as a liner between the cover fabric and the padding material. Three fire tests, one per couch type, were conducted.

In Test 1 , the couch with the polyester covering was used. In Test 2 , the cotton blend covering was used in combination with the barrier fabric. In Test 3 , the same cotton blend covering of Test 2 was used without barrier fabric. Additional information about the RUF materials and other items found in the compartment are provided in Section 3.

Table 1. Test matrix.

\begin{tabular}{lll}
\hline Test Name & RUF Description & Test Date \\
\hline Test 1 & Polyester cover fabric & $03 / 10 / 2020$ \\
Test 2 & Cotton blend cover fabric with barrier fabric & $03 / 12 / 2020$ \\
Test 3 & Cotton blend cover fabric & $03 / 16 / 2020$ \\
\hline
\end{tabular}

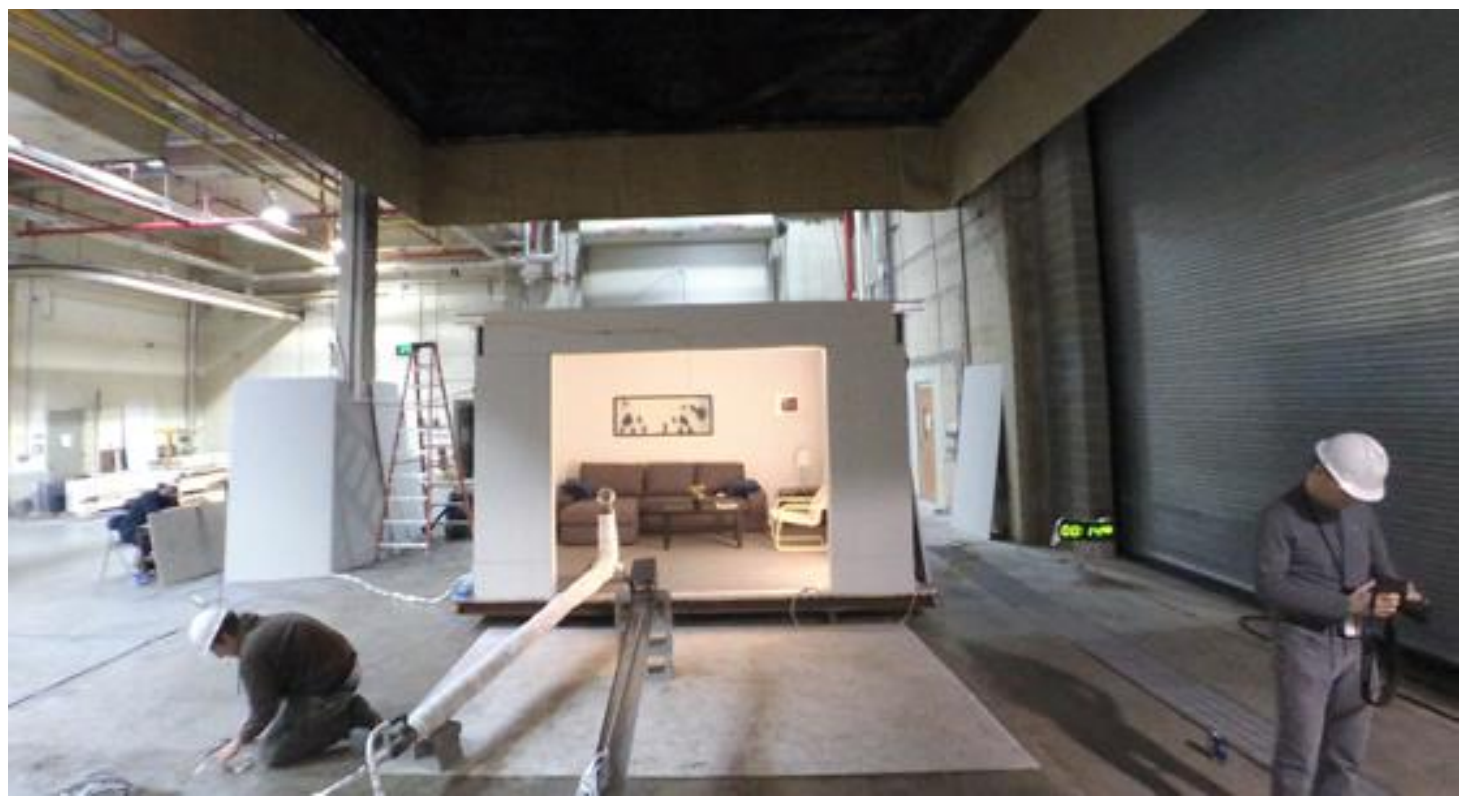

Fig. 2. Photograph of test setup under the $10 \mathrm{MW}$ hood at the National Fire Research Laboratory. 


\section{Test Setup and Procedure}

\subsection{RUF Specimens}

A schematic drawing including the nominal dimensions of the couch is shown in Fig. 3.

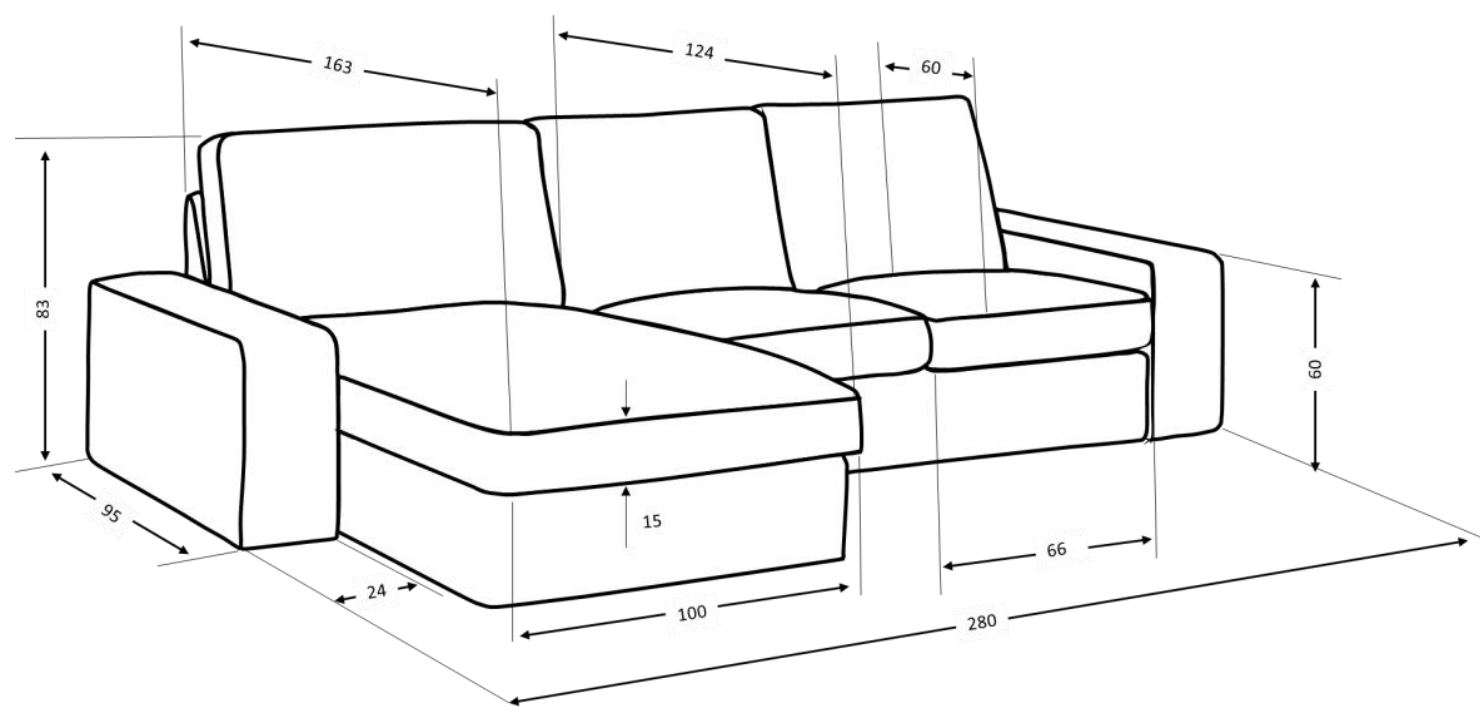

Fig. 3. Schematic drawing of the couch. Dimensions are in $\mathrm{cm}$ with a $\pm 2.5 \mathrm{~cm}$ expanded uncertainty.

All RUF specimens used an identical couch except for the cover fabric and the barrier fabric. The compositions of the cover fabrics and barrier fabric used in each specimen were as follows.

- Test 1 - cover fabric made of polyester fibers and no barrier fabric

- Test 2 - cover fabric made of $55 \%$ by mass cotton, $25 \%$ by mass polyester, $12 \%$ by mass viscose/rayon blend, $8 \%$ by mass linen, and a barrier fabric

- Test 3 - same cover fabric as in Test 2 but no barrier fabric

The cover fabric of Test 2 and 3 will be referred to as "cotton blend". The cover fabrics were labeled according to the California law (SB 1019) as fire retardant free [27]. The barrier fabric was identical to the one labelled barrier B6 in the chair mock-up study [22]. The barrier fabric was a commercial product. According to the manufacturer, the barrier fabric contained only inherently fire-resistent materials without any additional chemical flame retardants; this was confimed by indipendent laboratories analyses, hence, the barrier fabric is expected to comply with SB 1019 [22].

The barrier fabric had a bilayer structure where the layer in contact with the cover fabric was constructed of a nonwoven, needle-punched regenerated cellulose/polysilicic acid hybrid fibers [19] and the other layer, which was in contact with the padding material, was constructed of a woven glass yarn. Polysilicic acid is an inorganic material that decomposes 
endothermically to release water and dilute combustible products generated from the thermal decomposition and combustion of the RUF cover fabric and padding material [19,28]. Also, the incorporation of molecular chains of silicic acids into a cellulose matrix increases char yield during cellulose degradation. The areal density of the barrier fabric was $(275 \pm 4) \mathrm{g} \cdot \mathrm{cm}^{2}$ and the air permeability, measured in accordance to ASTM D737-18 [29], was $(57 \pm 2) \mathrm{cm} / \mathrm{s}^{\text {a }}$ The barrier fabric, as well as the cover fabrics, are expected to comply with the California State Bill (AB 2998), which banned the use of halogenated, organo-phosphorous, organo-nitrogen chemicals and nanofillers in RUF [13].

The couch was a sectional RUF with a chaise section (on the left) and a loveseat section (on the right) that included the following.

- Two small seat cushions with nominal dimensions of $66 \mathrm{~cm}$ (width) $\times 60 \mathrm{~cm}$ (depth) $\times 15 \mathrm{~cm}$ (thickness) for the loveseat section and one large seat cushion with nominal dimensions of $100 \mathrm{~cm}$ (width) $\times 124 \mathrm{~cm}($ depth) $\times 15 \mathrm{~cm}$ (thickness) for the chaise section;

- Two small back cushions with nominal dimensions of $66 \mathrm{~cm}$ (width) $\times 38 \mathrm{~cm}$ (height) $\times 15 \mathrm{~cm}$ (thickness) for the loveseat section and one large back cushion with nominal dimensions of $100 \mathrm{~cm}$ (width) $\times 38 \mathrm{~cm}$ (height) $\times 15 \mathrm{~cm}$ (thickness) for the chaise section;

- Two armrests with nominal dimensions of $24 \mathrm{~cm}$ (width) $\times 95 \mathrm{~cm}$ (depth) $\times$ $60 \mathrm{~cm}$ (height)

- A wood frame that served as structural component and included metal springs as support for the seat cushions.

The padding materials in the cushions were as follows.

- For the seat cushion, a combination of flexible polyurethane foam (FPUF) with a nominal density of approximately $35 \mathrm{~kg} / \mathrm{m}^{3}$ and a viscoelastic polyurethane foam with a nominal density of $50 \mathrm{~kg} / \mathrm{m}^{3}$, and

- For the back cushions, polyester fiber fill

All cushions were covered by a polyester wadding and the cover fabric. A barrier fabric was added as a liner between the cover fabric and the wadding in Test 2 only. Metal staples in place of sewing thread and zippers were used to close the barrier fabric seams because seam failure was previously observed even with fire resistant threads and aluminum zippers [30]. The seams were obtained by overlapping about $50 \mathrm{~mm}$ of barrier fabric on each side of the seam and by folding the overlapped barrier fabrics in half before stapling. All exposed surfaces of the couch except for the bottom were covered by the cover fabric. A picture of the couch frame without cover fabric is shown in Fig. 4.

\footnotetext{
${ }^{a}$ These are Type A uncertainties reported as \pm one experimental standard deviation calculated over three independent observations.
} 


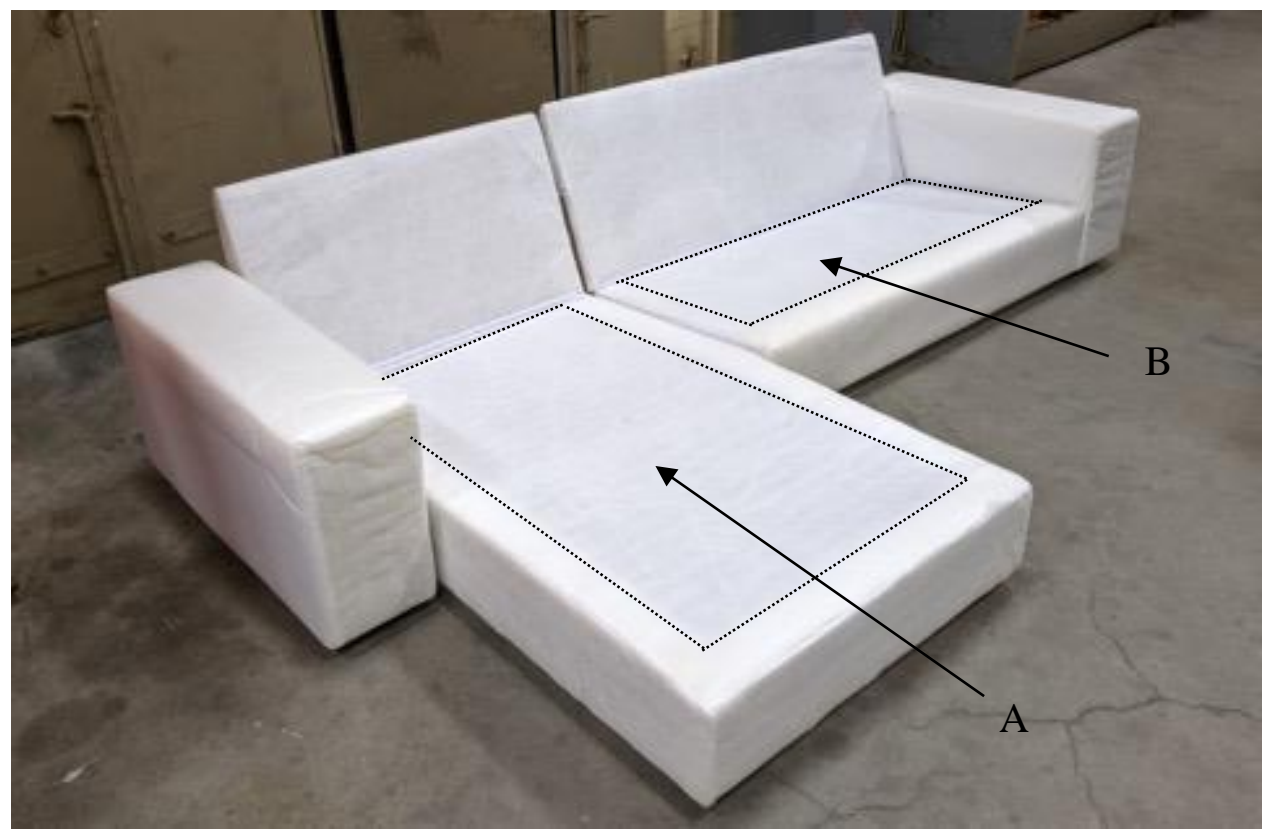

Fig. 4. Picture of the couch frame without cover fabric. In the dotted areas A and B, metal springs where used as a flexible substrate under the wadding fabric. Polyester wadding fabric fully covered the top and sides of the frame.

The frame was mainly made of wood (solid wood, fiberboard, plywood and particleboard), and few metal components such as reinforcing metal bars under the seating areas and flexible metal springs that acted as a flexible support (see the dotted areas A and B in Fig. 4). The top and sides of the frame were covered by a polyester wadding fabric. Underneath the polyester wadding, flexible polyurethane foam (about $13 \mathrm{~mm}$ thick) was used to cover and pad the solid wood panels located on all exposed surfaces of the couch, except areas A and B (where metal springs were present), and the back of the couch.

This padding polyurethane foam in the frame was covered by the barrier fabric in the RUF specimen of Test 2 as shown in Fig. 5. The barrier fabric was kept in place over the wood panels by metal staples which were applied using a staple gun. The mass of the main components in the RUF specimen (i.e., flexible polyurethane foam, fiber fill, cover fabric, barrier fabric and frame) and total mass of the RUF specimens are reported in Table 2. The flexible polyurethane foam mass reported in Table 2 is the mass of the foam in the cushions and does not include the foam mass in the frame, which was estimated to be about $0.1 \mathrm{~kg}$ (based on a rough measurement of flexible polyurethane foam density and volume). 


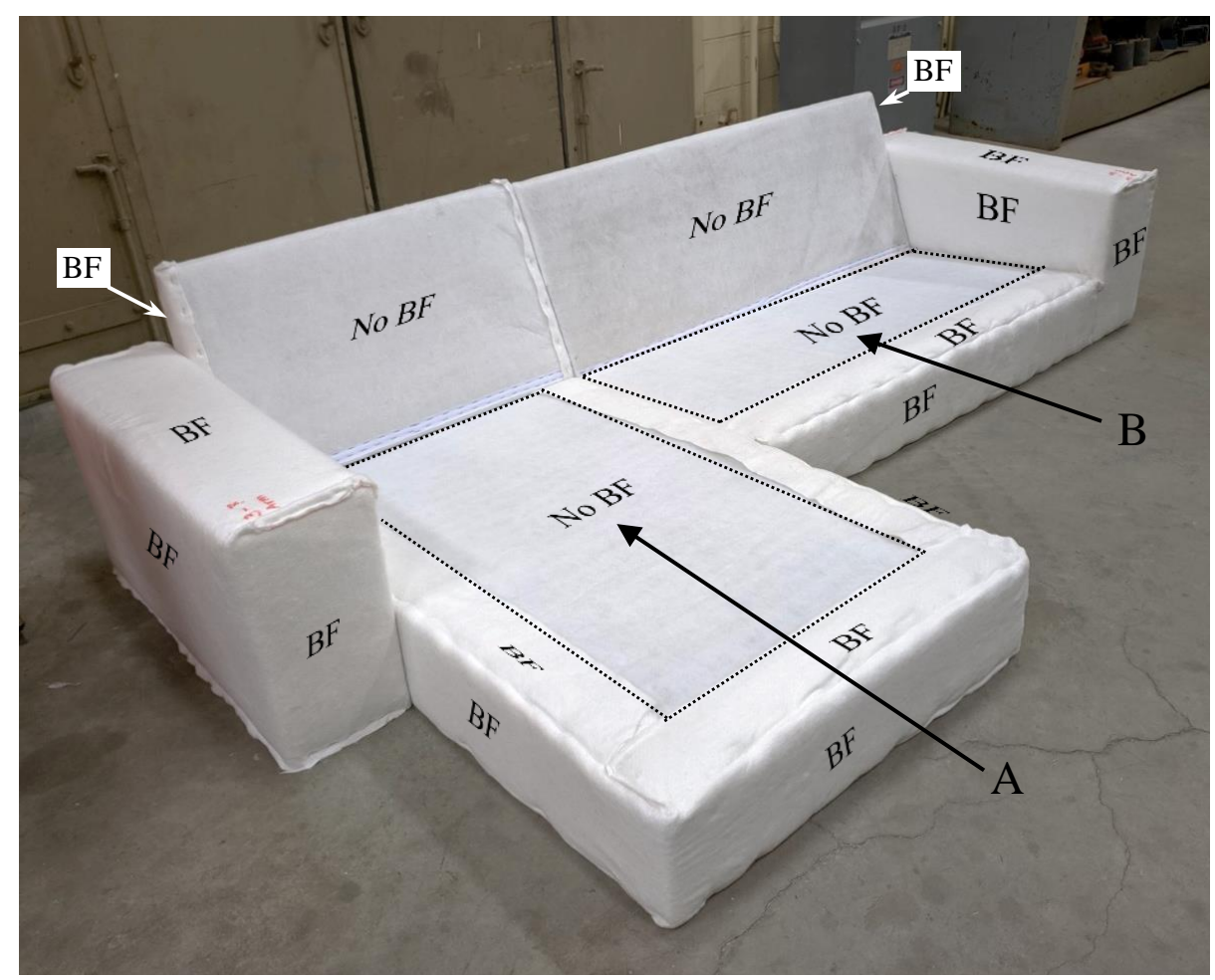

Fig. 5. Picture of the couch frame used in Test 2 showing the areas covered by barrier fabric (BF) and the areas not covered by barrier fabric (No BF). In the dotted areas A and B metal springs were used under the wadding fabric as a supporting flexible substrate. The back of the couch was not protected by the barrier fabric.

Table 2. Mass of the main components used for the construction of the RUF specimens.

\begin{tabular}{lccc}
\hline & Test 1 & Test 2 & Test 3 \\
\hline FPUF* $(\mathrm{kg})$ & 16.4 & 15.9 & 16.3 \\
Fiber fill $(\mathrm{kg})$ & 7.1 & 7.1 & 7.2 \\
Cover fabric $(\mathrm{kg})$ & 6.7 & 6.3 & 6.3 \\
Barrier fabric $(\mathrm{kg})$ & 0 & 4.1 & 0 \\
Frame $(\mathrm{kg})$ & 74.4 & 74.4 & 74.4 \\
\hline Total $(\mathrm{kg})$ & 121.0 & 123.6 & 120.5
\end{tabular}

*Flexible polyurethane foam (FPUF) mass of the cushions only; not including the FPUF mass in the frame, which was estimated to be about $0.1 \mathrm{~kg}$. The manufacturer's stated accuracy of the scale was $\pm 0.02 \mathrm{~kg}$. 


\subsection{Compartment}

Each compartment was constructed to mimic a typical living room. The room's nominal dimensions were $3.7 \mathrm{~m}$ by $3.7 \mathrm{~m}$ with a $2.4 \mathrm{~m}$ ceiling height. A $2.4 \mathrm{~m}$ wide by $2.1 \mathrm{~m}$ tall vertical opening was created in one wall, centered in the front of the room. This provided an opening factor of $0.14 \mathrm{~m}^{1 / 2}$; defined as $A_{O} \sqrt{H_{O}} / A_{t}$, where $A_{O}$ and $H_{O}$ are the area $\left(\mathrm{m}^{2}\right)$ and height $(\mathrm{m})$ of the opening and $A_{t}$ is the total area $\left(\mathrm{m}^{2}\right)$ of all compartment interior boundary surfaces. The walls and ceiling of the room were lined with two layers of $16 \mathrm{~mm}$ thick Type $\mathrm{X}$ gypsum board and the floor, made of the same gypsum board covered with cement board, was lined with a carpet. As an example, Fig. 6 shows a picture of the compartment used for Test 1.

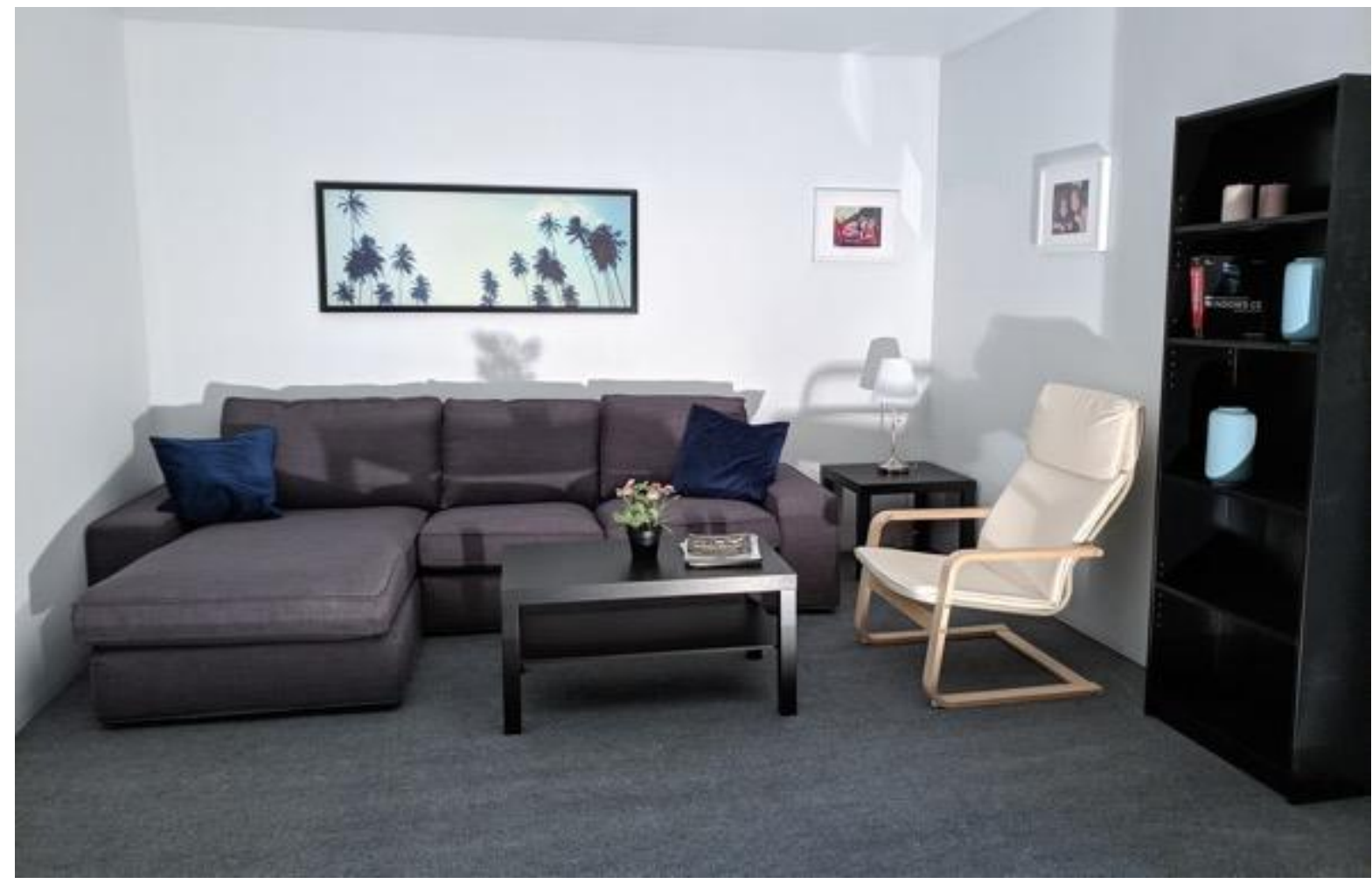

Fig. 6. Picture of the furnished compartment for Test 1.

Each compartment was furnished with one of the three couches (RUF specimens) described in the previous section, and the additional items listed in Table 3. The compartment layout is shown in Fig. 7; small decorative items are not shown in this schematic. As shown in Fig. 6, the artificial plant and magazines were placed on the coffee table, the table lamp was centered over the side table, and the three candles, two vases and one book were placed on the bookshelf. Framed pictures were hung on the walls. 
Table 3. List of the items used to furnish the compartment in addition to the couch, with respective dimensions, composition and mass.

\begin{tabular}{|c|c|c|c|c|c|}
\hline Item & $\begin{array}{l}\text { Nominal } \\
\text { dimensions } \\
\left(\mathrm{cm}^{3}\right)\end{array}$ & Composition & $\begin{array}{l}\text { Mass } \\
(\mathrm{kg})\end{array}$ & Qty ${ }^{B}$ & $\begin{array}{l}\text { Total } \\
\text { Mass } \\
(\mathrm{kg})\end{array}$ \\
\hline Chair & $67 \times 85 \times 96$ & $\begin{array}{l}\text { Polyurethane, polyethylene, } \\
\text { cotton, polyester, birch, steel }\end{array}$ & 7.8 & 1 & 7.8 \\
\hline Coffee table & $90 \times 55 \times 45$ & $\begin{array}{l}\text { Particleboard, paper, fiberboard, } \\
\text { acrylic paint, melamine foil }\end{array}$ & 8.9 & 1 & 8.9 \\
\hline Side table & $55 \times 55 \times 45$ & $\begin{array}{l}\text { Particleboard, paper, fiberboard, } \\
\text { acrylic paint, melamine foil }\end{array}$ & 4.0 & 1 & 4.0 \\
\hline Bookcase & $60 \times 24 \times 180$ & $\begin{array}{l}\text { Particleboard, paper, fiberboard, } \\
\text { acrylic paint, melamine foil }\end{array}$ & 19.7 & 1 & 19.7 \\
\hline Table lamp & $24 \times 24 \times 23$ & Polyester, steel & 1.4 & 1 & 1.4 \\
\hline $\begin{array}{l}\text { Framed } \\
\text { picture } 1\end{array}$ & $43 \times 32 \times 4$ & Fiberboard, polystyrene, paper & 0.9 & 2 & 1.8 \\
\hline $\begin{array}{l}\text { Framed } \\
\text { picture } 2\end{array}$ & $140 \times 56 \times 5$ & Aluminum, paper & 1.6 & 1 & 1.6 \\
\hline $\begin{array}{l}\text { Throw } \\
\text { pillow }\end{array}$ & $50 \times 50 \times 21$ & Polyester & 0.5 & 2 & 1.0 \\
\hline $\begin{array}{l}\text { Synthetic } \\
\text { plant }\end{array}$ & $12 \times 25 \times 25$ & $\begin{array}{l}\text { Polyethylene, polyester, } \\
\text { polypropylene }\end{array}$ & 0.3 & 1 & 0.3 \\
\hline Candles & $10 \times 7 \times 7$ & Paraffin/vegetable wax & 0.3 & 3 & 0.8 \\
\hline Vase & $22 \times 12 \times 12$ & Stoneware & 1.0 & 2 & 2.0 \\
\hline Magazine & $28 \times 22 \times 0.3$ & Paper & 0.1 & 4 & 0.6 \\
\hline Book & $19 \times 23 \times 4$ & Paper & 1.6 & 1 & 1.6 \\
\hline Carpet & $365 \times 365 \times 1$ & Polyester & 6.3 & 1 & 6.3 \\
\hline
\end{tabular}

A Mass data provided by the manufacturer.

${ }^{B}$ Quantity. 


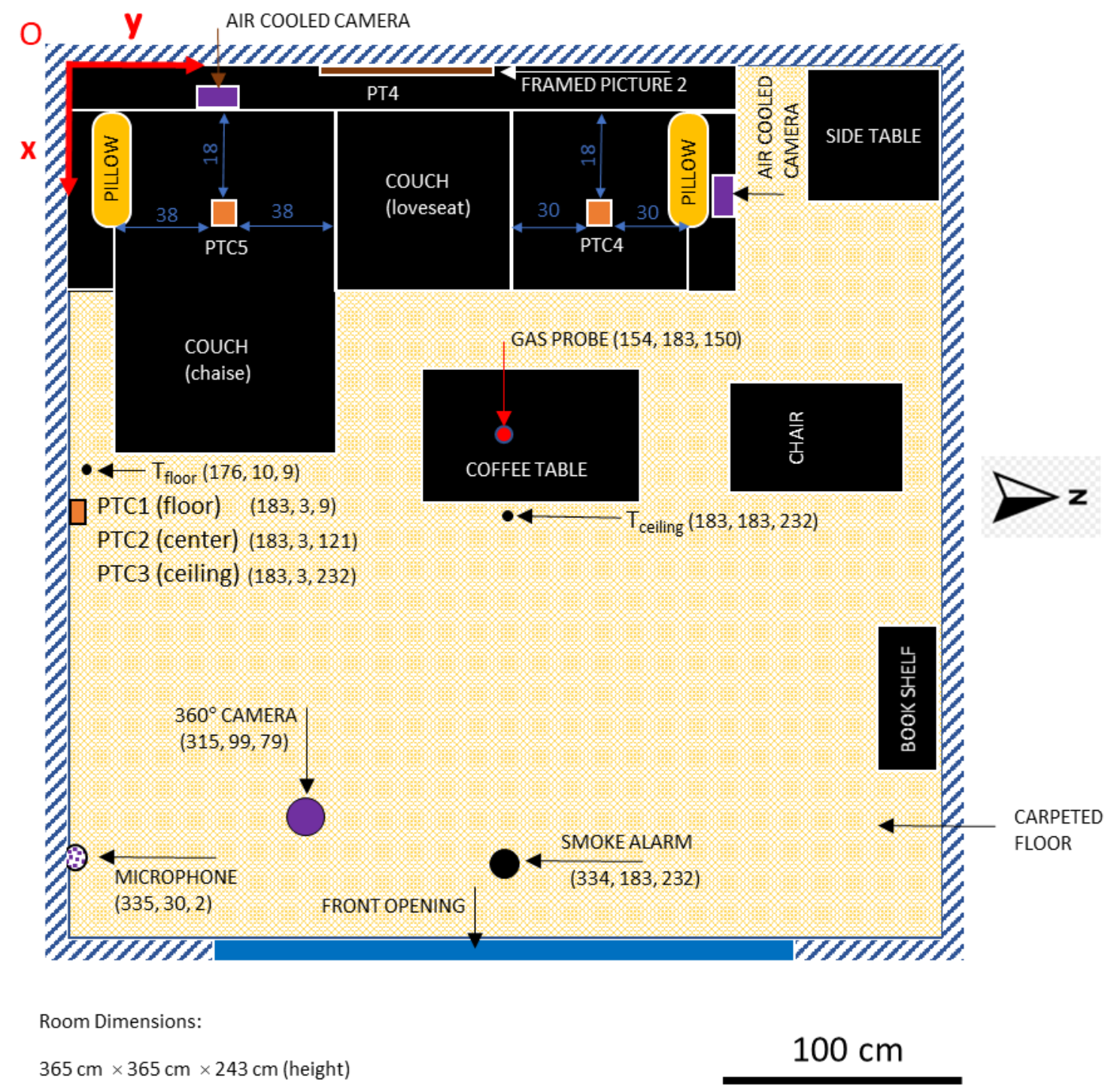

All dimensions in $\mathrm{cm}$

Expanded uncertainty $\pm 2.5 \mathrm{~cm}$

Water Cooled Camera

$(470,142,69)$

Fig. 7. Layout of the compartment showing: (1) the couch with the chaise section on the left and the loveseat section on the right; (2) additional furnishing items (bookshelf, coffee table, chair, side table, throw pillows, picture frame), and; (3) instrumentation including microphone, smoke alarm, cameras, thermocouples (Tceiling, Tfloor) and plate thermocouples (PTC1 to PTC5). Dimensions and positions are in $\mathrm{cm}$ with $\mathrm{a} \pm 2.5 \mathrm{~cm}$ expanded uncertainty. 


\subsection{Ignition Scenario}

Throw pillows are expected to act as significant ignition points and fire vectors in low flammability RUF items. This has been previously reported for low flammability mattresses [17].

At the start of each test, the throw pillow on the right arm of the couch was ignited by an approximately $3 \mathrm{~cm}$ long propane diffusion flame applied under the center of the pillow as shown in Fig. 8a. The propane flame was removed when the combustion of the cushion appeared to be sustained after about (25 to 30) s of flame impingement. The time at which the propane flame was removed was selected as test start $(t=0 \mathrm{~s})$. In this ignition scenario, the throw pillow acted as the first item ignited and the couch as the second item ignited.

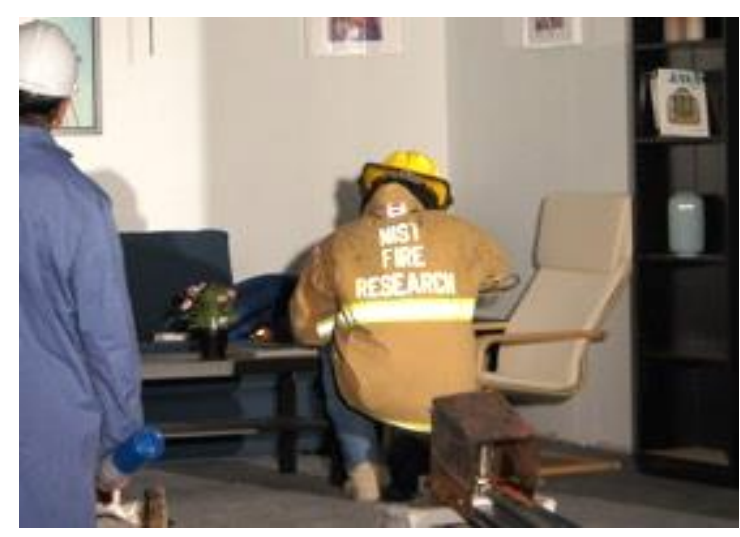

(a)

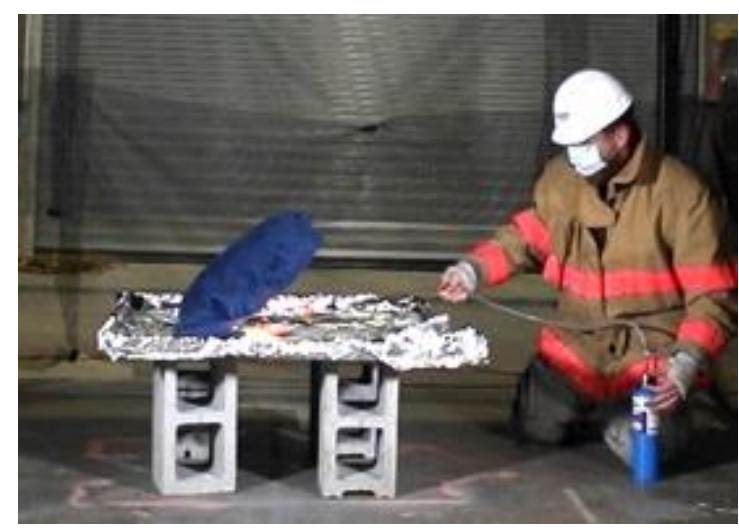

(b)

Fig. 8. Photographs showing the ignition of the throw pillow: (a) in the furnished compartment, and (b) without additional items.

To characterize the intensity of the ignition source to which the couch was exposed, the heat release rate of the throw pillow alone was measured in separate experiments where the pillow was the only burning item. In these tests, the throw pillow was supported by a metal wire frame at an angle of roughly $30^{\circ}$ with the floor (see Fig. 8b), which was intended to mimic the orientation of the throw pillow on the sofa at the time of ignition. Ignition was achieved using the same pilot flame size and impingement location adopted in the furnished room tests. Impingement time was about (11 to 17 ) s. Tests were run under a $0.5 \mathrm{MW}$ capacity open calorimeter with an air flow of about $2 \mathrm{~kg} / \mathrm{s}$. Two test repeats were conducted. The mass of the throw pillows varied between $463 \mathrm{~g}$ (Throw pillow 1) and $496 \mathrm{~g}$ (Throw pillow 2).

\subsection{Instrumentation}

The instrumentation used in these experiments is summarized below and details are provided in the subsequent subsections.

- Heat Release Rate (HRR) was determined using oxygen consumption calorimetry. 
- Plate thermocouples were used to calculate the incident heat flux to the compartment walls (PTC1 to PTC3) and couch (PTC4 and PTC5) with bare-bead thermocouples (PTCgas1 to PTCgas5) providing the gas temperature near each plate thermocouple.

- Thermocouples measured gas temperature near the compartment ceiling and floor ( $\mathrm{T}_{\text {ceiling }}$ and $\mathrm{T}_{\text {floor }}$, respectively) and in proximity to the wall-mounted microphone and the outflow water cooling the $360^{\circ}$ camera ( $\mathrm{T}_{\text {mic }}$ and $\left.\mathrm{T}_{\mathrm{bob}}\right)$.

- $\mathrm{O}_{2}, \mathrm{CO}_{2}, \mathrm{CO}$ sensors (O2_room, CO2_room, CO_room) measured gas species concentrations from the probe in the room.

- Video cameras.

- A photoelectric smoke detector was located on the ceiling along the centerline of the compartment, approximately $30.5 \mathrm{~cm}$ from the opening.

Fig. 7 shows the positions of the sensors in Cartesian coordinates $(x, y, z)$, where the origin $O$ is in the south-east corner of the room and $z$ measures the distance up from the compartment floor. Fig. 9 and Fig. 10 show a photograph and an equirectangular view, respectively, of the compartment before testing.

Probes to sample per- and poly-fluoroalkyl substances (PFAS) and hydrogen cyanide (HCN) were also used; however, no results were obtained for $\mathrm{HCN}$ measurements, due to problems encountered with sampling and post-test analysis. PFAS evolution data will be discussed in a separate publication.

All measurements collected in the compartment during the experiments were digitized using a National Instruments (NI) cDAQ-9184 data acquisition (DAQ) chassis populated with NI9213 I/O-Modules for thermocouples and NI-9215 modules for sensors with voltage outputs. An in-house software developed in LabVIEW ${ }^{\mathrm{TM}}$ called MIDAS (Modular In-situ Data Acquisition System) was used to allocate channels and control the data acquisition. Each channel was sampled at a rate of $90 \mathrm{~Hz}$ and mean values were recorded at a rate of $1 \mathrm{~Hz}$. The NI-9213 modules have a typical gain error $0.04 \%$ (percentage of voltage reading) and $0.017 \mathrm{mV}$ typical offset error under the operating conditions in these experiments. The NI9215 modules have a typical gain error $0.02 \%$ (percentage of voltage reading) and $0.14 \mathrm{~V}$ typical offset error (or $0.014 \%$ of range) under the operating conditions in these experiments. The resulting uncertainties from the DAQ are included implicitly in the uncertainty budgets provided in the Appendices which includes the entire measurement chain. The hardware configuration including channel description, and sensor name, type, manufacturer and model, is shown in Table 4. Heat Release Rate was determined using the NFRL's 10 MW large-scale oxygen consumption calorimeter.

Where expanded uncertainty is reported, a coverage factor of 2 corresponding to an approximately $95 \%$ confidence interval is used. Details about measurement uncertainties are provided in the Appendices. 
Table 4. Hardware configuration.

\begin{tabular}{|c|c|c|c|c|c|}
\hline Channel Description & Name/ID & Type / Range & $\begin{array}{c}\text { Scaled } \\
\text { Units }\end{array}$ & Manufacturer & Model Number \\
\hline Plate Thermocouple on wall low & PTC1 & Thermocouple & ${ }^{\circ} \mathrm{C}$ & Omega.com & GG-K-24-SLE \\
\hline Plate Thermocouple on wall mid & PTC2 & Thermocouple & ${ }^{\circ} \mathrm{C}$ & Omega.com & GG-K-24-SLE \\
\hline Plate Thermocouple on wall high & PTC3 & Thermocouple & ${ }^{\circ} \mathrm{C}$ & Omega.com & GG-K-24-SLE \\
\hline Plate Thermocouple on couch & PTC4 & Thermocouple & ${ }^{\circ} \mathrm{C}$ & Omega.com & GG-K-24-SLE \\
\hline Plate Thermocouple on couch & PTC5 & Thermocouple & ${ }^{\circ} \mathrm{C}$ & Omega.com & GG-K-24-SLE \\
\hline Plate Thermocouple gas temperature & PTCgas 1 & Thermocouple & ${ }^{\circ} \mathrm{C}$ & Omega.com & GG-K-24-SLE \\
\hline Plate Thermocouple gas temperature & PTCgas 2 & Thermocouple & ${ }^{\circ} \mathrm{C}$ & Omega.com & GG-K-24-SLE \\
\hline Plate Thermocouple gas temperature & PTCgas 3 & Thermocouple & ${ }^{\circ} \mathrm{C}$ & Omega.com & GG-K-24-SLE \\
\hline Plate Thermocouple gas temperature & PTCgas 4 & Thermocouple & ${ }^{\circ} \mathrm{C}$ & Omega.com & GG-K-24-SLE \\
\hline Plate Thermocouple gas temperature & \begin{tabular}{|l|} 
PTCgas 5 \\
\end{tabular} & Thermocouple & ${ }^{\circ} \mathrm{C}$ & Omega.com & GG-K-24-SLE \\
\hline Sheathed thermocouple on upper layer & Tceiling & Thermocouple & ${ }^{\circ} \mathrm{C}$ & Omega.com & KMQXL-125 \\
\hline Sheathed thermocouple on near floor & Tfloor & Thermocouple & ${ }^{\circ} \mathrm{C}$ & Omega.com & KMQXL-125 \\
\hline Wall microphone tc & Tmic & Thermocouple & ${ }^{\circ} \mathrm{C}$ & Omega.com & GG-K-24-SLE \\
\hline Water outflow temperature on $\mathrm{BOB}$ & Tbob & Thermocouple & ${ }^{\circ} \mathrm{C}$ & Omega.com & GG-K-24-SLE \\
\hline Mass Flow Controller for PFAS sample & MFC_PFAS & $\pm 10 \mathrm{~V}$ & $\mathrm{~V}$ & Alicat & N/A \\
\hline Portable Gas Rack O2 & O2_room & $\pm 10 \mathrm{~V}$ & $\%$ & CAI & 600 series \\
\hline Portable Gas Rack CO2 & CO2_room & $\pm 10 \mathrm{~V}$ & $\%$ & CAI & 600 series \\
\hline Portable Gas Rack CO & CO_room & $\pm 10 \mathrm{~V}$ & $\%$ & CAI & 600 series \\
\hline Portable Gas Rack Dew point & DP_room & $\pm 10 \mathrm{~V}$ & $\mathrm{C}$ & vaisala & DPT242 \\
\hline Mass Flow Controller 1 for $\mathrm{HCN}$ roof duct sample & MFC_HCN1 & N/A & SLPM & Alicat & N/A \\
\hline Mass Flow Controller 2 for $\mathrm{HCN}$ roof duct sa & MFC_HCN2 & N/A & SLPM & Alicat & N/A \\
\hline
\end{tabular}

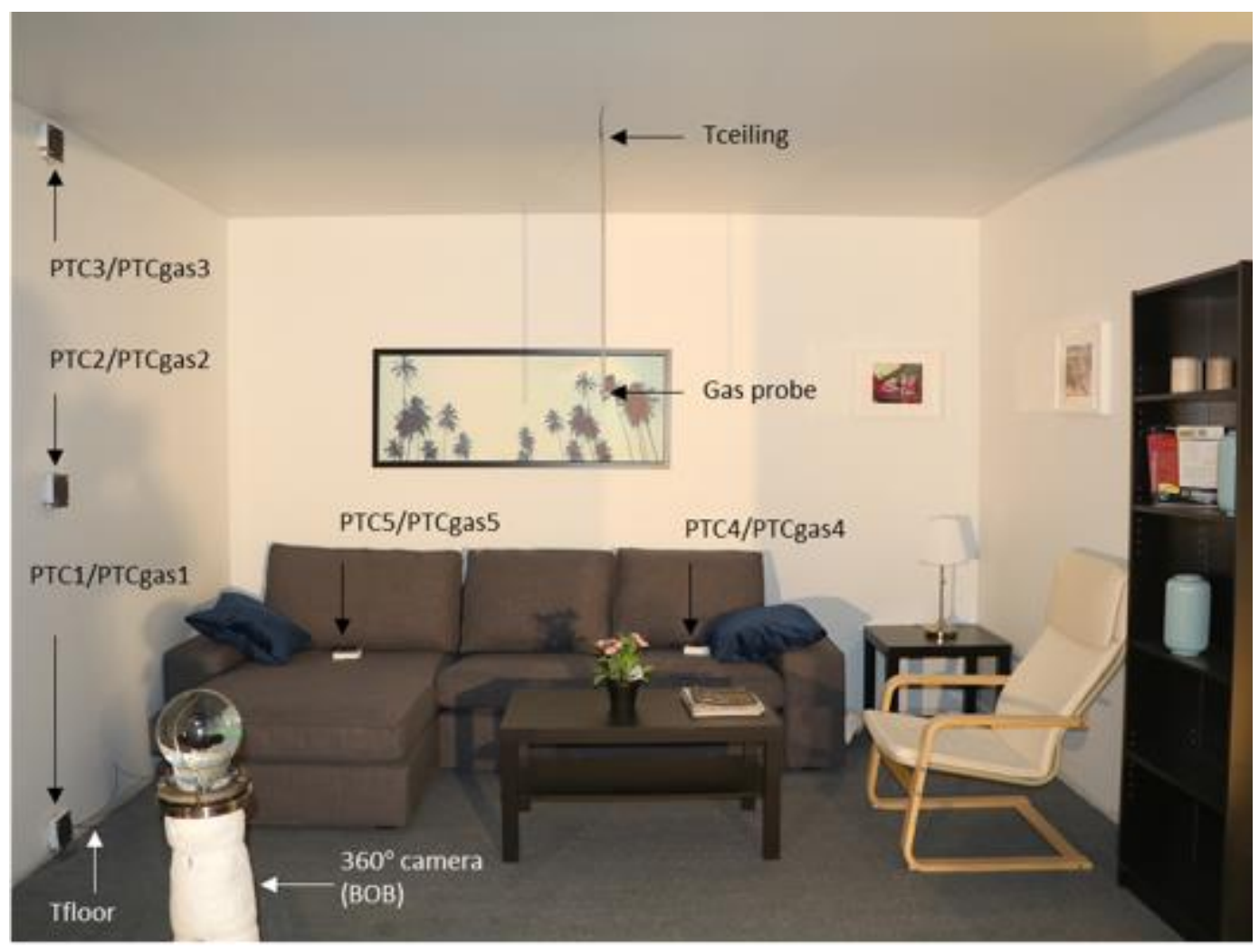

Fig. 9. Photograph of the compartment indicating the position of the plate thermocouples, thermocouples, gas probe and $360^{\circ}$ camera. 


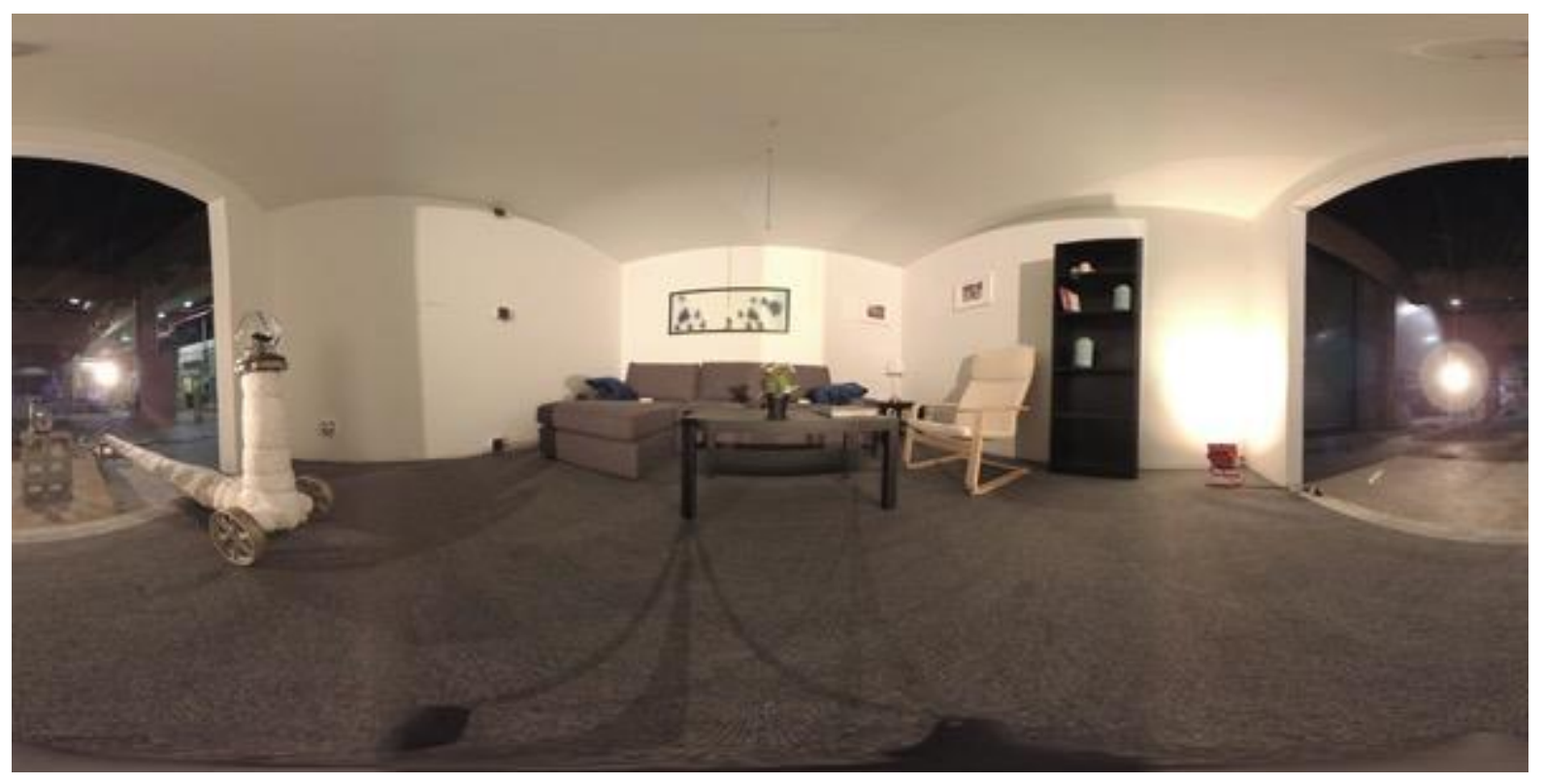

Fig. 10. Equirectangular view of $360^{\circ}$ photograph taken at the center of the compartment.

\subsubsection{Fire calorimetry}

The calorimetry measurement system at the National Fire Research Laboratory (NFRL) allows for measurement of heat release by 1 ) the principle of oxygen consumption calorimetry and 2) the principle of fuel consumption calorimetry (consumption of natural gas). The NFRL utilizes large canopy exhaust hoods to capture fire effluents for quantification of the heat release as a function of time. The system includes an emissions control system (ECS) to treat smoke particulates and combustion gases to comply with local environmental requirements. The facility has four canopy hoods, each denoted by its maximum fire capacity: $0.5 \mathrm{MW}$ $(3.1 \mathrm{~m} \times 3.2 \mathrm{~m}), 3 \mathrm{MW}(6.1 \mathrm{~m} \times 6.1 \mathrm{~m}), 10 \mathrm{MW}(8.4 \mathrm{~m} \times 12.4 \mathrm{~m})$, and $20 \mathrm{MW}$ $(13.8 \mathrm{~m} \times 15.4 \mathrm{~m})$. The average expanded uncertainty in heat release rate in the normal operating range for each hood for generic combustible fuel is $7.9 \%, 6.8 \%, 8.7 \%$, and $9.8 \%$, respectively. This uncertainty is valid for near steady state fires. Transient events (less than 30 s) may have larger uncertainty because of system response time. The range of expanded uncertainty for the natural gas (fuel consumption) verification burners is $1.4 \%$ to $1.8 \%$. Detailed information on the NFRL calorimetry measurement system is provided by Bryant and Bundy [31].

These experiments utilize only oxygen consumption calorimetry on the 10 MW hood. Verification (confirmation) of the oxygen consumption calorimeter using fuel consumption calorimetry as a reference was conducted immediately prior to this test series. Confirmation was performed within the calorimeter's normal operating range using five fire sizes up to $8 \mathrm{MW}$.

\subsubsection{Heat flux}

Plate thermocouples were positioned inside the compartment: three mounted on the south wall (Fig. 11a) and two on the top surface of seat cushions on the couch (Fig. 11b). Fig. 7 and Fig. 9 show the locations of the plate thermocouples in the compartment. 


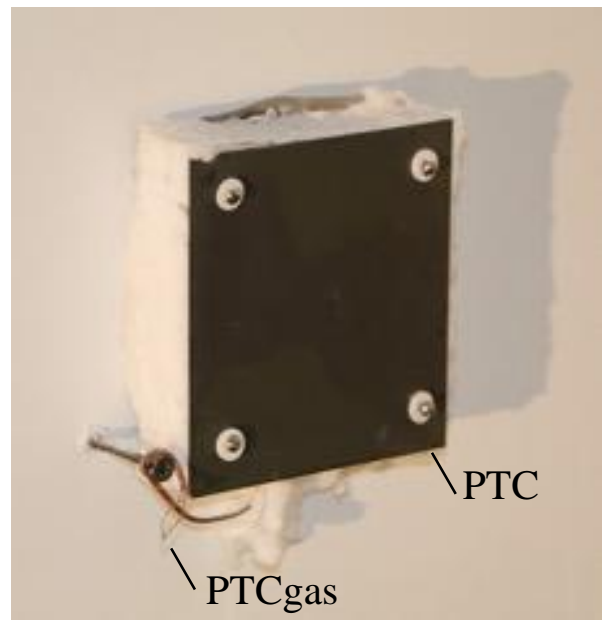

(a)

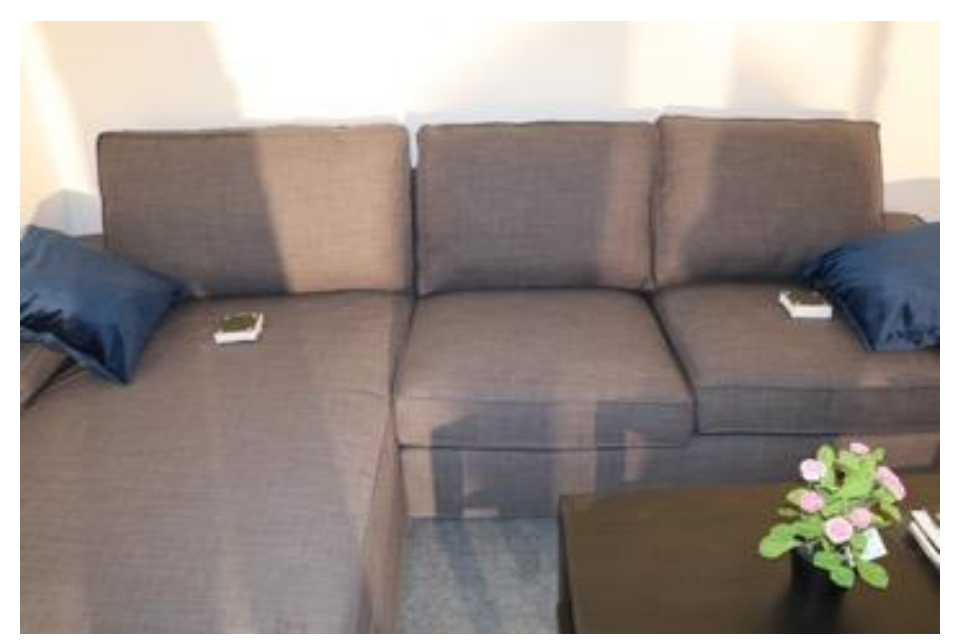

(b)

Fig. 11. Photographs of plate thermocouples and their co-located gas thermocouples: (a) wall mounting, and (b) on couch.

The plate thermocouples were made and calibrated as described by Putorti [32]. They were similar to those described in literature [33-35] but were modified for faster response. To decrease response time, the specified sheathed thermocouple was replaced by $0.51 \mathrm{~mm}$ diameter (24 AWG) Type K thermocouple wires welded directly to the rear of an Inconel ${ }^{\circledR} 600$ plate. The thickness of the mineral fiber blanket was increased to approximately $25.4 \mathrm{~mm}$ to decrease heat loss. A square plate of Inconel, approximately $100 \mathrm{~mm}$ by $100 \mathrm{~mm}$ in size, replaces the bent plate to reduce heat losses from the sides and simplify electrical isolation.

The expanded uncertainty of the plate temperature measurement in this experiment is estimated to be $\pm 1.8 \%$. Gas temperature directly adjacent to each plate was measured using an exposed junction, $2 \mathrm{~mm}$ diameter Type $\mathrm{K}$ thermocouple with an expanded uncertainty of $\pm 7.7 \%$. This is the uncertainty of the thermocouple bead temperature. The gas temperature may have added uncertainty due to radiative loss/gain and response time effects that were not considered here.

The incident heat flux on a plate thermocouple $\left(\dot{\mathrm{q}}_{\text {inc }}^{\prime \prime}\right.$, in $\left.\mathrm{W} / \mathrm{m}^{2}\right)$ can be calculated using the measured temperature of the plate thermocouple $\left(T_{P T}\right.$, in $\left.\mathrm{K}\right)$ and the gas temperature near the plate thermocouple ( $T_{\text {gas }}$, in $\mathrm{K}$ ), using the following relation, a rearrangement of Equation 18 from Ingason and Wickstrom [33]:

$$
\dot{q}_{i n c}^{\prime \prime}=\sigma \cdot T_{P T}^{4}+\frac{\left(h_{P T}+k_{P T}\right)\left(T_{P T}-T_{g a s}\right)}{\varepsilon_{P T}}+\frac{\rho_{S T} \cdot C_{S T} \cdot \delta \cdot\left(\frac{\Delta T_{P T}}{\Delta t}\right)}{\varepsilon_{P T}}
$$

where the time $(t)$ is in seconds, the Stefan Boltzmann constant $(\sigma)$ is $5.670 \mathrm{E}-8 \mathrm{~W} /\left(\mathrm{m}^{2} \cdot \mathrm{K}^{4}\right)$, the convective heat transfer coefficient $\left(h_{\mathrm{PT}}\right)^{\mathrm{b}}$ is taken to be $10 \mathrm{~W} /\left(\mathrm{m}^{2} \cdot \mathrm{K}\right)$, the conduction correction factor determined from NIST cone calorimeter data $\left(\mathrm{kPT}_{\mathrm{PT}}\right)$ is $4 \mathrm{~W} /\left(\mathrm{m}^{2} \cdot \mathrm{K}\right), \rho_{\mathrm{ST}}$ is the

\footnotetext{
${ }^{b}$ Values for the convective heat transfer coefficient and the conduction correction factor for the plate thermocouples are taken from Putorti [32]. No attempt was made to differentiate for the sensor orientation or variation with smoke impingement. Raw plate thermocouple temperatures are also provided in the appendices.
} 
alloy plate density, $8470 \mathrm{~kg} / \mathrm{m}^{3}$ from the alloy manufacturer, $C_{\mathrm{ST}}$ is the alloy plate heat capacity, $502 \mathrm{~J} /(\mathrm{kg} \cdot \mathrm{K})$ at $300{ }^{\circ} \mathrm{C}$ from the alloy manufacturer, $\delta$ is the alloy plate thickness, $0.79 \mathrm{~mm}$, and the emissivity of the plate thermocouple $\left(\varepsilon_{P T}\right)$ is taken to be 0.85 at $480{ }^{\circ} \mathrm{C}$. The expanded uncertainty in steady state heat flux under ideal conditions measured by the plate thermocouples is $5 \%$ at $75 \mathrm{~kW} / \mathrm{m}^{2}[32,36]$.

\subsubsection{Temperature}

Fig. 7 and Fig. 9 show the locations of the thermocouples in the compartment. Upper layer $\left(\mathrm{T}_{\text {ceiling }}\right)$ and lower layer $\left(\mathrm{T}_{\text {floor }}\right)$ gas temperatures were measured about $10 \mathrm{~cm}$ from the ceiling and the floor, respectively using Inconel-sheathed, $3.175 \mathrm{~mm}$ outside diameter, grounded junction Type $\mathrm{K}$ thermocouples with an estimated expanded uncertainty of $\pm 2.7 \%$. This is the uncertainty of the thermocouple bead temperature. The gas temperature may have added uncertainty due to radiative loss/gain and response time effects that were not considered here. Temperature directly behind the thermal protection for the wall-mounted microphone $\left(\mathrm{T}_{\mathrm{mic}}\right)$ and in the outflow water for the $360^{\circ}$ camera $\left(\mathrm{T}_{\text {bob }}\right)$ was measured using exposed junction (bare-bead) Type $\mathrm{K}$ thermocouples with estimated expanded uncertainties of $\pm 3.5 \%$ and $\pm 2.1 \%$, respectively.

\subsubsection{Room gas sampling}

Gas samples to measure concentrations of $\mathrm{O}_{2}, \mathrm{CO}$ and $\mathrm{CO}_{2}$ in the room were extracted from a $6 \mathrm{~mm}$ diameter stainless steel tube with its opening approximately $93 \mathrm{~cm}$ below the ceiling of the compartment. A Permapure MiniGASS sample conditioning system was used to filter and dry the sample gas. The sample gas flow rate was $1 \mathrm{slpm}$ for these tests. The delay time from the room inlet port to the gas rack was approximately $45 \mathrm{~s}$.

. The oxygen concentration was measured using a paramagnetic oxygen analyzer. Carbon dioxide and carbon monoxide concentrations were measured using a nondispersive infrared (NDIR) analyzer, 600D NDIR manufactured by Cal, USA. The analyzers were calibrated prior to the test using calibrated zero and span gases. Nitrogen gas was used to zero each analyzer and room air was used to span the oxygen analyzer. Room air was assumed to have an oxygen concentration of $(20.95 \pm 0.05) \%$. The carbon dioxide span gas consisted of $(9.0 \pm 0.09) \%$ $\mathrm{CO}_{2}$ in $\mathrm{N}_{2}$ and the carbon monoxide span gas consisted of $(4.0 \pm 0.04) \% \mathrm{CO}$ in $\mathrm{N}_{2}$. The maximum range of the $\mathrm{CO}$ and $\mathrm{CO}_{2}$ measurements was $20 \%$. All gas measurements are reported on a dry basis.

\subsubsection{Video cameras}

Wide-angle high-definition video of the experiment was captured using a single-lens reflex digital camera (Canon EOS 5D Mark IV) at a large stand-off distance outside of compartment.

High-definition video footage of the inside of the compartment during the fire was captured using a sports action camera (GoPro Hero6) in a purpose-built enclosure located about $100 \mathrm{~cm}$ from the front opening of the compartment (see "water cooled camera" in Fig. 7). The water served the dual purposes of cooling the camera and filtering out the infrared thermal radiation produced by the fire that would otherwise damage the camera's imaging sensor. The camera was placed in a modified waterproof case so that power could be provided to the camera and video could be streamed from the camera in real time during the experiments. The enclosure was set in an open beaker made of borosilicate glass. A photograph of the setup is shown in Fig. 12. Fabrication details for this setup are provided by Hoehler [37]. 


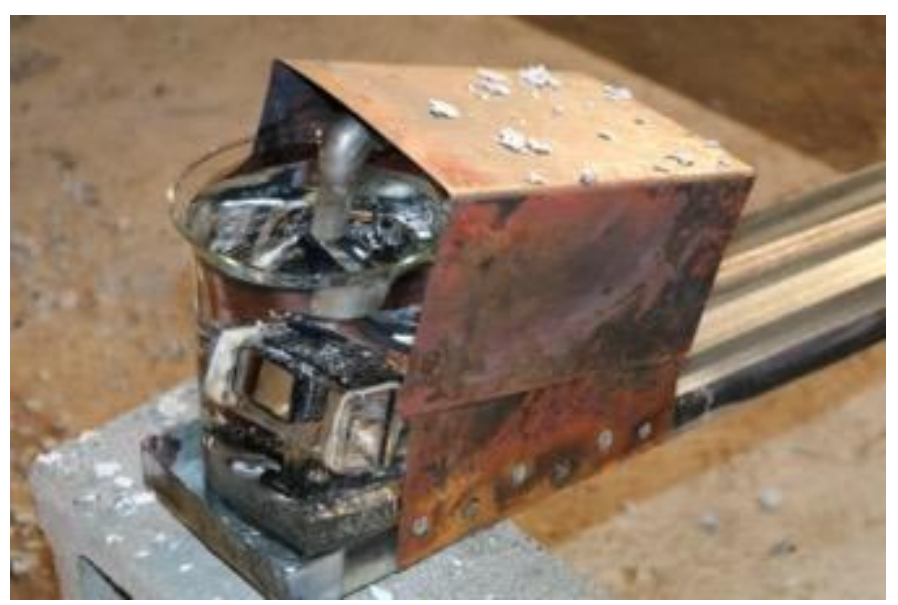

Fig. 12. Photograph of the setup used for the water-cooled video camera.

A newly developed, water-cooled transparent enclosure built to house waterproof $360^{\circ}$ video cameras (Garmin VIRB 360) in severe fires was placed inside the compartment (refer to Fig. 7) to record high-definition (monoscopic) spherical video of the tests. A photograph of the apparatus is shown Fig. 13a. As with the other water-cooled camera, the water both cooled the camera and filtered out the infrared thermal radiation produced by the fire. Unlike the other setup, the $360^{\circ}$ system is a pressurized (closed) around the camera. Details about the functionally and fabrication of this system are provided by Hoehler [38]. A cardioid condenser microphone with thermal protection ( $25 \mathrm{~mm}$ or less of either Aramid fabric or thermal ceramic fiber blanket covered in a silver thermal radiation reflecting scrim) was mounted low on the south wall near the front opening (see Fig. 7) to record audio. Fig. 13b shows a photograph of the thermal protection for the microphone.

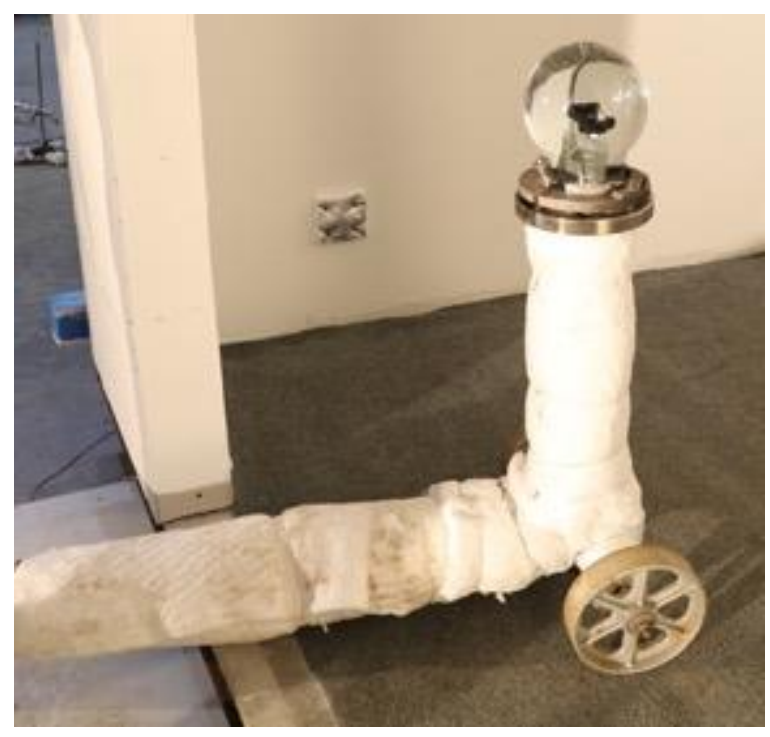

(a)

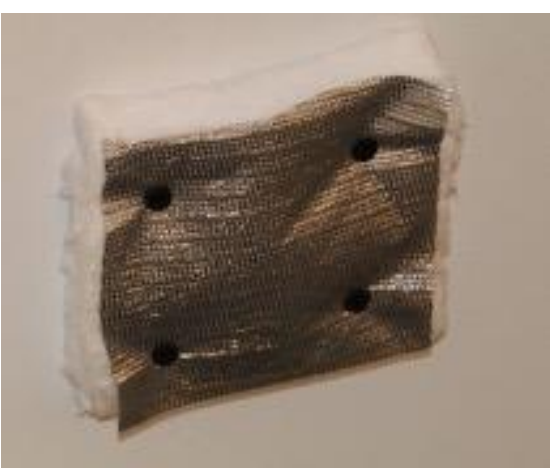

(b)

Fig. 13. Photograph of (a) the $360^{\circ}$ camera Burn Observation Bubble (BOB) on a wheeled base, and (b) the thermal protection for the in-wall microphone 
Air-cooled web cameras (Logitech C920) were installed under the loveseat and chaise sections of the couch (refer to Fig. 7). The cameras were placed in custom-built metal camera enclosures connected to copper tubing to allow air inflow and outflow. Infrared radiation reflecting glass (Edmund part number \#64-458) was used as a window on the enclosure. The enclosures were mounted to the frame of couch and then insulated with a ceramic fiber insulation blanket as shown in Fig. 14. The cameras provided videos at 30 frames/s and a resolution of $1280 \times 720$ pixels.

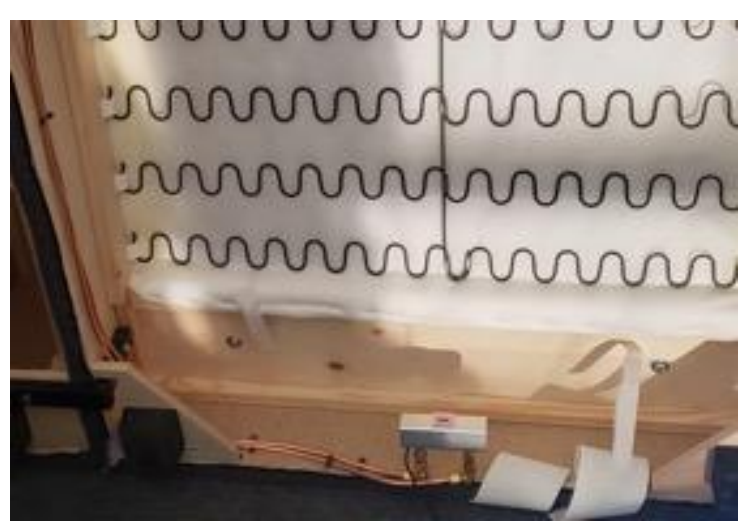

(a)

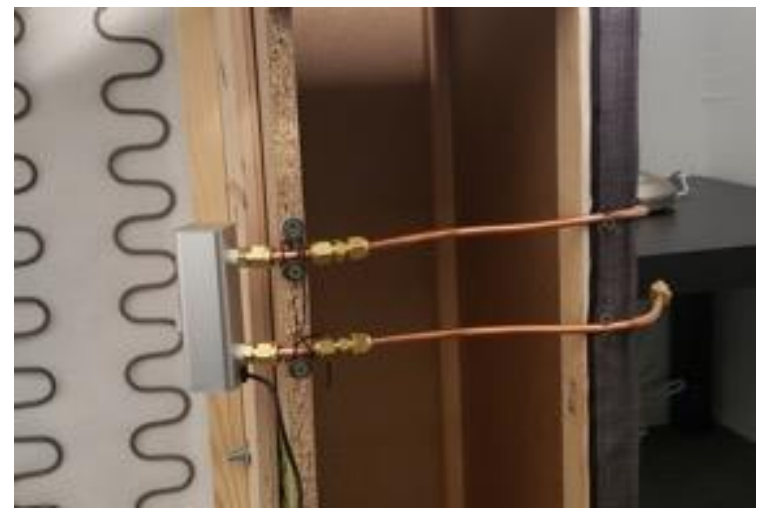

(b)

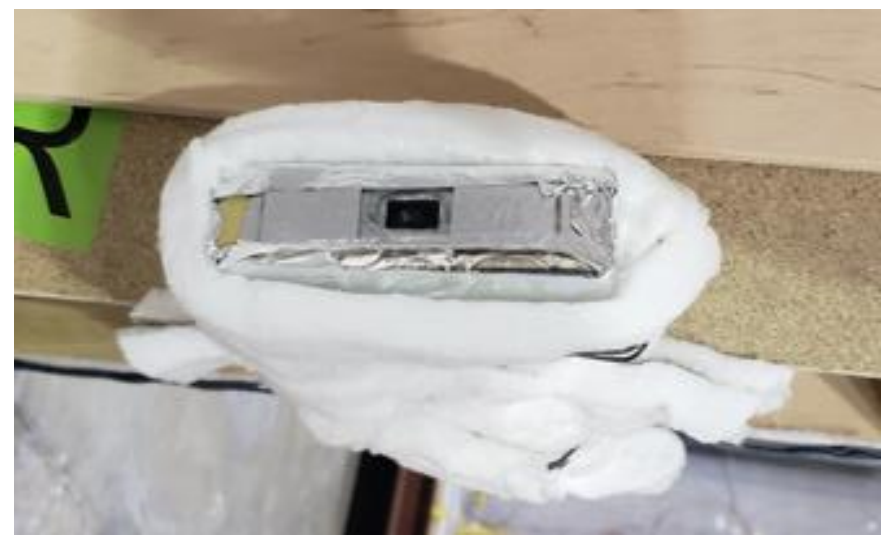

(c)

Fig. 14. Photographs showing the installation of the air-cooled cameras: (a) camera under the chaise section (camera installed on the back of the couch and facing the room opening); (b) camera under the loveseat section (camera installed under the right arm and facing the left wall of the room), and (c) detail of the insulation used to protect the cameras. 


\subsection{Test Procedure}

The following procedure was used.

1. Pre-test

a. Call the NIST Fire Department to deactivate automatic fire suppression systems.

b. Turn on exhaust fans and open makeup air dampers.

c. Verify that area $\mathrm{CO}$ detectors and alarms are functioning.

d. Turn on measurement systems and verify that they are functioning.

e. Turn on lighting and verify camera settings.

f. Prepare the ignition source (spark, pilot tube, etc.).

2. Test Director conducts Safety Briefing and completes safety checklist.

3. Start data acquisition.

4. Turn on video cameras and audio recording.

5. Acquire background data for Heat Release Rate.

6. Ignite throw pillow with propane flame.

7. Collect experimental data and video.

8. End of Test: The test will proceed until total fuel burnout unless the Test Director, in consultation with the Safety Officer and a representative from the project team, decide to suppress the fire.

9. Stop data acquisition

10. Post-test/Tear-down:

a. Safety Officer calls NIST fire department to reactivate automatic fire suppression systems.

b. Debris and material are properly stored or discarded by NFRL staff. 


\section{Results and Discussion}

Detailed results for each compartment fire are provided in the Appendices. This section presents key comparisons and discussion.

\subsection{Observations}

For all tests, the smoke alarm triggered within the first minute after fire ignition ( $42 \mathrm{~s}$ in Test 1 , $47 \mathrm{~s}$ in Test 2 and $45 \mathrm{~s}$ in Test 3) presumably due to the rapid burning of the throw pillow. A dark smoke layer that spread over the compartment ceiling was generated within 2 min. Subsequently, the burning behavior varied significantly between samples without a barrier fabric (Test 1 and Test 3) and the sample with a barrier fabric (Test 2). Fig. 15 compares snapshots of the three tests at $2 \mathrm{~min}, 4 \mathrm{~min}, 6 \mathrm{~min}$ and $8 \mathrm{~min}$ from ignition. At $2 \mathrm{~min}$, a similar smoke layer, flame spread and flame size were observed in all tests. In Test 1 and Test 3, after 2 min the flame spread and fire intensity increase continuously until flashover conditions were reached. In Test 2, after $2 \mathrm{~min}$ the flame spread decreased; 4 min after ignition, the smoke layer dissipated and did not reappear until approximately $10 \mathrm{~min}$ later in the test. The photographs in Fig. 15 qualitatively demonstrate the efficacy of the barrier fabric to reduce flame spread over the couch.

The air-cooled cameras installed underneath the couches failed shortly after flashover in all tests. In Test 1 , the water-cooled $360^{\circ}$ camera enclosure remained intact throughout the experiment. In Test 2 and Test 3 the borosilicate glass globe fractured shortly after flashover. In Test 2 the glass was hit by fragment from the smoke detector when the Li-battery appeared to explode due to overheating, which caused the glass to fail. In Test 3, the glass failed presumably due to excessive thermal gradient in the glass. Fig. 16 show a photograph of a failed glass globe. In future experiments where intense thermal radiation from the fire is expected, e.g., during room flashover, the use of more temperature resistant glass such as fused silica or quartz should be explored. It is noted that in all tests the cameras could be safely extracted from the room after the glass failed due to the wheels on the base of the Burn Observation Bubble and the video footage recovered; however, permanent thermal damage to the camera housing occurred. The camera in front of the opening ("water-cooled camera") remained intact and performed as designed throughout all experiments.

The thermal protection for the cardioid condenser microphone mounted flush with the surface of the compartment drywall was varied for each test. The microphone was mounted low on the compartment wall to minimize temperature exposure. In Test 1, one layer of $25 \mathrm{~mm}$ thick thermal ceramic fiber blanket with a sliver scrim cover was used and the temperature at the microphone capsule reached nearly $120{ }^{\circ} \mathrm{C}$. In Test 2, two layers of $25 \mathrm{~mm}$ thick thermal ceramic fiber blanket were used which reduced the temperatures at the microphone capsule to $60{ }^{\circ} \mathrm{C}$; however, the audio signal was significantly attenuated. In Test 3 , one layer of $25 \mathrm{~mm}$ thick thermal ceramic fiber blanket over an "acoustically-transparent" non-combustible $25 \mathrm{~mm}$ thick Aramid fabric was used and the temperatures at the microphone capsule reached approximately $80^{\circ} \mathrm{C}$ and the audio signal was less attenuated than in Test 2. For large, sustained compartment fires, further development is needed to improve audio measurement. 
Test 1
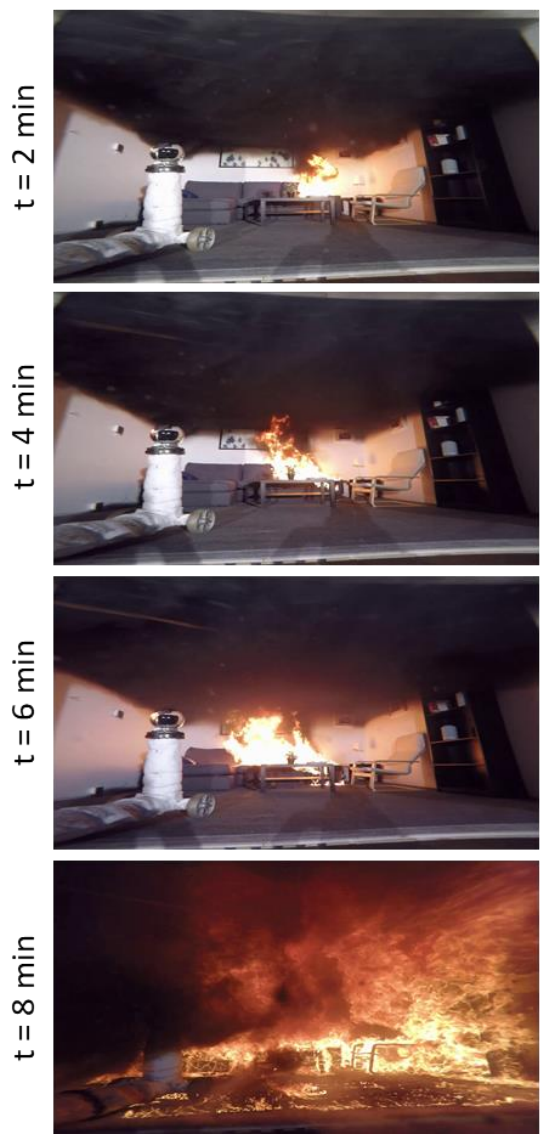

Test 2
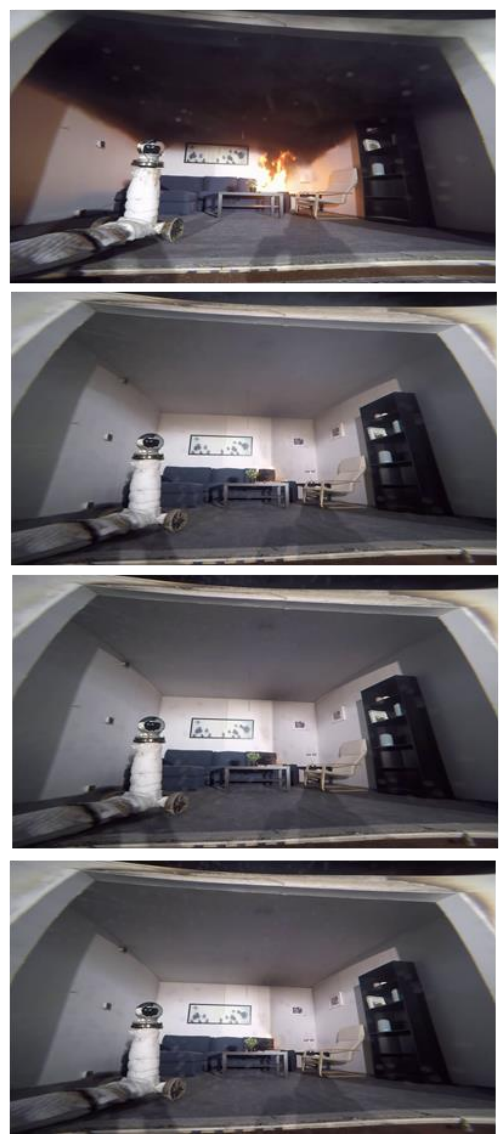

Test 3
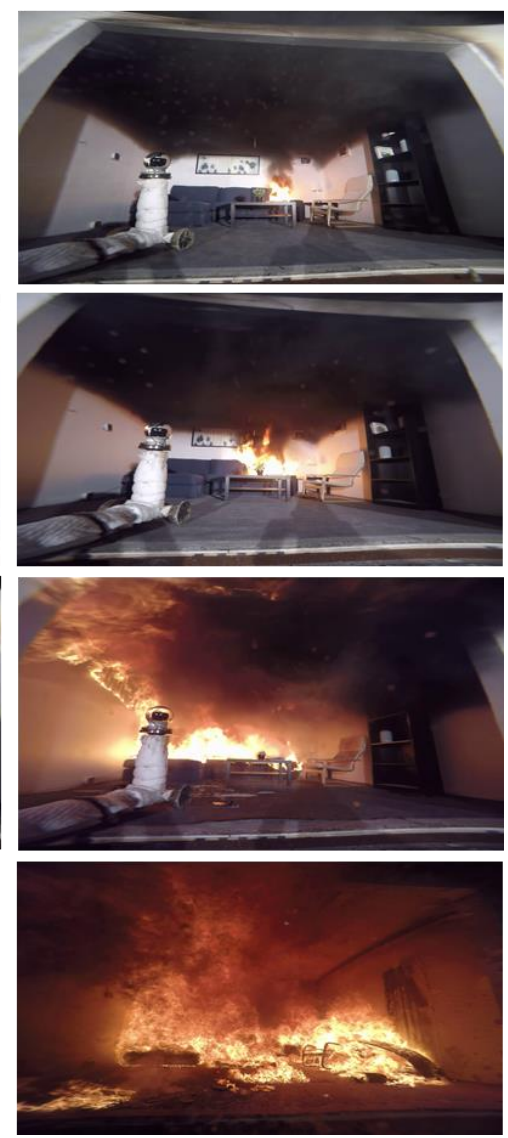

Fig. 15. Photographs of the compartments at $2 \mathrm{~min}, 4 \mathrm{~min}, 6 \mathrm{~min}$ and $8 \mathrm{~min}$ after ignition. These photographs qualitatively demonstrate the efficacy of the barrier fabric. At $t=2$ min, a similar smoke layer, flame spread and flame size were observed in all tests. For $t>2$ min, the flame spread and fire intensity increased continuously in Test 1 and Test 3, until flashover conditions were reached. In Test 2 , the flame spread decreased; at $t=4$, the smoke layer dissipated and did not reappear until approximately 10 min later. 


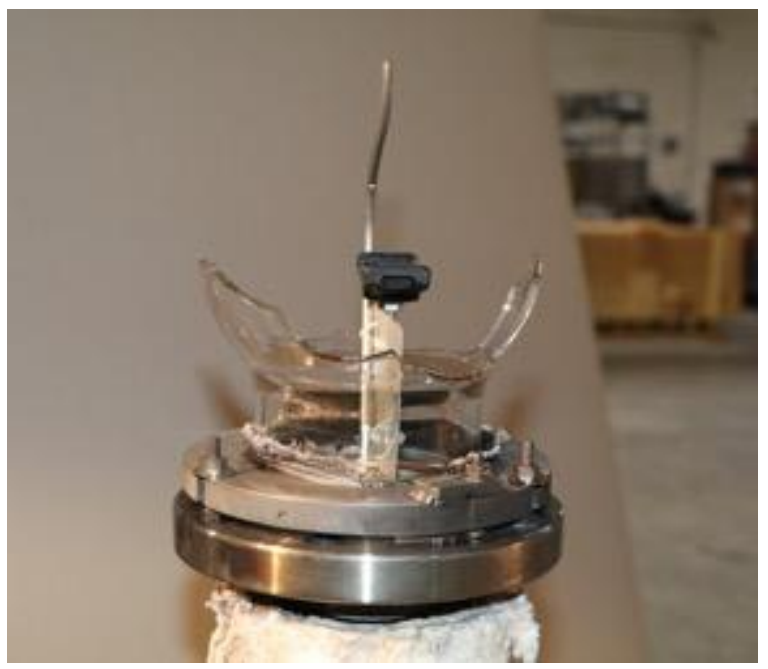

Fig. 16. Photograph of the Burn Observation Bubble after failure of the borosilicate glass.

\subsection{Heat Release Rate}

Tests of individual throw pillows were conducted to characterize the ignition source and study how the source interacted with the investigated couches and subsequent fire development. Fig. 17 shows the heat release rate curves measured for two test repeats of burning throw pillows without additional combustible items, and; the nominal heat release rate curve produced by a TB 133 burner (18 kW square propane burner for $80 \mathrm{~s}$ ) [39]. The TB 133 burner was adopted as the ignition source in California Technical Bulletin 133, which is a flammability test procedure for seating furniture in public occupancies, and simulates the combustion of five sheets of crumpled newspaper. TB 133 was in use until repealed in January 2019 [40, 41]. As shown in Fig. 17, the throw pillows generated a more severe ignition than a TB 133 burner in terms of maximum heat release rate $(35 \mathrm{~kW}$ to $45 \mathrm{~kW}$ for the throw pillow versus $18 \mathrm{~kW}$ for the TB 133 burner) and total heat released (4.0 MJ to 4.2 MJ for the throw pillow versus 1.44 MJ for the TB 133 burner). Table 5 summarizes the values of mass, peak of heat release rate, total heat released, effective heat of combustion and residue for the two tested pillows. 


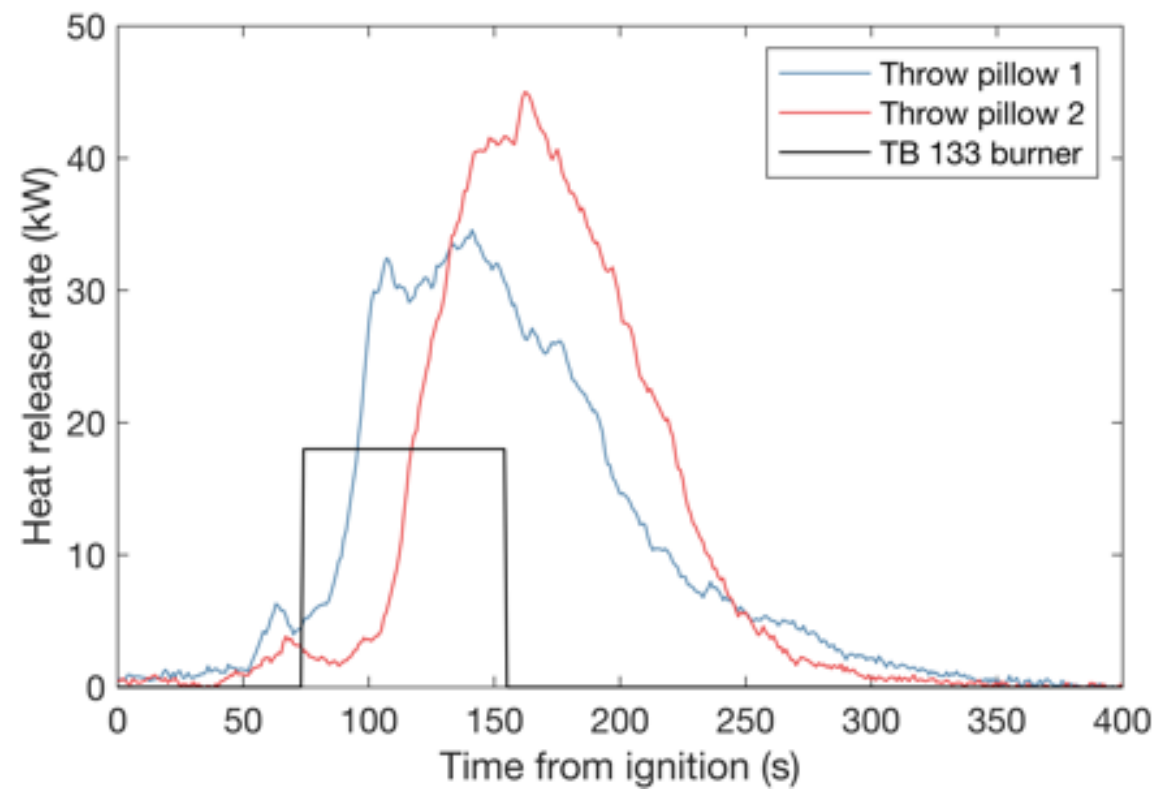

Fig. 17. Experimental heat release rate curves measured for two throw pillows and nominal heat release rate curve for a TB 133 burner.

Table 5. Values of mass, peak of heat release rate (PHRR), total heat released (THR), effective heat of combustion (EHC) and residue measured for two tested throw pillows ignited by a nominally $3 \mathrm{~cm}$ non-premixed propane flame.

\begin{tabular}{lccccc}
\hline & $\begin{array}{c}\text { Mass } \\
(\mathrm{g})\end{array}$ & $\begin{array}{c}\text { PHRR } \\
(\mathrm{kW})\end{array}$ & $\begin{array}{c}\text { THR } \\
(\mathrm{MJ})\end{array}$ & $\begin{array}{c}\text { EHC } \\
(\mathrm{MJ} / \mathrm{kg})\end{array}$ & $\begin{array}{c}\text { Residue } \\
(\%)\end{array}$ \\
\hline Throw pillow 1 & $463 \pm 2$ & $35 \pm 2$ & $4.0 \pm 0.3$ & $15.5 \pm 1$ & $45 \pm 1$ \\
Throw pillow 2 & $496 \pm 2$ & $45 \pm 3$ & $4.2 \pm 0.3$ & $14.6 \pm 1$ & $42 \pm 1$ \\
\hline
\end{tabular}

Fig. 18 shows the heat release rates for Test 1, Test 2, Test 3, and Throw Pillow 1 during the first $500 \mathrm{~s}$ after ignition. While the measured amplitudes are within the specified uncertainty, the timing has some uncharacterized variability. In the first several minutes of the compartment tests (Test 1 to Test 3) there is an influence of the room geometry on the transport of combustion product to the exhaust hood and an associated delay in the measurement of the heat release rate that is not compensated for in this study. This delay is not present in the pillow tests (Throw pillow 1). However, there was a delay in the early fire growth on Throw pillow 1 possibly due to (1) a shorter pilot flame impingement time or (2) absence of flaming and flamefeedback from the couch in proximity of the throw pillow. The influence of the room geometry on the timing of the heat release rate becomes much less pronounced at flashover where flames extend out of the compartment opening. Moreover, the total energy is correct and unaffected by the timing variability. 
The heat release rate for the throw pillow and for Test 1 are comparable and reach a maximum value of about $30 \mathrm{~kW}$ within the first $100 \mathrm{~s}$. Thus, during the first few minutes of Test 1 (couch with polyester cover fabric), the heat release rate was dominated by the heat release rate of the throw pillow and the contribution of the cover fabric and flexible polyurethane foam in the couch was negligible. This was not the case for Test 2 and Test 3 (couches with cotton blend cover fabric) where the heat release rates were significantly higher than for the throw pillow by itself after about $100 \mathrm{~s}$ (about $30 \mathrm{~kW}$ for the throw pillow, $84 \mathrm{~kW}$ for Test 2, and $115 \mathrm{~kW}$ for Test 3). A lower heat release rate was expected for Test 2 (couch with cotton blend cover fabric and barrier fabric) as compared to Test 3 (couch with cotton blend cover fabric only) due to the inclusion of the barrier fabric. The lower heat release rate for Test 1 (couch with polyester cover fabric) as compared to Test 3, however, is surprising because cotton blend cover fabrics are typically expected to be less flammable than polyester cover fabrics even though the behavior of fabric blends are often unpredictable [42].

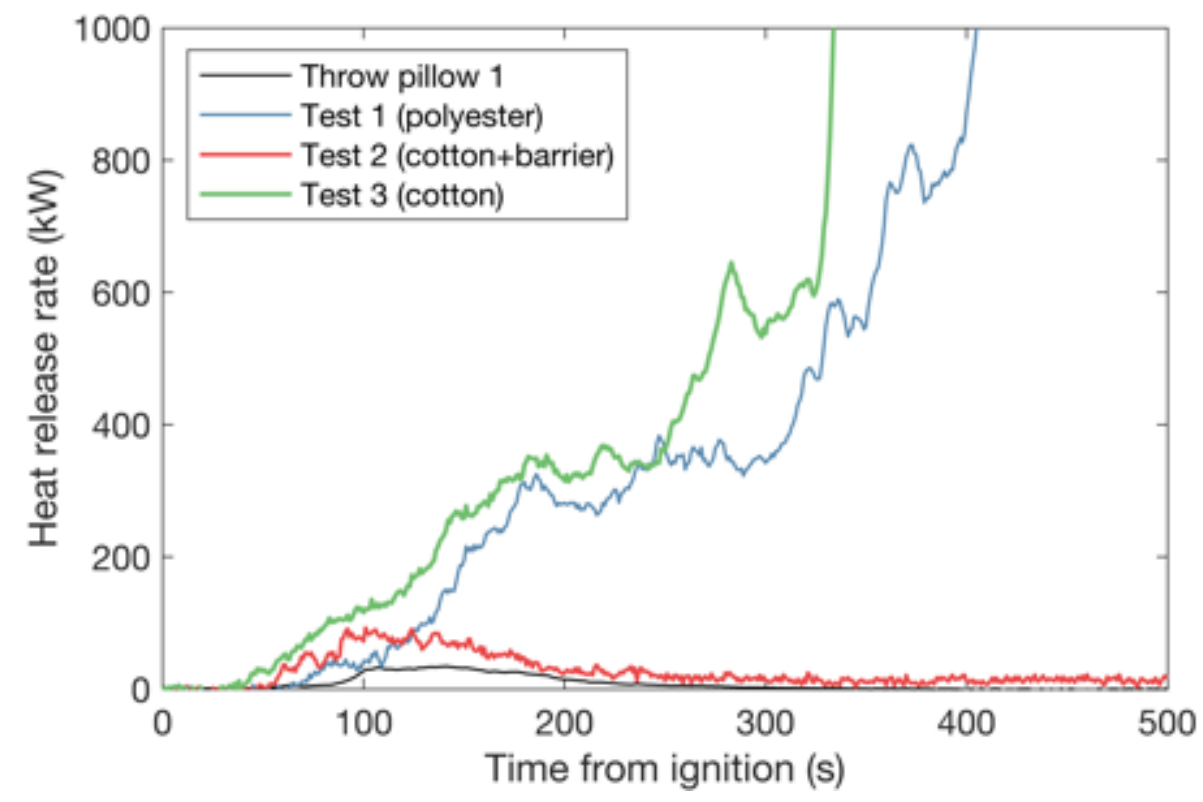

Fig. 18. Heat release rate curves measured for Test 1 to Test 3 and for the Throw Pillow 1 during the first $500 \mathrm{~s}$ after ignition.

The heat release rate curves from ignition to extinguishment for Test 1, Test 2 and Test 3 are shown in Fig. 19. The values of peak heat release rate (PHRR), time to peak heat release rate (tPHRR), and total heat release (THR) are summarized in Table 6. All tests were extinguished with water about (25 to 30 ) min after PHRR.

In terms of PHRR, Test 3 had the highest PHRR of $(9639 \pm 575) \mathrm{kW}$, followed by Test 1 with $(9175 \pm 548) \mathrm{kW}$, and Test 2 with $(8422 \pm 501) \mathrm{kW}$. The differences in PHRR between Test 1 (polyester fabric cover) and Test 3 (cotton blend cover fabric) were not significant and the PHRR reduction in Test 2 (cotton blend cover fabric and barrier fabric) was marginal.

In contrast, tPHRR showed substantial variations. The tPHRR was $(6.72 \pm 0.17)$ min for Test 3 , $(8.12 \pm 0.17) \mathrm{min}$ for Test 1 , and $(21.68 \pm 0.17) \mathrm{min}$ for Test 3 . Compared to Test 3 , the use of the barrier fabric with the same cover fabric in Test 2 offered a $300 \%$ increase in tPHRR (i.e., it 
took approximately 3 times longer for the PHRR to be observed when a barrier fabric was used). This increase in tPHRR was associated with the formation of a quasi-steady state burning with a minimum heat release rate plateau value of about $15 \mathrm{~kW}$ at $\mathrm{t} \approx 8 \mathrm{~min}$ in the early burning stage of Test 2 when the combustion of the throw pillow was complete.

There was a small but not significant effect of the cover fabric type on THR; compare Test 1 to Test 3 in Table 6 . The THR in Test 2 decreased by about $15 \%$ compared to Test 3 due to the addition of the barrier fabric to the cotton blend cover fabric.

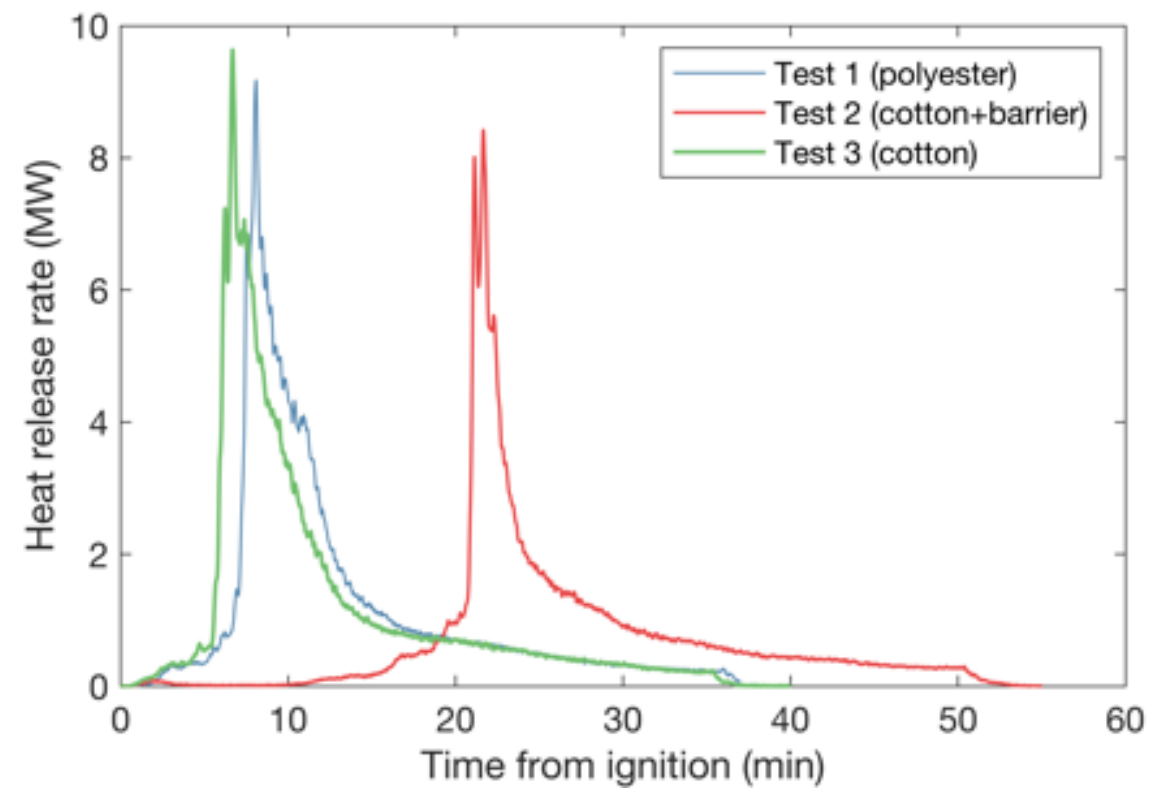

Fig. 19. Heat release rate curves for Test 1, Test 2, and Test 3.

Table 6. Values of time to peak heat release rate, peak heat release rate and total heat release rate measured in Test 1 , Test 2 , and Test 3.

\begin{tabular}{cccc}
\hline & $\begin{array}{c}\text { Time to peak heat } \\
\text { release rate, tPHRR } \\
(\mathrm{min})\end{array}$ & $\begin{array}{c}\text { Peak heat release } \\
\text { rate, PHRR } \\
(\mathrm{kW})\end{array}$ & $\begin{array}{c}\text { Total heat release } \\
\text { rate, THR } \\
(\mathrm{MJ})\end{array}$ \\
\hline Test 1 & $8.1 \pm 0.2$ & $9180 \pm 550$ & $2550 \pm 160$ \\
Test 2 & $21.7 \pm 0.2$ & $8420 \pm 500$ & $2250 \pm 140$ \\
Test 3 & $6.7 \pm 0.2$ & $9640 \pm 580$ & $2640 \pm 160$ \\
\hline
\end{tabular}

\subsection{Time to Flashover}

Flashover is the last phase in fire growth that leads to a fully-developed compartment fire. Flashover occurs when the room is hot enough (or heat transfer from the upper smoke layer is large enough) that all combustible solids in the room begin pyrolyzing and producing gaseous volatiles, despite the presence or absence of direct flame impingement. Ignition of these 
gaseous pyrolyzates yields an abrupt increase in heat release rate [43]. In this study, it is assumed that flashover conditions in the compartment were reached when the magazines and the single upholstered chair ignited almost simultaneously. The time to flashover and the time to smoke alarm triggering for Test 1 to Test 3 are reported in Table 7.

Table 7. Time to smoke alarm triggering and flashover in Test 1, Test 2, and Test 3.

\begin{tabular}{ccc}
\hline & $\begin{array}{c}\text { Time to smoke alarm triggering } \\
(\mathrm{s})\end{array}$ & $\begin{array}{c}\text { Time to flashover } \\
(\mathrm{min})\end{array}$ \\
\hline Test 1 & $42 \pm 2$ & $7.0 \pm 0.2$ \\
Test 2 & $47 \pm 2$ & $21.0 \pm 0.2$ \\
Test 3 & $45 \pm 2$ & $6.0 \pm 0.2$ \\
\hline
\end{tabular}

The smoke alarm triggering times were similar for all tests. The time to flashover increased by less than 1 min when the cotton blend cover fabric (Test 3) was replaced by the polyester cover fabric (Test 1). Thus, the effect of the cover fabric was statistically significant, but small. In comparison, the influence of the barrier fabric on the time to flashover was large. The presence of the barrier fabric delayed the time to flashover by about $15 \mathrm{~min}$ in Test 2 (cotton blend cover fabric and barrier fabric) compared to Test 3 (cotton blend cover fabric only).

Based on the data from this limited test series, the rapid fire growth observed in Test 1 and Test 3 may present a significant hazard to life and property before first responders can arrive. Thus, a 15 min delay of flashover observed in Test 2 can drastically reduce this hazard. This can be contextualized by analyzing the objective (target) fire service response times in NFPA 1720 [44]. The target response time is $9 \mathrm{~min}$ in urban areas (for at least $90 \%$ of the responses), $10 \mathrm{~min}$ in suburban areas (for at least $80 \%$ of the responses), and $14 \mathrm{~min}$ in rural areas (for at least $80 \%$ of the responses). Response time begins upon completion of the dispatch notification to the fire department and ends at the time a prescribed number of staff members start mitigation measures at the fire scene. After ignition, assuming an average smoke alarm triggering time of $45 \mathrm{~s}$, an alarm answer time of $15 \mathrm{~s}$ to $40 \mathrm{~s}$ and an alarm processing time of $64 \mathrm{~s}$ to $106 \mathrm{~s}$ (see NFPA 1710 for response objectives [45]), the response time will start about $2 \mathrm{~min}$ to $3 \mathrm{~min}$ after ignition. Thus, considering the target response time, the first responders are expected to intervene within $12 \mathrm{~min}$ in urban areas, $13 \mathrm{~min}$ in suburban areas and $17 \mathrm{~min}$ in rural areas. A graphic representation of time to flashover for Test 1, Test 2, and Test 3 versus response time is shown in Fig. 20.

If these experiments are representative of available couches, the graphic suggests that first responders may not be able to intervene before flashover when a couch without barrier fabric is involved in the types of compartment fires represented by Test 1 and Test 3 , even in urban areas. However, under the same conditions, first responders would likely be able to intervene and prevent flashover when a barrier fabric is adopted in the couch (Test 2) in urban, suburban, and rural areas. Flashover prevention is critical because it can prevent fire spread to adjacent rooms and buildings, which is where the majority of fire deaths occur in RUF fires [5]. 


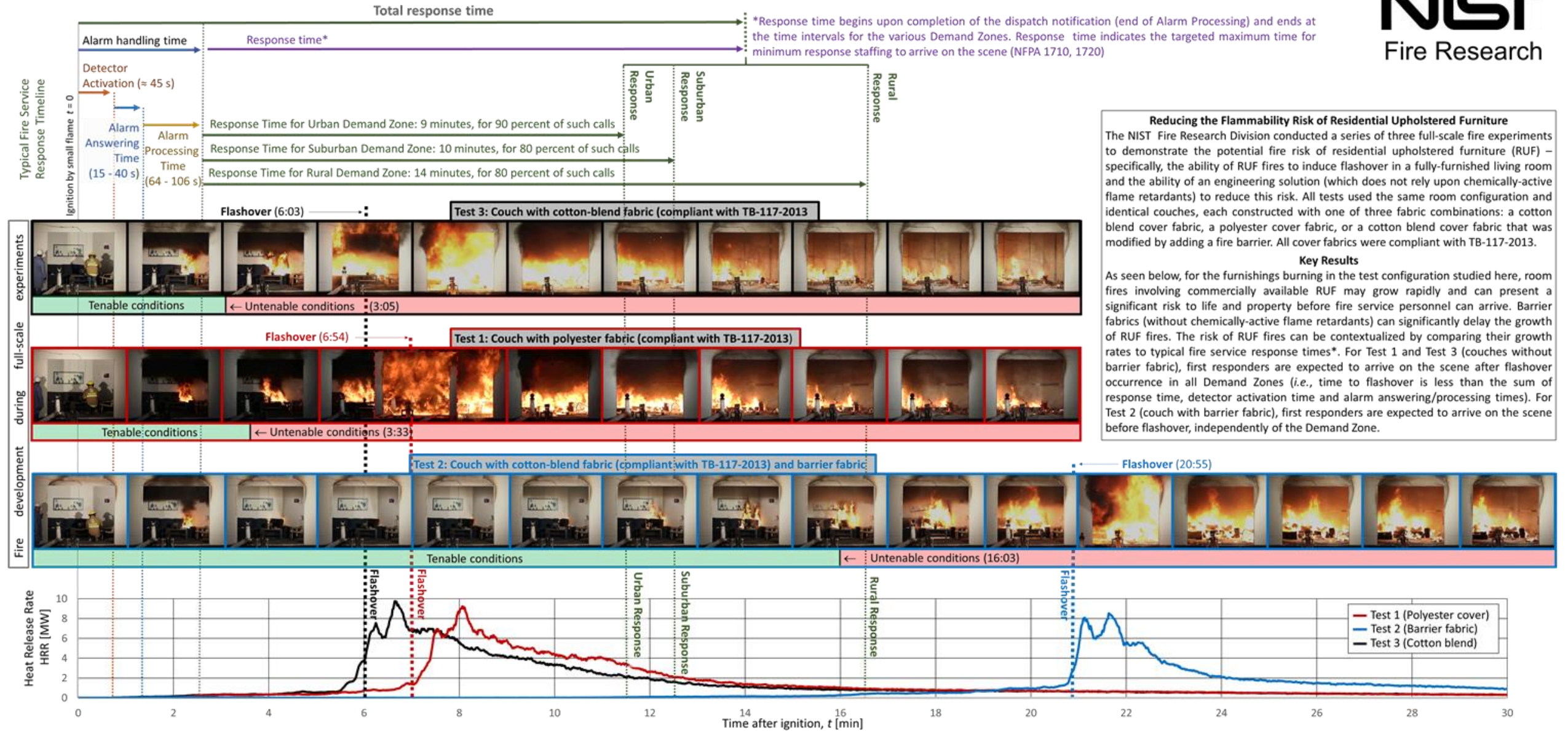

Fig. 20. Graphic representation of time to flashover for Test 1, Test 2, and Test 3 versus "total response time" (alarms, and response of first responders/fire service personnel). An upper layer temperature of $200{ }^{\circ} \mathrm{C}$ at Tceiling or a flux of $2.5 \mathrm{~kW} / \mathrm{m}^{2}$ at PTC2 are used as tenability criterion (see section 4.5). 
Fig. 21 shows video frames at flashover for Test 1, Test 2, and Test 3 captured by the watercooled camera, the $360^{\circ}$ camera and the air-cooled camera under the chaise section of the couch. The water-cooled camera (top row in Fig. 21) shows that by the time flashover occurred, flames appeared to cover the entire couch except the front vertical surface of the chaise section. The $360^{\circ}$ camera (middle row in Fig. 21) confirms this for Test 1 and Test 3, however, for Test 2 , it also shows that flame spread over the top surface of the chaise section was not complete, i.e., flaming was not present over the extremity of the top seat cushion which was opposite to the back cushion. The air-cooled cameras under the chaise section (bottom row in Fig. 21) show that there was no flaming underneath the chaise section at flashover for all tests.

The presence of flaming underneath the RUF item is important because it increases: (1) the incident heat flux on the couch padding material where most of the fuel, i.e., FPUF, is located and thus, (2) the rate of FPUF pyrolysis, (3) the rate at which combustible volatiles are released, and (4) the rate at which liquid product of FPUF decomposition (i.e., regenerated polyols [46]) are generated. All these phenomena promote an increase in heat release rate. Flaming under the loveseat section is initially due to the ignition of the polyester wadding and cover fabric on the bottom of the seat cushion and, afterwards, the ignition of regenerated polyols. The flaming ignition of regenerated polyol underneath the RUF item, referred to as "bottom ignition" in the remainder of this report, is particularly important because about $70 \%$ of the FPUF heat released is due to regenerated polyol combustion [47].

For this limited of experiments, in RUF items without barrier fabrics, bottom ignition occurs approximately simultaneously with the ignition of the wadding and cover fabric, but, in the presence of a barrier fabric, a significant delay can exist between bottom ignition and appearance of flaming ignition under the RUF item due to a reduction of heat and mass transfer. In terms of heat transfer, the barrier fabric is expected to delay FPUF degradation and, thus, the generation of flammable regenerated polyol and gaseous pyrolyzates. In terms of mass transfer, the barrier fabric is expected to slow down the flow of regenerated polyol, which feeds flaming underneath the couch and can generate a pool fire. In fact, the regenerated polyol needs to slowly percolate through the intact barrier fabric before it can feed flaming underneath the couch. Ultimately, bottom ignition is a key factor that triggers an abrupt increase in heat release rate [22].

Fig. 22 shows video frames captured by the air-cooled cameras under the loveseat section at various times during Test 1 (top row), Test 2 (center row), and Test 3 (bottom row). In all cases, no obvious degradation was observed at $t=6 \mathrm{~min}$ (compare column 1 to column 2 ).

In Test 1, flaming became visible at about $6 \min 9 \mathrm{~s}$ and was caused by the formation of a pool fire underneath the couch. The pool fire was generated by flaming liquids produced on the top of the seat cushion that flowed from the front of the loveseat section to the floor. In this test, flashover occurred about $50 \mathrm{~s}$ after flaming appeared under the loveseat section. At this time a significant flame spread underneath the loveseat section was observed in Test 1 (see video frame in the top row on the far right). Thus, bottom ignition briefly contributed to flashover conditions in Test 1 , but the pool fire was mainly fed by the top of the seat cushion.

In Test 3, flames appeared in the same location and by the same mechanism observed for Test 1 but a few seconds after flashover. Thus, flashover conditions could be reached in Test 3 without any contribution from bottom ignition. In Test 2, flames appeared at about $12 \mathrm{~min}$ in the back- 
right corner of the sofa, i.e., northwest corner of the couch in Fig. 7. At this early stage, flaming under the loveseat section was likely supported by burning of the polyester wadding and the cover fabric but not by FPUF, which was protected by the barrier fabric. Flames continued to spread under the loveseat and by $t=16 \mathrm{~min}$ the bottom right of the loveseat was engulfed in flames. 
Test 1
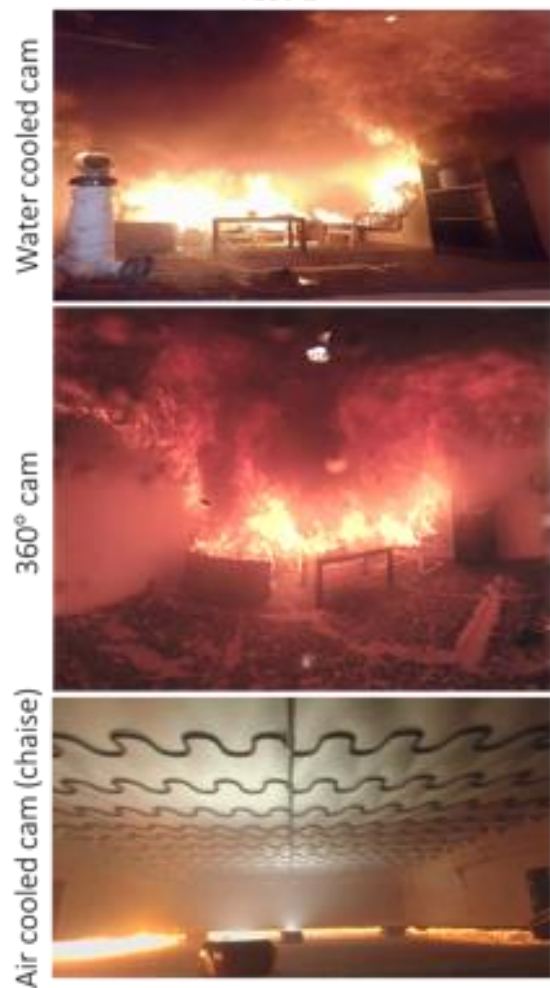

Test 2
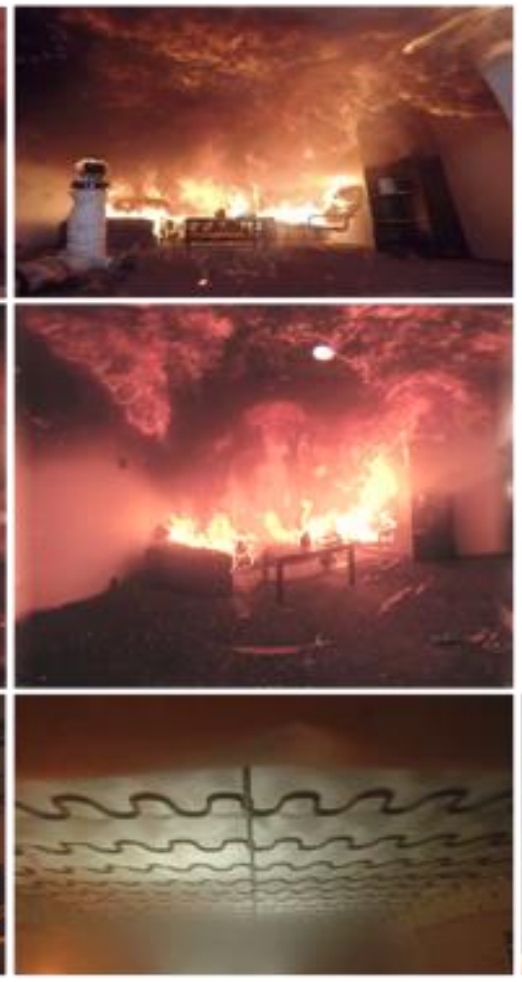

Test 3
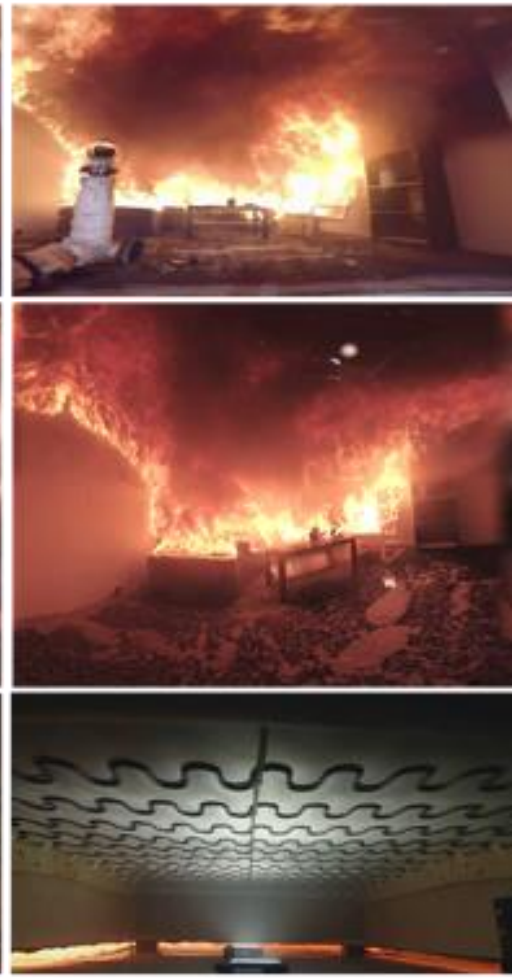

Fig. 21. Video frames at the time of flashover for Test 1 (left column), Test 2 (center column), and Test 3 (right column) captured by the water cooled camera (top row), $360^{\circ}$ camera (center row), and air-cooled camera under the chaise section of the couch (bottom row).
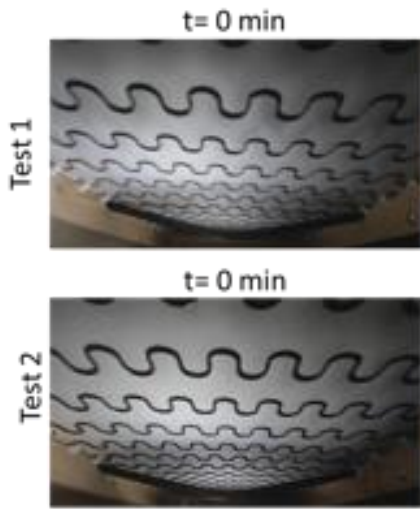

$\mathrm{t}=0 \mathrm{~min}$

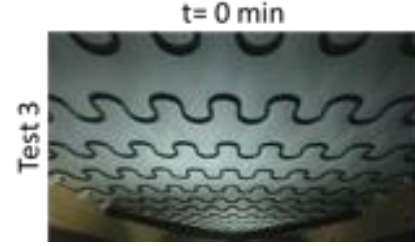

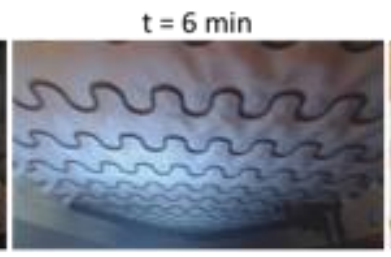

$\mathrm{t}=6 \mathrm{~min}$

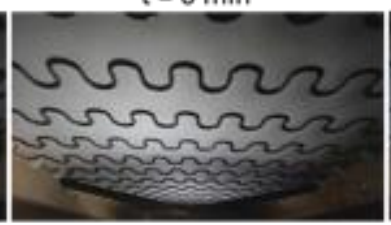

$\mathrm{t}=6 \mathrm{~min}$

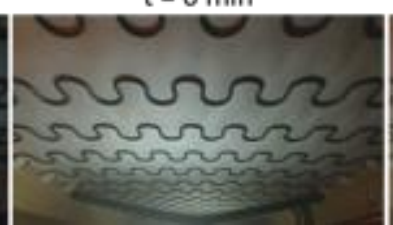

$t=6 \min 9 s$

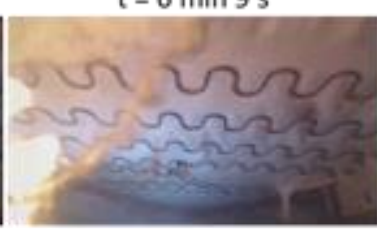

$\mathrm{t}=12 \mathrm{~min}$

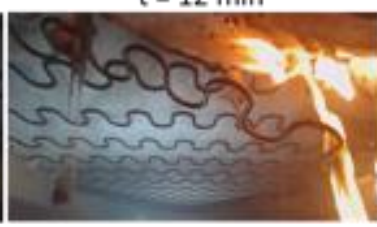

$\mathrm{t}=6 \min 3 \mathrm{~s}$ (flashover)

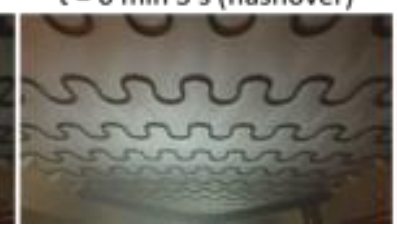

$t=6 \min 59 \mathrm{~s}$ (flashover)

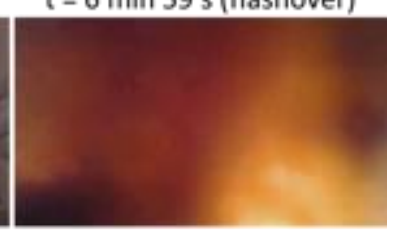

$\mathrm{t}=16 \mathrm{~min}$

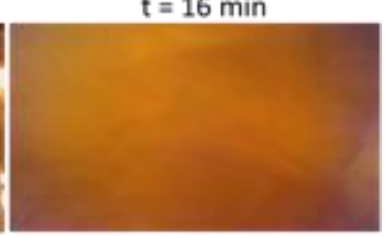

$\mathrm{t}=6 \min 9 \mathrm{~s}$

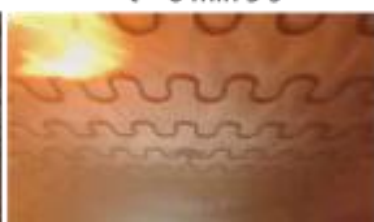

Fig. 22. Video frames captured by the air-cooled cameras under the loveseat section at various times during Test 1 (top row), Test 2 (center row), and Test 3 (bottom row) 
To better describe the phenomena that led to flashover in Test 2, Fig. 23 shows four video frames captured by the $360^{\circ}$ camera $6 \mathrm{~min}, 8 \mathrm{~min}, 10.2 \mathrm{~min}$, and $18 \mathrm{~min}$ after ignition. At $t=6 \mathrm{~min}$, the combustion of the throw pillow was complete and the heat release rate was below $15 \mathrm{~kW}$. Flames were localized to the right side of the couch on the top of the seat cushion and front of the back cushion. At $t=8 \mathrm{~min}$ the heat release rate was still below $15 \mathrm{~kW}$ but the flames propagated to the back of the couch where the polyester wadding fabric, and wood frame were not protected by the barrier fabric and an increase in flame size was observed near the back right corner. Noticeably, only the padding material, i.e., FPUF and polyester fiberfill, were protected and covered by the barrier fabric. At $\underline{t}=10.2 \mathrm{~min}$, the flame spread further over the back of the couch and the HRR increased to about $30 \mathrm{~kW}$. It was evident that the combustion of the back of the couch sustained flaming and promoted an increase in HRR. These observations indicate that the addition of barrier fabric over the back of the couch could have further improved the fire performance of the couch. Shortly after at $t=12 \mathrm{~min}$, as already shown in Fig. 22, flames had spread to the bottom of the loveseat. At $t=18 \mathrm{~min}$, an obvious pool fire formed underneath the loveseat section. This is a clear indication that, by this time in the test, bottom ignition occurred, and the regenerated polyols were involved in the burning process. An abrupt increase in HRR observed at approximately $t=17 \mathrm{~min}$ (see Fig. 19) could be attributed to bottom ignition. Bottom ignition preceded flashover in Test 2, which occurred at about $t=20.9 \mathrm{~min}$, by roughly $3 \mathrm{~min}$. This finding agrees with previous work where the PHRR occurred about 2 min to 4 min after bottom ignition [22].
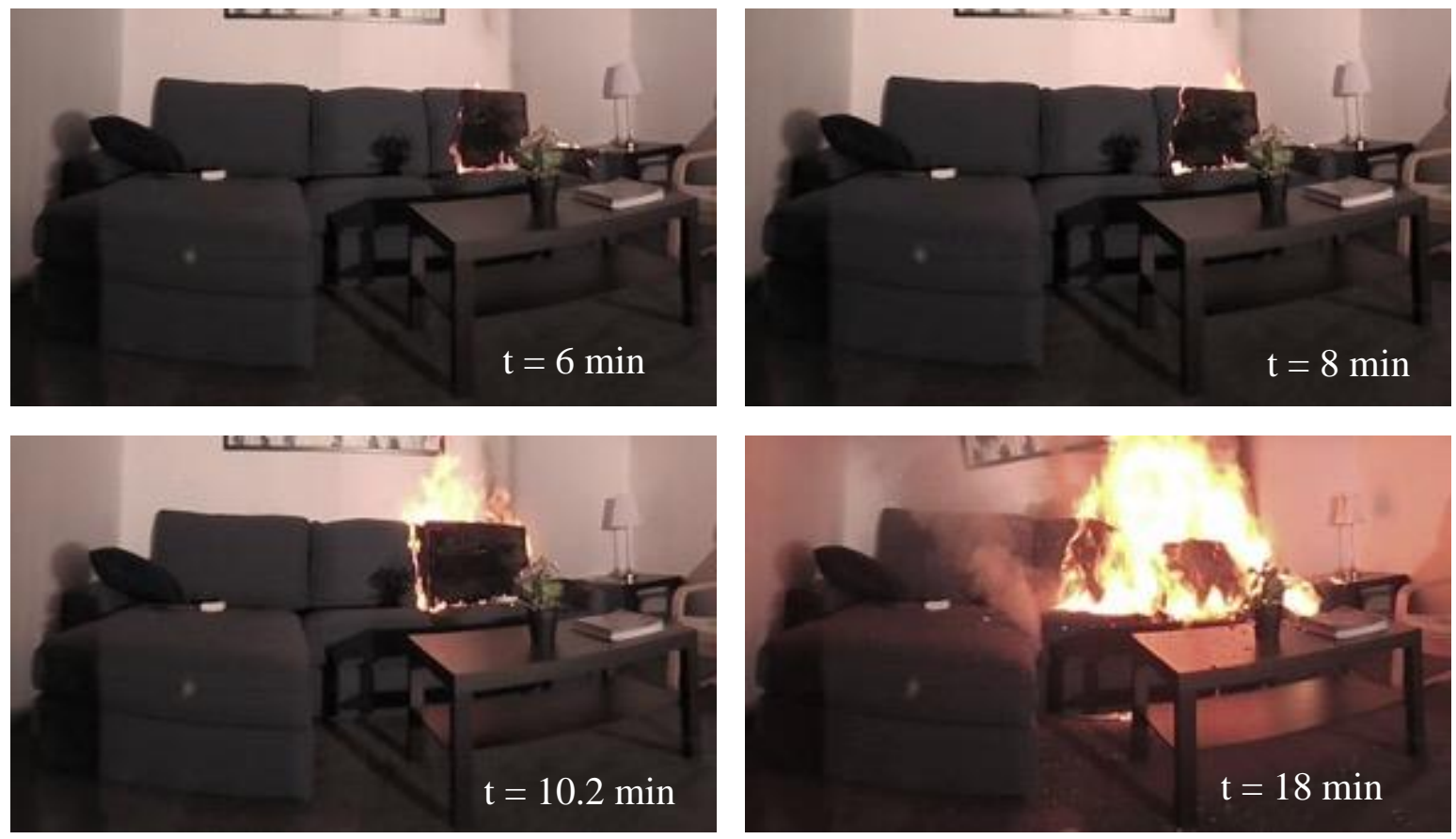

Fig. 23. Video frames captured during Test 2 at $\mathrm{t}=6 \mathrm{~min}, 8 \mathrm{~min}, 10.2 \mathrm{~min}$, and $18 \mathrm{~min}$. 
The failure mechanism of the barrier fabric in Test 2, which led to a rapid increase in heat release rate and flashover, appeared to be triggered by bottom ignition and the consequent mass transfer of regenerated polyols through the pores of the barrier fabric while the barrier fabric was still intact. This failure mechanism was previously observed in a series of chair mock-up tests carried out at NIST [22]. The so-called "Cube Test" is a cone-calorimeter based test that was developed at NIST to predict this failure mechanism and its effect on heat release rate by capturing mass and heat transfer phenomena throughout the burning process [42].

\subsection{Heat Flux}

Fig. 24 shows the heat fluxes measured on the couch near the ignition location (PTC4). In Test 1 and Test 3, the heat flux reached about $75 \mathrm{~kW} / \mathrm{m}^{2}$ after about $4 \mathrm{~min}$. These data suggest that values of incident heat flux over $50 \mathrm{~kW} / \mathrm{m}^{2}$ are advisable for a robust evaluation of the fire performance of barrier fabric at bench scale. Values of incident heat flux of $75 \mathrm{~kW} / \mathrm{m}^{2}$ were adopted in the Cube Test for ranking the performance of barrier fabrics [23]. In Test 3, the heat flux peaks at about $10 \mathrm{~kW} / \mathrm{m}^{2}$ at about 2 min when the throw pillow is still burning, and then drops to below $5 \mathrm{~kW} / \mathrm{m}^{2}$ until bottom ignition. After flashover the heat flux reached peak values above $150 \mathrm{~kW} / \mathrm{m}^{2}$ in all three tests. Noticeably, the highest peak value was achieved in Test 2 (about $200 \mathrm{~kW} / \mathrm{m}^{2}$ ) despite the presence of the barrier fabric, possibly due to the strong and prolonged flame heat feedback between the pool fire and the unburned portions of the couch. Comparable peak flux values were measured on the left side of the couch on PTC5 (see Appendices).

The heat fluxes along the wall reached the highest values at PTC 3 close to the ceiling; the peak value of heat flux was about $175 \mathrm{~kW} / \mathrm{m}^{2}$ in Test 1 and Test 3 and about $150 \mathrm{~kW} / \mathrm{m}^{2}$ for Test 2 .

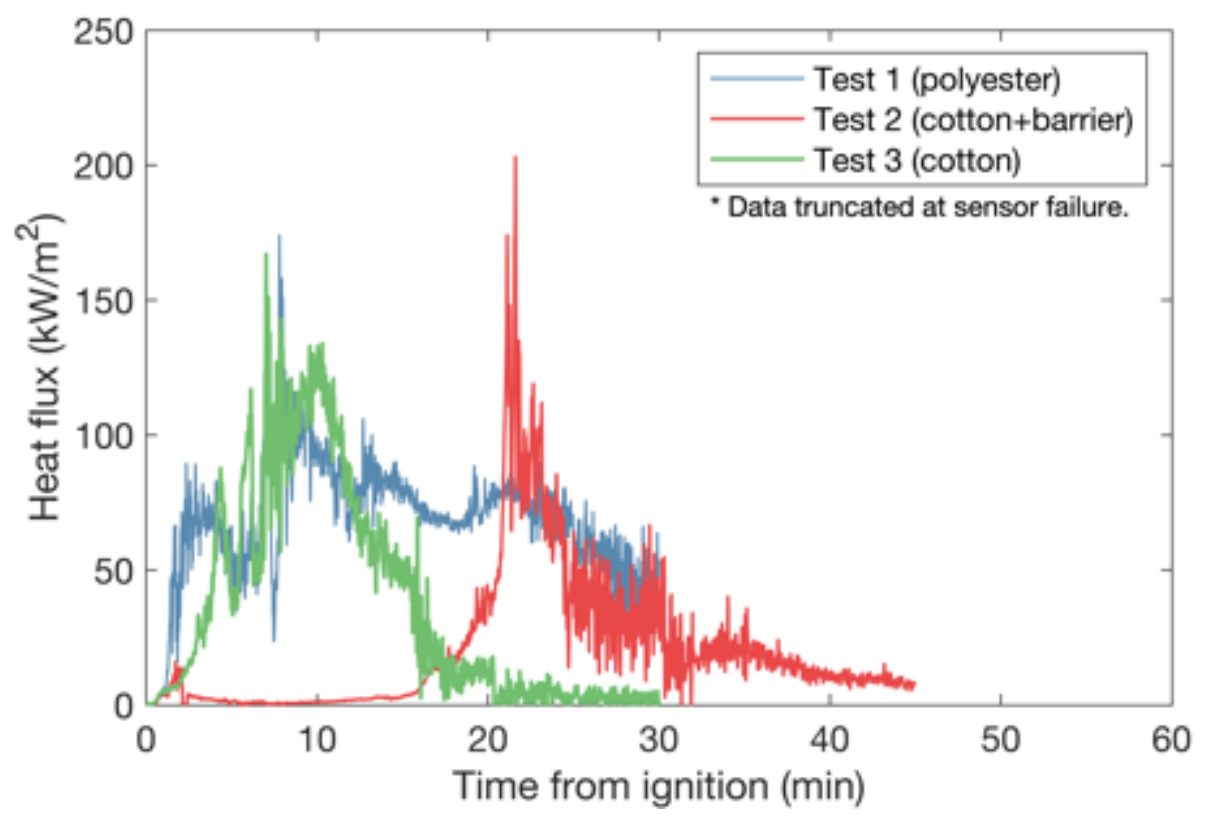

Fig. 24. Heat flux measured on top of the couch near the ignition location (PTC4) for Test 1, Test 2, and Test 3. 


\subsection{Tenability Conditions}

During and immediately after a fire, conditions may become untenable such that the occupants are incapacitated and cannot escape by themselves, in which case they are likely to die unless rescued. The leading cause of incapacitation and death during and immediately after fires is exposure to asphyxiant gases: carbon monoxide $(\mathrm{CO})$, hydrogen cyanide $(\mathrm{HCN})$, and carbon dioxide $\left(\mathrm{CO}_{2}\right)$, with some additional effects from low-oxygen hypoxia and inhaled irritants [48]. The effect of fire effluents on incapacitation can be estimated using the Fractional Effective Dose [49]. In upholstery furniture flammability without chemical fire retardants, carbon monoxide is the main hazard, although the contribution of hydrogen cyanide is also significant [50, 51].

The CO concentration at which there is danger of incapacitation after approximately $5 \mathrm{~min}$ exposure in a person engaged in light activity is about $6000 \mathrm{ppm}$ to $8000 \mathrm{ppm}$ [48]. These values are never reached in our tests (see Fig. 25) due to the high ventilation factor of $0.14 \mathrm{~m}^{1 / 2}$ but could be easily achieved in more realistic room scenarios [50].

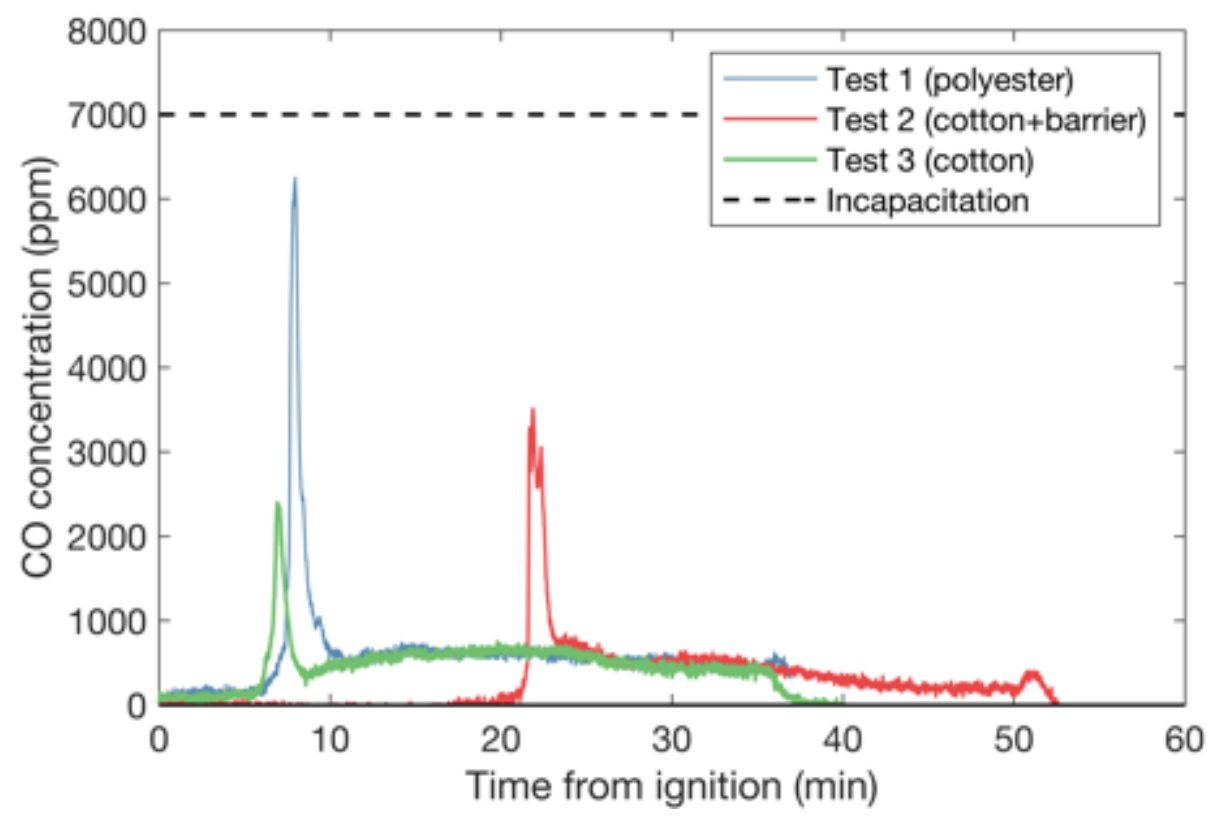

Fig. 25. CO concentration measured for Test 1, Test 2, and Test 3 (from gas probe inside the room shown in Fig. 7) and $\mathrm{CO}$ incapacitation level after approximately 5 min exposure according to [48].

Alternate tenability criteria include: a maximum upper layer gas temperature of $200{ }^{\circ} \mathrm{C}$ and an exposure to radiant heat fluxes above $2.5 \mathrm{~kW} / \mathrm{m}^{2}$ [48]. For each test, Table 8 shows the times at which: (1) a temperature of $200{ }^{\circ} \mathrm{C}$ at Tceiling was reached $\left(\mathrm{t}_{200}{ }^{\circ} \mathrm{C}\right)$, and; (2) a heat flux of

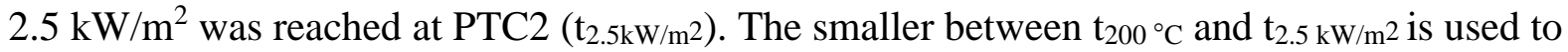


estimate the time at which untenable conditions were reached. The onset of untenable conditions for each Test is shown in Fig. 20. These data indicate that untenable conditions were reached before flashover and, thus, heat exposure rather than gas toxicity seems to be the main hazard in this scenario.

Table 8 also shows the Available Safe Egress Time (ASET) in the enclosure fire calculated as the time between smoke alarm triggering (see Table 7) and the onset of untenable conditions [52].

Available Safe Egress Time values below $3 \mathrm{~min}$ for both Test 1 and Test 3 indicated an extremely high fire hazard. The adoption of a barrier fabric in Test 2 allowed a significant increase in the ASET value from about $3 \mathrm{~min}$ to about $15 \mathrm{~min}$ which would drastically increase the likelihood of survival for an occupant.

Table 8. Time at which an upper layer temperature of $200{ }^{\circ} \mathrm{C}$ at Tceiling $\left(\mathrm{t}_{200}{ }^{\circ} \mathrm{C}\right)$ and flux of $2.5 \mathrm{~kW} / \mathrm{m}^{2}$ at PTC2 $\left(\mathrm{t}_{2.5} \mathrm{~kW} / \mathrm{m}^{2}\right)$ were met and calculated Available Safe Egress Time (ASET).

\begin{tabular}{cccc}
\hline & $\mathrm{t}_{200}{ }^{\circ} \mathrm{C}(\min )$ & $\mathrm{t}_{2.5 \mathrm{~kW} / \mathrm{m} 2}(\min )$ & ASET $(\min )$ \\
\hline Test 1 & 3.92 & 3.33 & 2.63 \\
Test 2 & 16.03 & 16.56 & 15.25 \\
Test 3 & 3.05 & 3.05 & 2.30 \\
\hline
\end{tabular}




\section{Summary and Conclusions}

This study conducted a series of three full-scale compartment fire experiments to help characterize the potential fire hazard of residential upholstered furniture (RUF) and the potential ability of a barrier fabric to decrease such hazard. The barrier fabric used in this series of experiments did not contain fire retardant chemicals; instead, it relied on intrinsically fire resistant materials and on physical mechanisms of fire retardancy - such as reduction in mass and heat transfer - to slow the combustion of the gaseous and liquid products of decomposition produced by the furniture padding material.

A representative living room was constructed and furnished identically except for three different couches that were the same except for the following.

- Test 1 - couch with polyester cover fabric in Test 1

- Test 2 - couch with a cotton blend cover fabric and a barrier fabric (made of intrinsically fire resistant fibers without any additional fire retardant)

- Test 3 - couch with only a cotton blend cover fabric (same cover fabric as Test 2).

A throw pillow on the right arm of the couch ignited using a $3 \mathrm{~cm}$ propane diffusion flame acted as an ignition source for each of the couches.

Measurements during the compartment fires included heat release rate, gas species $\left(\mathrm{O}_{2}, \mathrm{CO}\right.$, $\mathrm{CO}_{2}$ ), video, plate thermocouples and exposed junction or sheathed thermocouples.

From this limited set of experiments, the results demonstrate that the use of a fire barrier without chemically active flame retardants can remarkably delay the growth of RUF fires. The two couches without a barrier fabric, which were compliant with TB-117-2013, posed a severe fire hazard with rapid fire growth leading to flashover within approximately 6 minutes of ignition. The addition of the barrier fabric delayed flashover by about $15 \mathrm{~min}$ from about $6 \mathrm{~min}$ to $21 \mathrm{~min}$, and increased the estimated Available Safe Egress Time (ASET) from less than 3 min to over $15 \mathrm{~min}$.

Considering target fire service response times, this delay is important because allows first responders additional time to intervene before flashover (alarming time plus response time is typically 12 min to 17 min depending on whether the location is urban or rural) and potentially prevent flashover occurrence. Flashover prevention is critical because it can stop fire spread to adjacent rooms and building; where most fire losses occur.

For this test series, the barrier fabric in these experiments covered all padding material but not the back of the couch, where flaming rapidly spread over the wadding and cover fabric once ignited. Thus, a further improvement in fire performance could be expected if the back of the couch was also protected by additional barrier fabric.

The presence of the barrier fabric also affected the mechanism by which flashover conditions were reached and the role of pool fire formation. Without barrier fabric, flashover conditions could occur before a regenerated polyol pool formed on the floor with little to no flaming on the bottom of the couch. With the barrier fabric, flashover occurred several minutes after the appearance of flaming underneath the couch and the formation of a pool fire; pool fire 
increased the pyrolysis rate of the residual padding material and, in turn, caused an additional increase in heat release rate that lead to flashover.

In summary, the limited set of data in this report suggest that:

a) despite compliance with cigarette ignition tests, residential upholstered furniture may still pose a considerable fire hazard due to rapid fire growth and flame spread in presence of a flaming ignition source;

b) technologies promoting fire safety and health/environment safety for residential upholstered furniture are not mutually exclusive as these tests demonstrate that nontoxic technologies, which can meet both requirements, not only exist but are commercially available;

c) the presence of a barrier fabric resulted in a 15 min delay in time to flashover and 12 min increase in estimated ASET drastically decreased the fire hazard;

d) the mechanisms that lead to failure of the barrier fabric and consequent flashover in the compartment appear to be triggered by the ignition of liquid pyrolyzates percolating through the bottom barrier fabric in the residential upholstered furniture item. 


\section{References}

[1] Ahrens M (2019) Home Structure Fires (National Fire Protection Association).

[2] Ahrens M (2020) Soft furnishing fires: They're still a problem. Fire and Materials:19.

[3] Hall JR (2015) Estimating Fires When a Product is the Primary Fuel But Not the First Fuel, With an Application to Upholstered Furniture. Fire Technology 51(2):381-391. https://doi.org/10.1007/s10694-014-0391-8

[4] Ohlemiller T (1995) Smoldering Combustion. SFPE Handbook of Fire Protection Engineering, eds DiNenno PJ, Beyler CL, Custer RLP, \& Walton WD (National Fire Protection Association, Quincy, MA), Vol. 2, Chapter 11, 2 Ed., pp 171-179.

[5] Ahrens M (2017) Home Fires That Began With Upholstered Furniture. (National Fire Protection Association, Quincy, MA).

[6] Hall JR (2015) Estimating fires when a product is the primary fuel but not the first fuel, with an application to upholstered furniture. Fire Technology 51:381-391. https://doi.org/10.1007/s10694-014-0391-8

[7] Agency NFP (2013)-NFPA 260 - Standard Methods of Tests and Classification System for Cigarette Ignition Resistance of Components of Upholstered Furniture).

[8] ASTM (2008)-Standard E1353, Standard Test Methods for Cigarette Ignition Resistance of Components of Upholstered Furniture. West Conshohocken, PA.). https://doi.org/10.1520/E1353-08AE01

[9] Anonymous (2013) Technical Bullettin 117-2013. Requirements, Test Procedure and Apparatus for Testing the Smolder Resistance of Materials Used in Upholstered Furniture. ed Insulation B-BoEaARHFaT (Sacramento, CA).

[10] Anonymous (2018) NFPA 261 - Standard Method of Test for Determining Resistance of Mock-Up Upholstered Furniture Material Assemblies to Ignition by Smoldering Cigarettes.

[11] Anonymous (2016) ASTM E1352-16 Standard Test Method for Cigarette Ignition Resistance of Mock-Up Upholstered Furniture Assemblies.

[12] Yang J, Rein G, Chen H, Zammarano M (2020) Smoldering propensity in upholstered furniture: Effects of mock-up configuration and foam thickness. Applied Thermal Engineering 181:115873.

https://doi.org/https://doi.org/10.1016/j.applthermaleng.2020.115873

[13] Anonymous (2018) AB-2998 Consumer products: flame retardant materials. (State of California).

[14] Anonymous (2018) An Act To Protect Firefighters by Establishing a Prohibition on the Sale and Distribution of New Upholstered Furniture Containing Certain Flameretardant Chemicals (State of Maine).

[15] Anonymous ed (2017) Amending Annex XVII to Regulation (EC) No 1907/2006 of the European Parliament and of the Council concerning the Registration, Evaluation, Authorisation and Restriction of Chemicals (REACH) as regards bis(pentabromophenyl)ether).

[16] Papaspyrides CD , Kiliaris P (2014) Polymer Green Flame Retardants (Elsevier, Amsterdam), p 924.

[17] Babrauskas V (1985) Pillow burning rates. Fire Safety Journal 8(3):199-200. https://doi.org/https://doi.org/10.1016/0379-7112(85)90015-3 
[18] Nazare S , Davis R (2012) A Review of Fire Blocking Technologies for Soft Furnishings. Fire Science Reviews 1(1):1.

[19] Weil ED, Levchik SV (2008) Flame Retardants in Commercial Use or Development for Textiles. Journal of Fire Sciences 26(3):243-281. https://doi.org/10.1177/0734904108089485

[20] Nazaré S, Pitts WM, Matko S, Davis RD (2014) Evaluating smoldering behavior of fire-blocking barrier fabrics. Journal of Fire Sciences. https://doi.org/10.1177/0734904114543450

[21] Heidari S, Parén A, Nousiainen P (1993) The mechanism of fire resistance in viscose/silicic acid hybrid fibres. Journal of the Society of Dyers and Colourists 109(7-8):261-263. https://doi.org/10.1111/j.1478-4408.1993.tb01572.x

[22] Thompson AL, Kim I, Hamins A, Bundy M, Zammarano M (2020) Fire Barrier Fabrics in Residential Upholstered Furniture: Understanding their Performance and Failure Mechanism. In preparation.

[23] Zammarano M, Shields J, Leventon IT, Kim I, Nazare S, Thompson AL, Davis D, Rick, Chernovsky A, Bundy M (2020) Reduced-Scale Test to Assess the Effect of Fire Barriers on the Flaming Combustion of Cored Composites: An UpholsteryMaterial Case Study.

[24] Babrauskas VRF, Arlene Blum (2014) Flame Retardant Additives in Polymers: When do the Fire Safety Benefits Outweigh the Toxicity Risks? (Vytenis Babrauskas, Rebecca Fuoco Arlene Blum). Polymer Green Flame Retardants: A comprehensive Guide to Additives and Their Applications, eds Papaspyrides CD \& Kiliaris P (Elsevier Science), Chapter 3 pp 87-118.

[25] National Academies of Sciences E , Medicine (2019) A Class Approach to Hazard Assessment of Organohalogen Flame Retardants (The National Academies Press, Washington, DC), p 114.

[26] Chemicals. NRCUSoF-R (2000) Toxicological Risks of Selected Flame-Retardant Chemicals. (National Research Council). https://doi.org/10.17226/9841

[27] Petreas M, Gill R, Takaku-Pugh S, Lytle E, Parry E, Wang M, Quinn J, Park J-S (2016) Rapid methodology to screen flame retardants in upholstered furniture for compliance with new California labeling law (SB 1019). Chemosphere 152:353-359.

[28] Heidari S, Paren A, Nousiainen P (1993) The mechanism of fire resistance in viscose/silicic acid hybrid fibres. Journal of the Society of Dyers and Colourists banner 109(7-8):261-263. https://doi.org/10.1111/j.1478-4408.1993.tb01572.x

[29] ASTM (2018)- D737-18 Standard Test Method for Air Permeability of Textile Fabrics).

[30] Pitts W, Werrel M, Fernandez M, Long AM, Eisenberg EA, Runyon CD (2020) Assessing the Predictive Capability for Real-Scale Residential Upholstered Furniture Mock-Up Fires using Cone Calorimeter Measurements. Part 1: Real-Scale Experiments. https://doi.org/https://doi.org/10.6028/NIST.SP.1246

[31] Bryant RA, Bundy MF (2019) Calorimetry Measurement System for Large-Fire Research.

[32] Putorti A, Melly NB, Bareham S, Praydis Jr J (2015) Characterizing the Thermal Effects of High Energy Arc Faults. 23th International Conference on Structural Mechanics in Reactor Technology (SMiRT 23)-14th International Post Conference Seminar on Fire Safety in Nuclear Power Plants and Installations. 
[33] Ingason H, Wickström U (2007) Measuring incident radiant heat flux using the plate thermometer. Fire Safety Journal 42(2):161-166.

[34] Wickström U (1994) The plate thermometer-a simple instrument for reaching harmonized fire resistance tests. Fire Technology 30(2):195-208.

[35] Wickström U, Anderson J, Sjöström J (2019) Measuring incident heat flux and adiabatic surface temperature with plate thermometers in ambient and high temperatures. Fire and Materials 43(1):51-56.

[36] Taylor BN , Kuyatt CE (1994) Guidelines for evaluating and expressing the uncertainty of NIST measurement results.

[37] Hoehler MS (2020) Improved Video Capture for Severe Fire Environments. Available at https://tsapps.nist.gov/publication/get_pdf.cfm?pub_id=930361.

[38] Hoehler MS (2020) On the development of a transparent enclosure for $360^{\circ}$ video cameras to observe severe fires in Situ. Fire Safety Journal:103024.

[39] Ohlemiller TJ, Villa KM (1990) Furniture Flammability: An Investigation of the California Bulletin 133 Test. Part II: Characterization of the Ignition Source and a Comparable Gas Burner (US Department of Commerce, National Institute of Standards and Technology).

[40] Anonymous (1991) Flammability test procedure for seating furniture for use in public occupancies. Technical Bulletin 133.

[41] Anonymous (2019) Government Code Section 11349.3. ed Bureau of Electronic and Appliance Repair HFaTtI.

[42] Ohlemiller T, Shields J (1995) NISTIR 5653. Behavior of Mock-Ups in the California Technical Bulletin 133 Test Protocol: Fabric and Barrier Effects. (NIST, Gaithersburg, MD).

[43] Graham T, Makhviladze GM, Roberts JP (1995) On the theory of flashover development. Fire Safety Journal 25(3):229-259.

[44] NFPA (2010)-NFPA 1720, Standard for the Organization and Deployment of Fire Suppression Operations, Emergency Medical Operations, and Special Operations to the Public by Volunteer Fire Departments).

[45] Association NFP (2010) NFPA 1710, standard for the organization and deployment of fire suppression operations, emergency medical operations, and special operations to the public by career fire departments (National Fire Protection Association).

[46] Ravey M , Pearce EM (1997) Flexible Polyurethane Foam. I. Thermal Decomposition of a Polyether-based, Water-blown Commercial Type of Flexible Polyurethane Foam. Journal of Applied Polymer Science 63(1):47-74. https://doi.org/10.1002/(SICI)10974628(19970103)63:1<47::AID-APP7>3.0.CO;2-S

[47] Krämer RH, Zammarano M, Linteris GT, Gedde UW, Gilman JW (2010) Heat release and structural collapse of flexible polyurethane foam. Polymer Degradation and Stability 95(6):1115-1122. https://doi.org/https://doi.org/10.1016/i.polymdegradstab.2010.02.019

[48] Purser DA, McAllister JL (2016) Assessment of hazards to occupants from smoke, toxic gases, and heat. SFPE handbook of fire protection engineering, (Springer), pp 2308-2428.

[49] ISO (2012)-ISO 13571:2012 - Life-threatening Components of Fire-Guidelines for the Estimation of Time to Compromised Tenability in Fires). 
[50] McKenna ST, Birtles R, Dickens K, Walker RG, Spearpoint MJ, Stec AA, Hull TR (2018) Flame retardants in UK furniture increase smoke toxicity more than they reduce fire growth rate. Chemosphere 196:429-439.

[51] Babrauskas V, Levin BC, Gann RG, Paabo M, Harris RH, Peacock RD, Yusa S (1992) Toxic potency measurement for fire hazard analysis. Fire Technology 28(2):163-167. https://doi.org/10.1007/BF01857942

[52] Cooper LY (1983) A concept for estimating available safe egress time in fires. Fire Safety Journal 5(2):135-144. https://doi.org/https://doi.org/10.1016/03797112(83)90006-1

[53] Bryant RA, Bundy MF (2019) The NIST 20 MW Calorimetry measurement system for large-fire research. 


\section{Appendix A: Uncertainty of Measurements}

The measurements in this report include sensor positions, heat release rate, temperature, and gas species concentration. Heat fluxes calculated from the temperatures are also provided. For each measurand, Type A and/or Type B uncertainties, combined standard uncertainties, and total expanded uncertainties were estimated. As defined in Taylor and Kuyatt [36], Type A uncertainty was evaluated using statistical methods; Type B uncertainty was estimated by other means such as the information available in manufacturer's specifications, from pastexperience, or engineering judgement. The combined standard uncertainty was estimated by combining the individual uncertainties using "root-sum-of-squares". The expended uncertainty was computed by multiplying the combined uncertainty by a coverage factor of 2 corresponding to an approximately $95 \%$ confidence interval.

Table 9 summarizes the components of the measurement uncertainty. All uncertainties are assumed to be symmetric ( \pm ). The following definitions are used:

Precision: Uncertainty in the ability of the measurement instrument to resolve information from the sensor.

Bias: Uncertainties from the calibration of the sensor or estimated based on the resolution of the sensor, as well as uncertainties from other known sources of error.

Random error: Uncertainty due to random, unpredictable variations in the measurement process during a typical steady-state period.

Table 9. Uncertainty in the reported data.

\begin{tabular}{|c|c|c|c|c|}
\hline Measurement / Component & $\begin{array}{l}\text { Estimation } \\
\text { Method }\end{array}$ & $\begin{array}{l}\text { Component } \\
\text { Standard } \\
\text { Uncertainty }\end{array}$ & $\begin{array}{l}\text { Combined } \\
\text { Standard } \\
\text { Uncertainty }\end{array}$ & $\begin{array}{c}\text { Total } \\
\text { Expanded } \\
\text { Uncertainty }\end{array}$ \\
\hline \multicolumn{5}{|l|}{ Sensor location, $\mathrm{mm}$} \\
\hline Precision (ability to read tape measure with eye) & Type B & 0.8 & & \\
\hline Bias (accuracy of tape measure increments) & Type B & 0.8 & 25 & 50 \\
\hline Random error (estimate) & Type B & 25 & & \\
\hline \multicolumn{5}{|l|}{ Temperature (gas; sheathed thermocouple), \% RD } \\
\hline Precision & Type B & 0.01 & & \\
\hline Bias $^{\text {a }}$ & Type B & 0.75 & 1.3 & 2.7 \\
\hline Random error $(\mathrm{N}=100)$ & Type A & 1.1 & & \\
\hline \multicolumn{5}{|l|}{ Temperature (mic; bare bead thermocouple), \% RD } \\
\hline Precision & Type B & 0.01 & 1.8 & 3.5 \\
\hline Bias a & Type B & 0.75 & & \\
\hline Random error (N=100) & Type A & 1.6 & & \\
\hline \multicolumn{5}{|l|}{ Temperature (BOB; bare bead thermocouple), \% RD } \\
\hline Precision & Type B & 0.01 & 1.0 & 2.1 \\
\hline Bias $^{\text {a }}$ & Type B & 0.75 & & \\
\hline Random error (N=100) & Type A & 0.7 & & \\
\hline \multicolumn{5}{|l|}{ Temperature (gas; bare bead thermocouple), \% RD } \\
\hline Precision & Type B & 0.01 & 3.9 & 7.7 \\
\hline Bias a & Type B & 0.75 & & \\
\hline Random error (N=100) & Type A & 3.8 & & \\
\hline
\end{tabular}




\begin{tabular}{|c|c|c|c|c|}
\hline Measurement / Component & $\begin{array}{c}\text { Estimation } \\
\text { Method }\end{array}$ & $\begin{array}{c}\text { Component } \\
\text { Standard } \\
\text { Uncertainty }\end{array}$ & $\begin{array}{c}\text { Combined } \\
\text { Standard } \\
\text { Uncertainty }\end{array}$ & $\begin{array}{c}\text { Total } \\
\text { Expanded } \\
\text { Uncertainty }\end{array}$ \\
\hline \multicolumn{5}{|l|}{ Temperature (plate thermocouple), \% RD } \\
\hline Precision & Type B & 0.01 & & \\
\hline Bias $^{\text {a }}$ & Type B & 0.75 & 0.9 & 1.8 \\
\hline Random error $(\mathrm{N}=100)$ & Type A & 0.5 & & \\
\hline Heat flux ${ }^{\mathrm{b}}, \% \mathrm{RD}$ & - & - & - & 5.0 \\
\hline Calorimeter heat release rate ${ }^{c}, \%$ RD & - & - & - & 7.9 to 9.6 \\
\hline
\end{tabular}

$\mathrm{RD}=$ reading; $\mathrm{N}=$ number of samples

a The standard limit of error is the greater of $\pm 0.75 \%$ or $2.2{ }^{\circ} \mathrm{C}$.

${ }^{\mathrm{b}}$ Average for steady state heating at $75 \mathrm{~kW} / \mathrm{m}^{2}$ per Putorti et al [32].

${ }^{c}$ Range of U/Qoc for the NFRL 10 MW calorimeter for "generic combustible fuel" per Bryant and Bundy (2020). [53] 


\section{Appendix B: Data for Test 1}

Remarks:

- Peak in ceiling temperature (Tceiling) in Fig. 32 just prior to ignition is caused by momentary heating with a propane touch as a visual marker for synchronizing the 360degere video and measured data. 


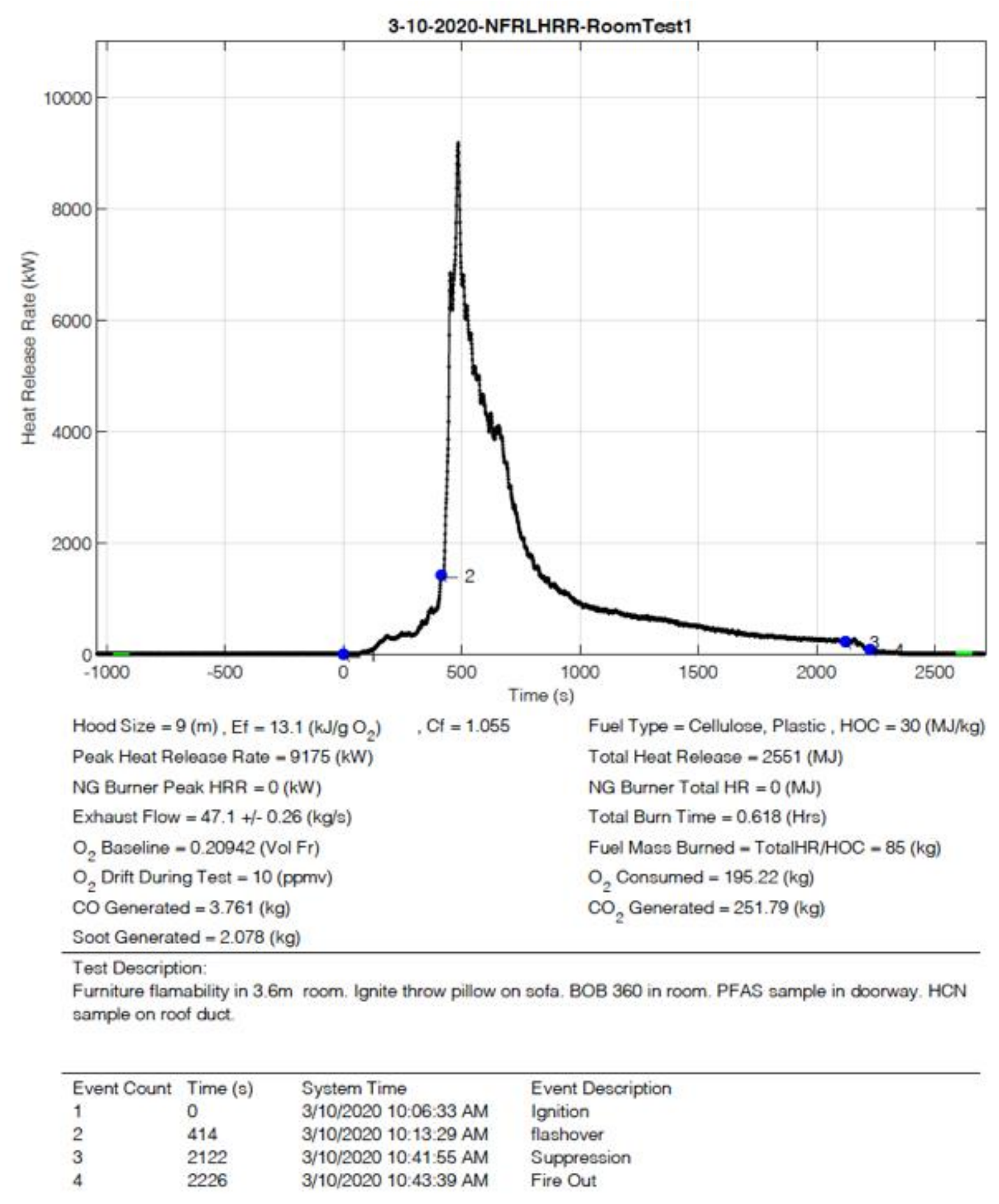

Fig. 26. Test 1 - Summary report file generated by the NFRL calorimetry system. 


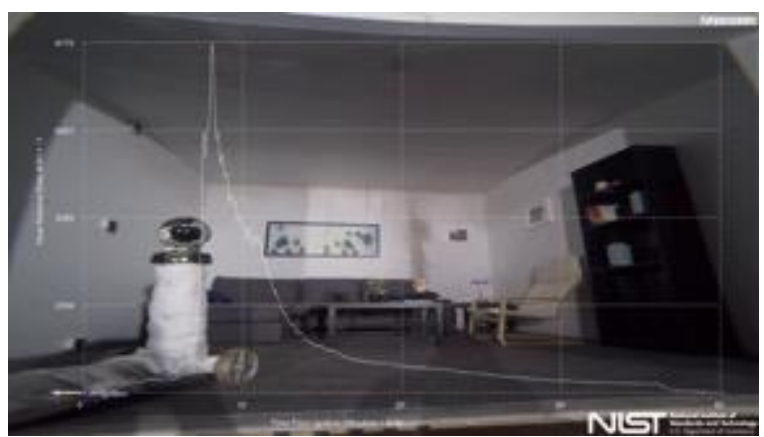

(a)

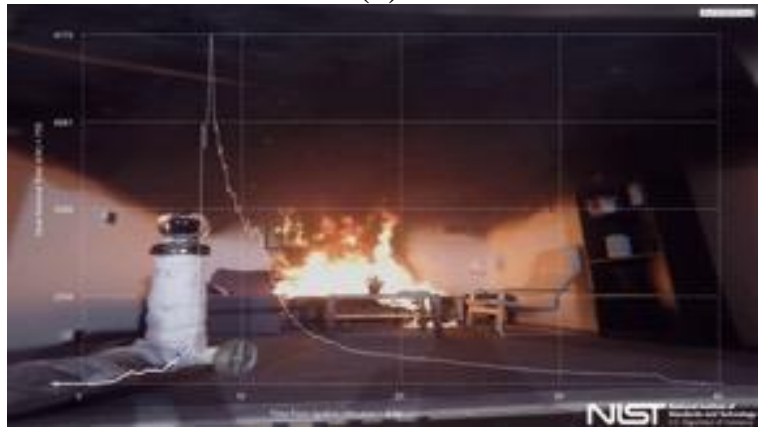

(c)

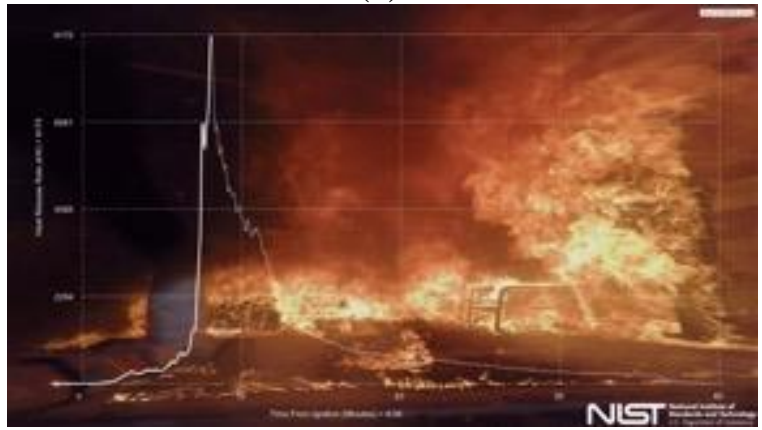

(e)

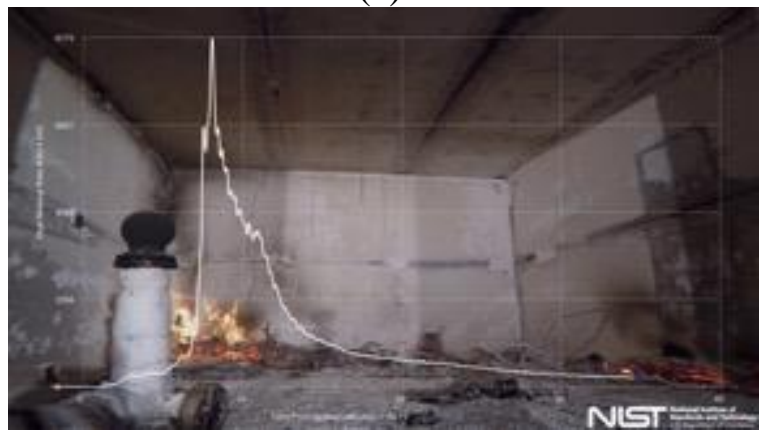

(g)

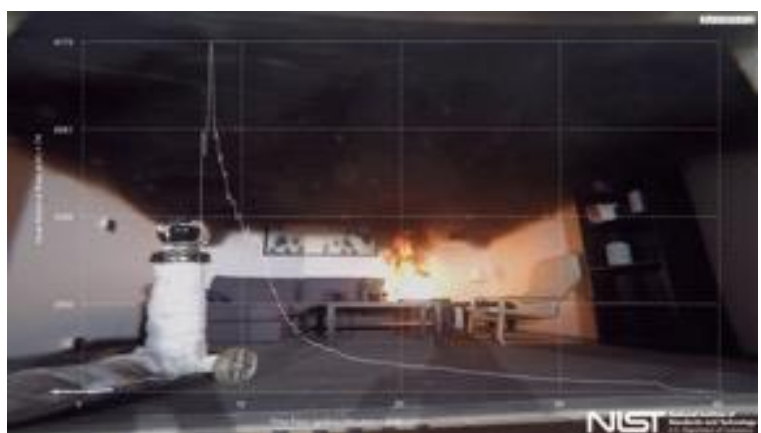

(b)

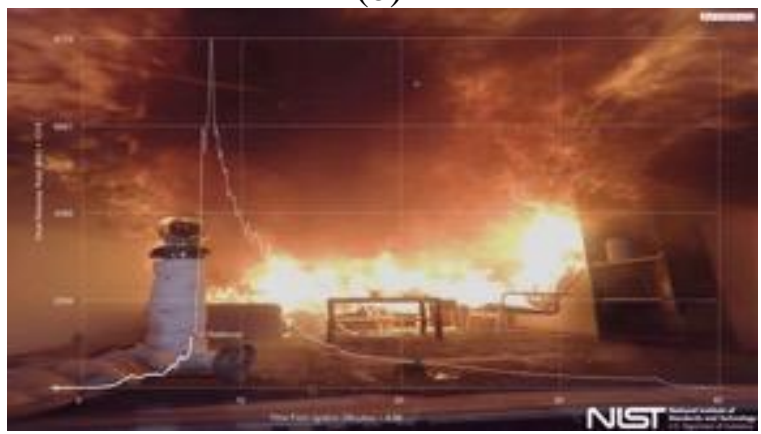

(d)

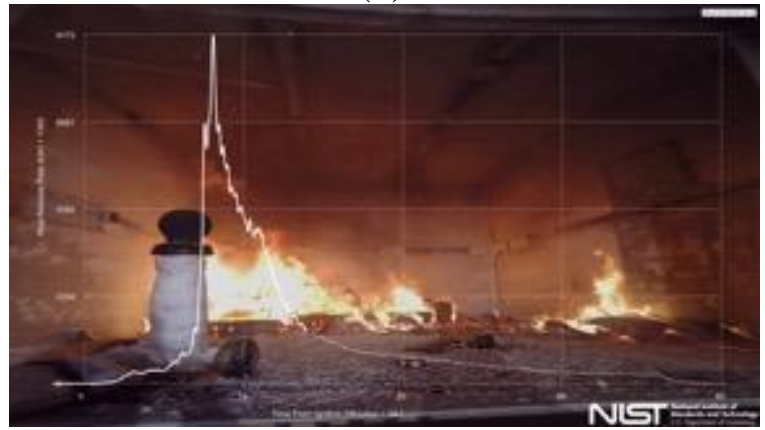

(f)

Fig. 27. Test 1 - Video snapshots with heat release rate curve overlaid. Times are relative to fire ignition: (a) just after ignition; (b) $2.02 \mathrm{~min}$; (c) $6.02 \mathrm{~min}$; (d) $6.98 \mathrm{~min}$ (near flashover); (e) $8.08 \mathrm{~min}$ (near peak HRR); (f) $14.1 \mathrm{~min}$ (well into decay); (g) $34.73 \mathrm{~min}$ (just prior to fire suppression). 


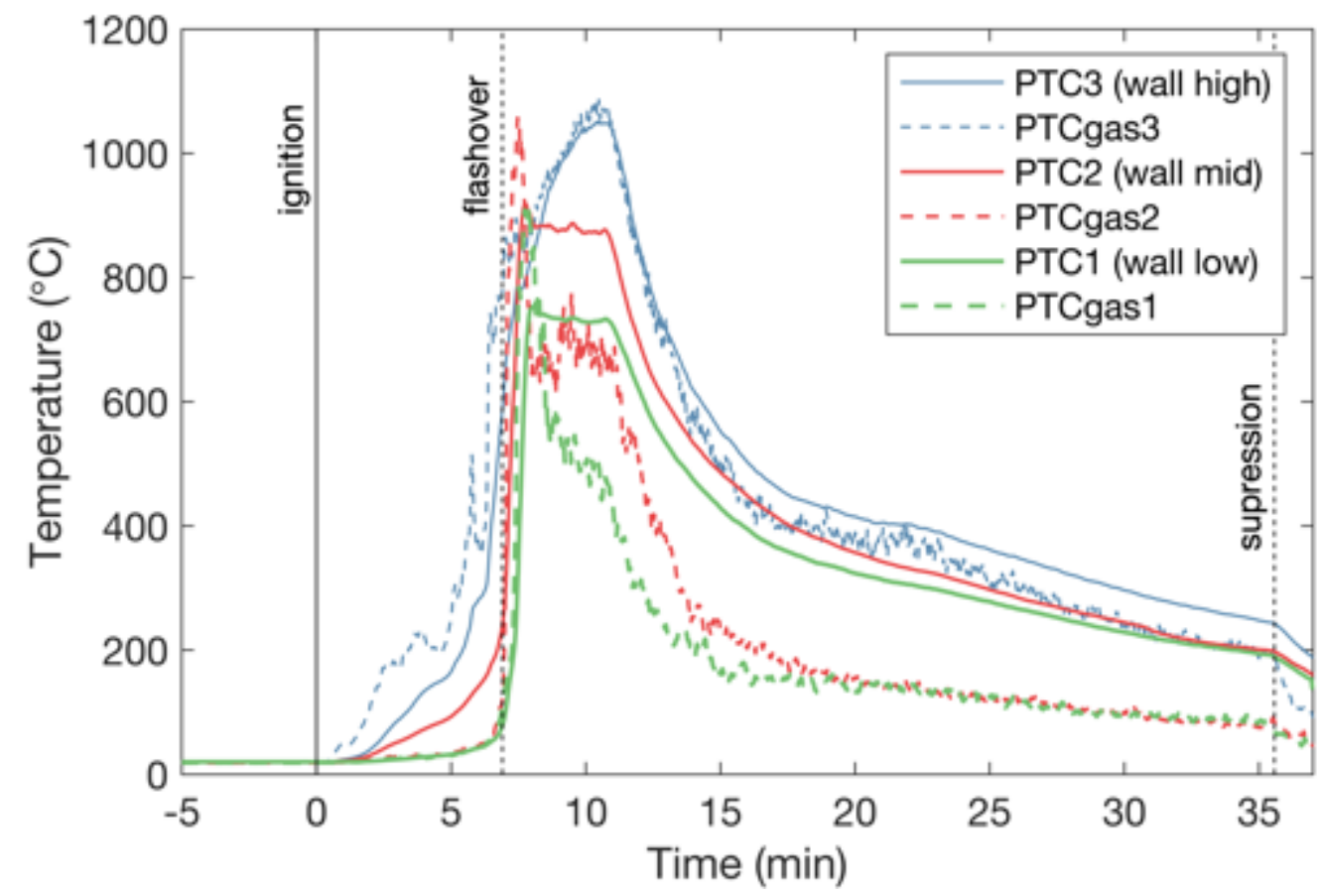

Fig. 28. Test 1 - Temperature measured by the plate thermocouples (PTC) and co-located bare bead thermocouples (PTCgas) on the compartment wall.

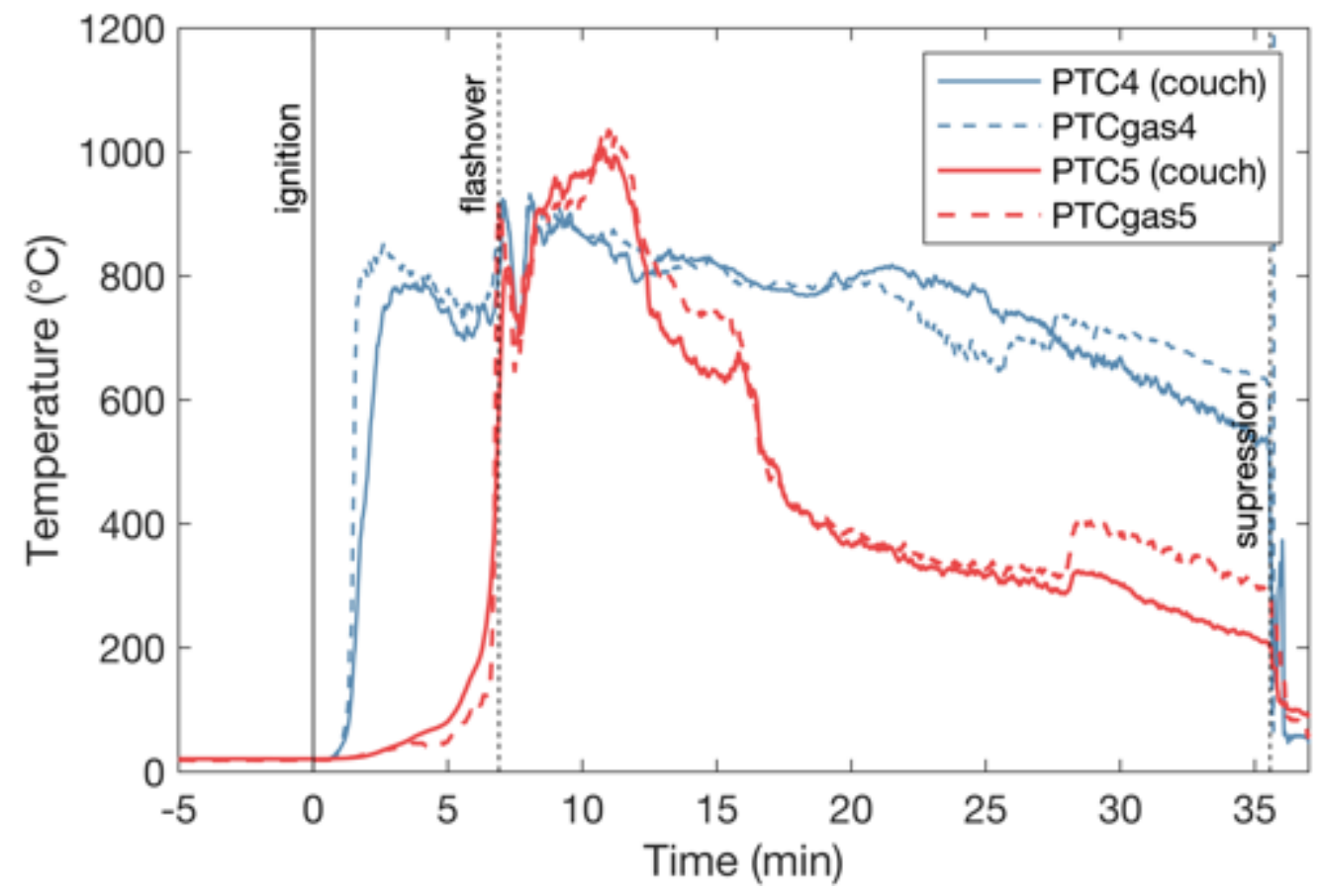

Fig. 29. Test 1 - Temperature measured by the plate thermocouples (PTC) and co-located bare bead thermocouples (PTCgas) on the couch. 


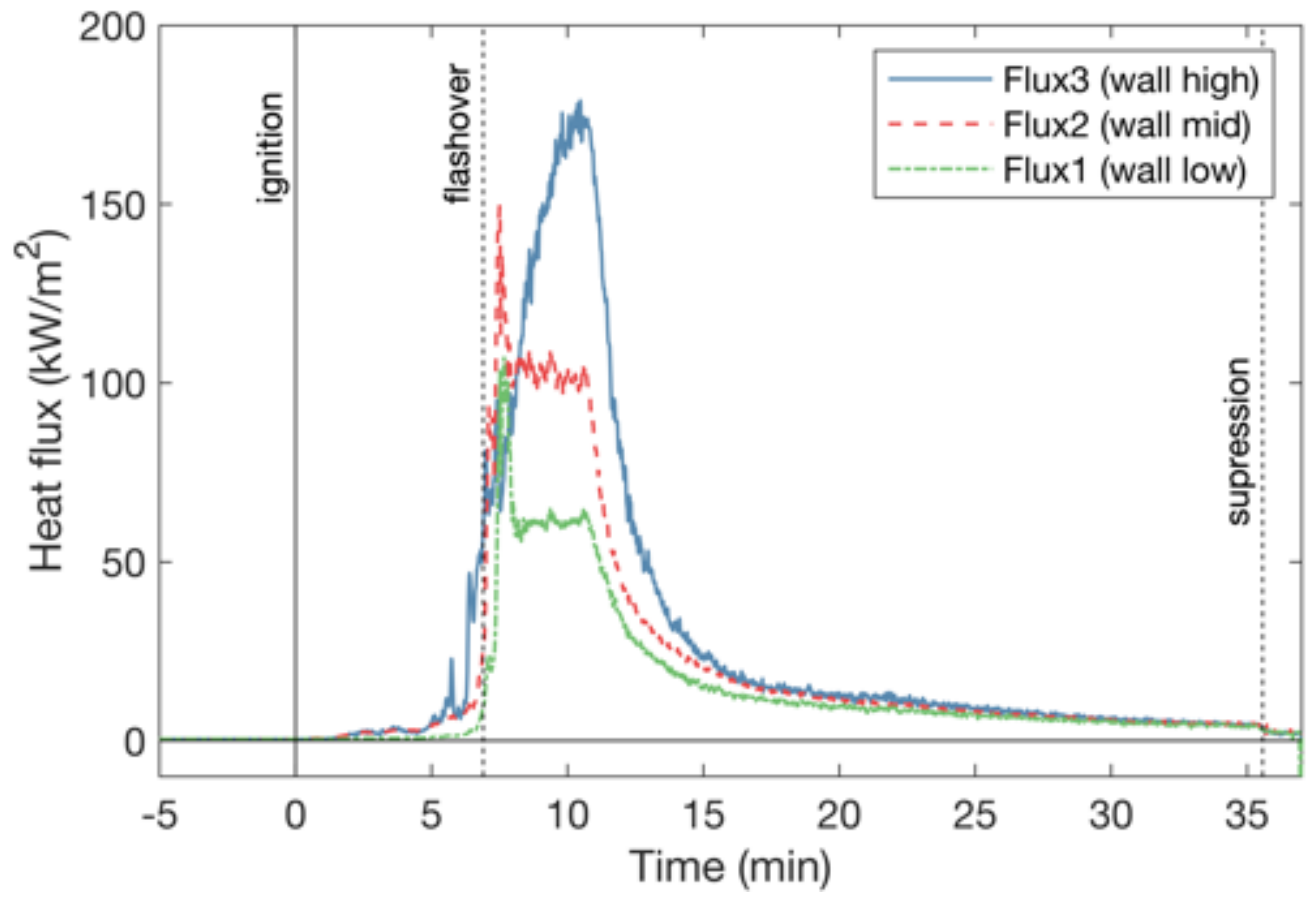

Fig. 30. Test 1 - Heat flux calculated for the plate thermocouples on the compartment wall.

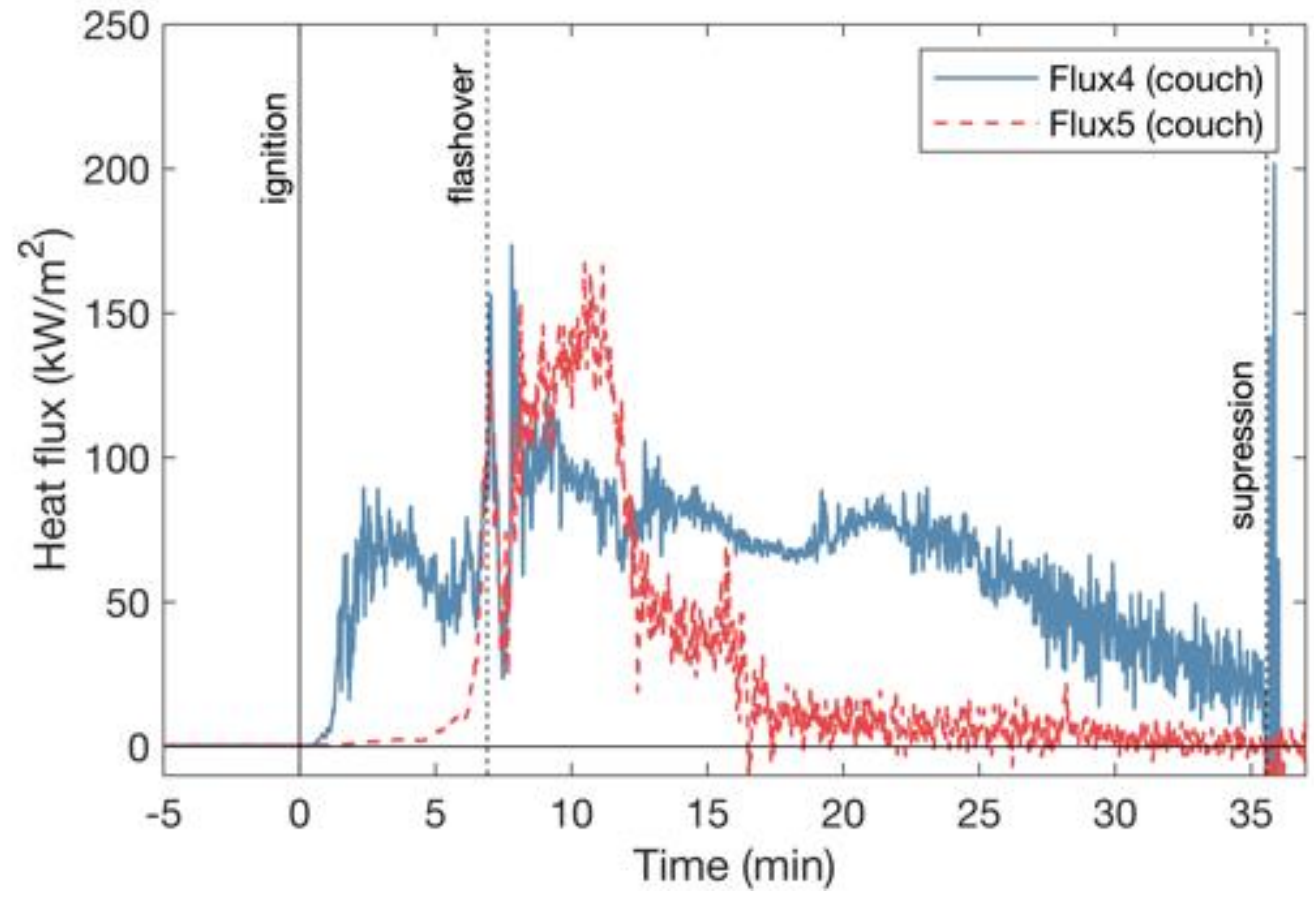

Fig. 31. Test 1 - Heat flux calculated for the plate thermocouples on the couch. 


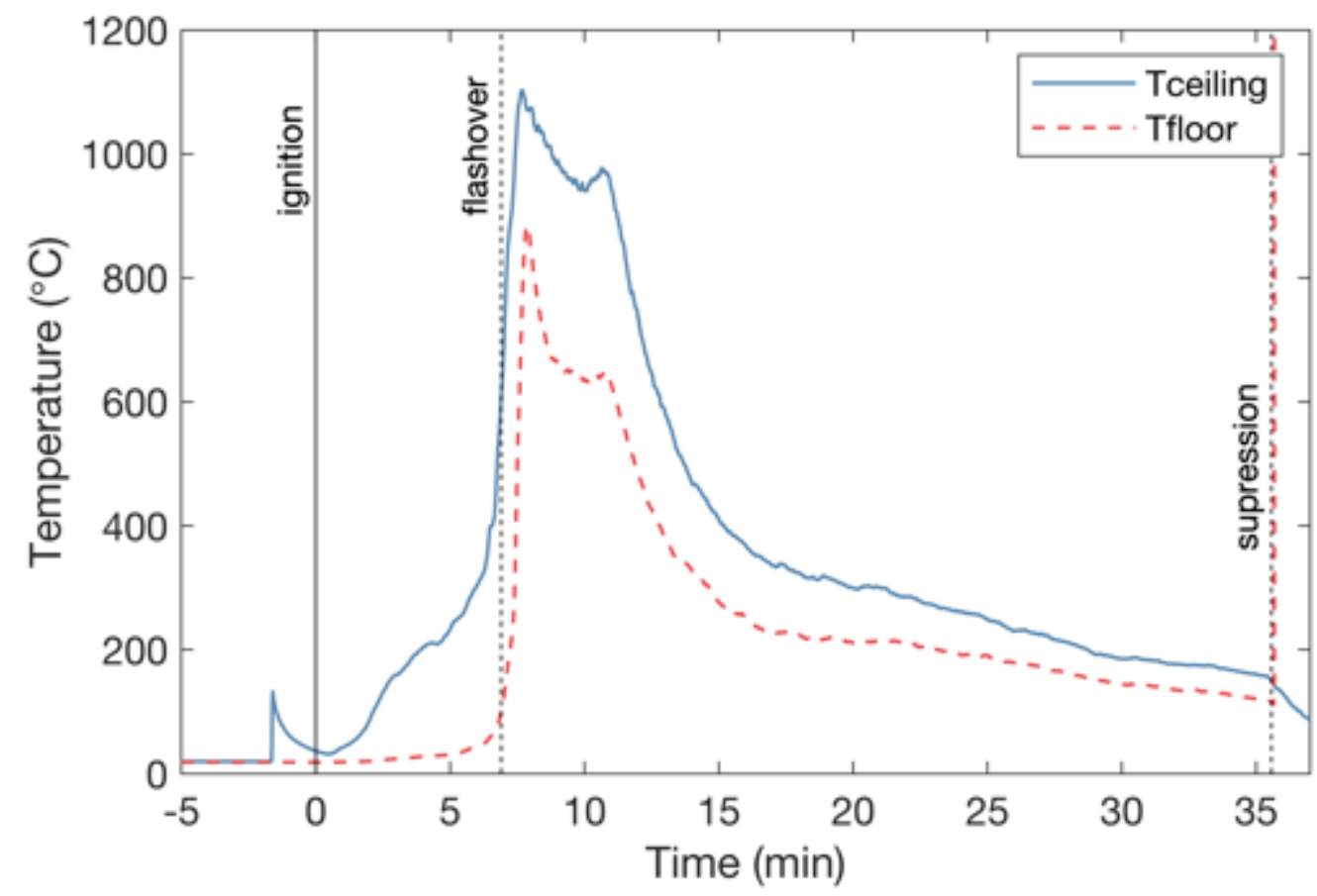

Fig. 32. Test 1 - Temperatures measured using shielded thermocouples near the ceiling and floor of the compartment.

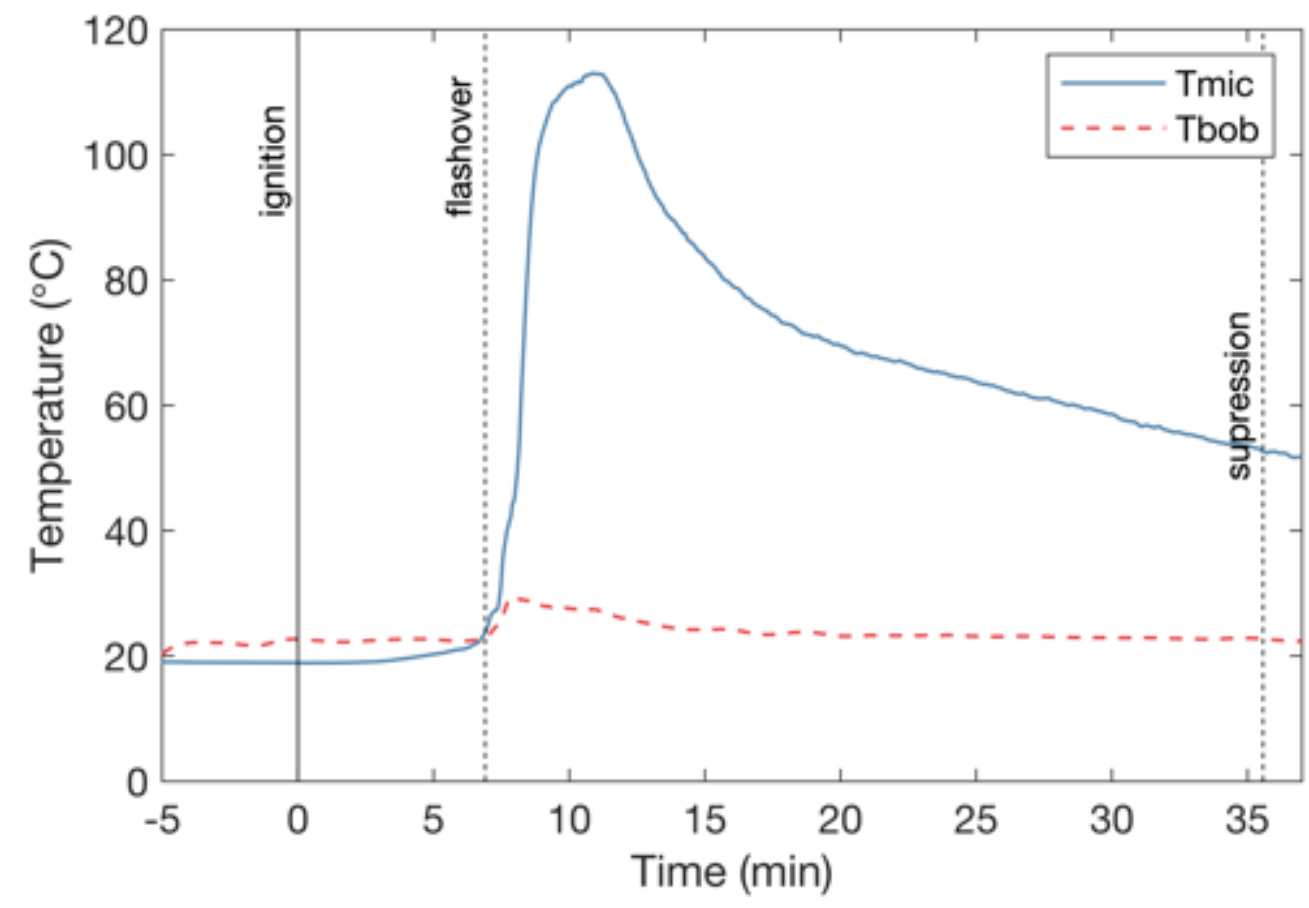

Fig. 33. Test 1 - Temperatures measured using thermocouples at the audio microphone embedded in the compartment wall and in the outflow of the cooling water for the Burn Observation Bubble. 


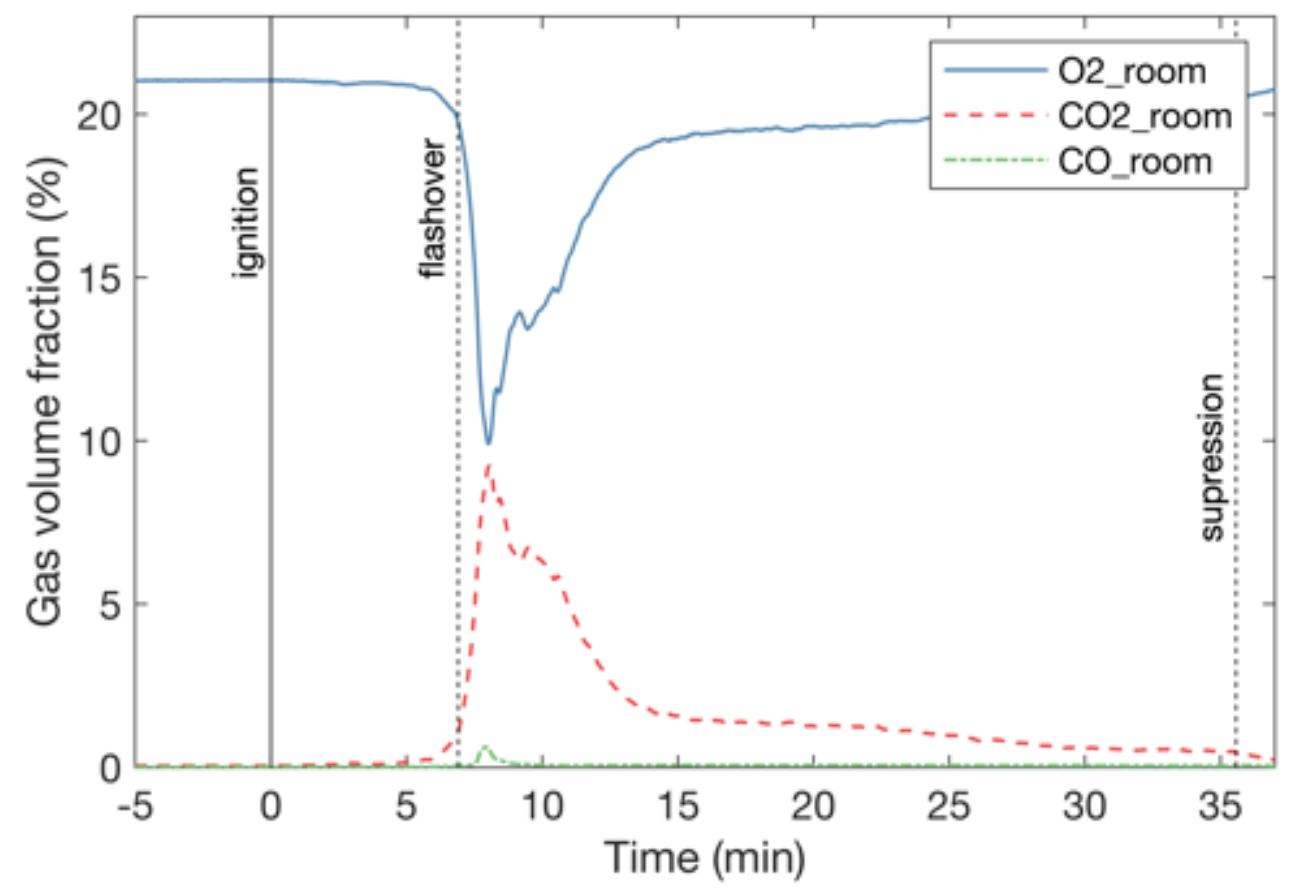

Fig. 34. Test $1-\mathrm{O}_{2}, \mathrm{CO}_{2}$ and $\mathrm{CO}$ concentrations in the upper gas layer inside the compartment. 


\section{Appendix C: Data for Test 2}

Remarks:

- Increased covering on the audio microphone embedded in the compartment wall from one to two layers of $25 \mathrm{~mm}$ thick thermal ceramic fiber blanket to lower peak temperature.

- Peak in ceiling temperature (Tceiling) in Fig. 41 just prior to ignition is caused by momentary heating with a propane touch as a visual marker for synchronizing the 360-degree video and measured data.

- The borosilicate glass dome on the Burn Observation Bubble (BOB) shattered shortly after compartment flashover when it was hit by a fragment from the smoke detector battery when it overheated and burst. 
3-12-2020-NFRLHRR-RoomTest2

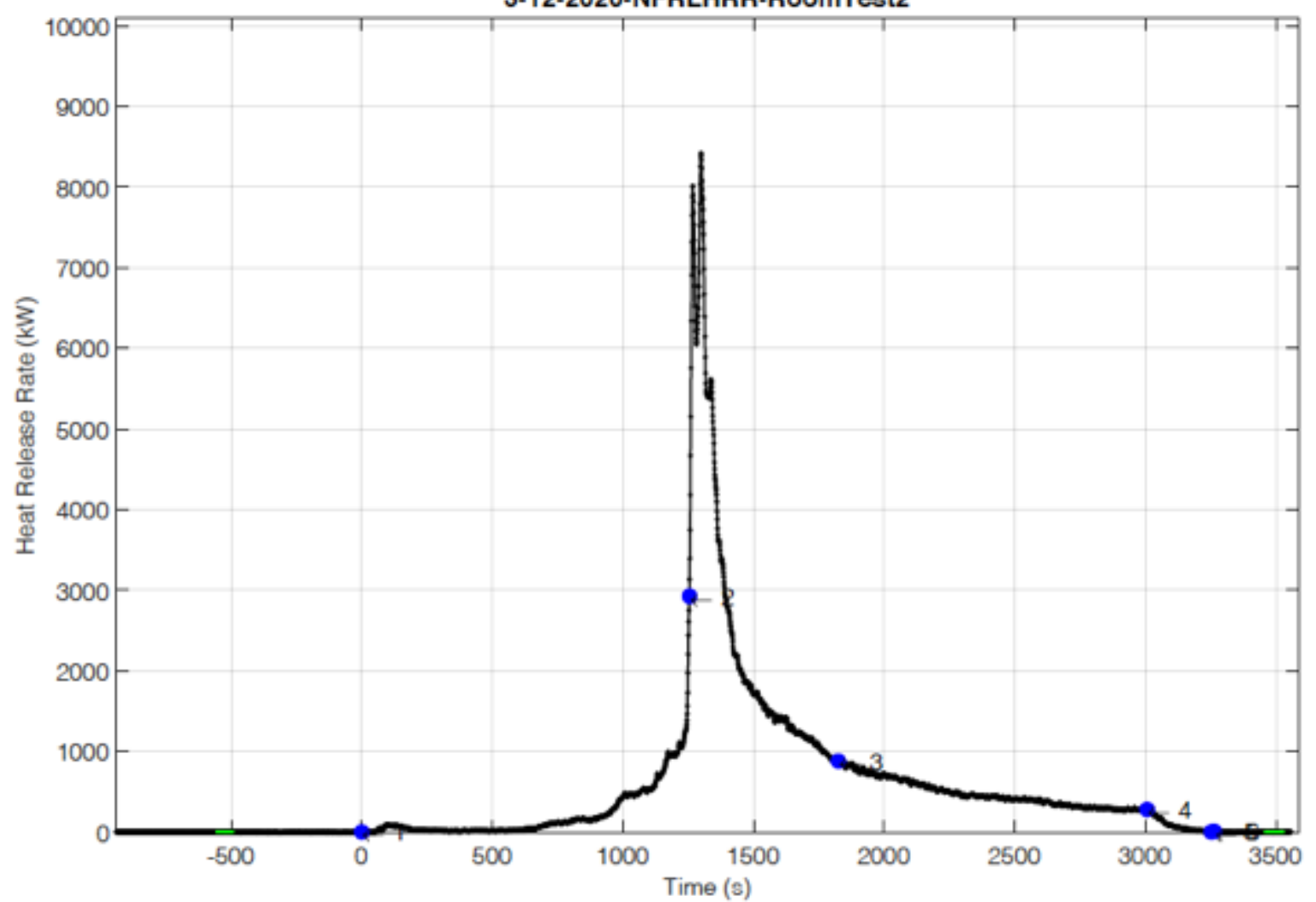

Hood Size $=9(\mathrm{~m}), \mathrm{Ef}=13.1\left(\mathrm{~kJ} / \mathrm{g} \mathrm{O}_{2}\right) \quad, \mathrm{Cf}=1.055$

Fuel Type $=$ Cellulose, Plastic, $\mathrm{HOC}=30(\mathrm{MJ} / \mathrm{kg})$

Peak Heat Release Rate $=8422(\mathrm{~kW})$

Total Heat Release $=2246$ (MJ)

NG Burner Peak HRR - $1(\mathrm{~kW})$

NG Burner Total HR = 0 (MJ)

Exhaust Flow $=46.2+/-0.23(\mathrm{~kg} / \mathrm{s})$

Total Burn Time $=0.904$ (Hrs)

$\mathrm{O}_{2}$ Baseline $=0.20938(\mathrm{Vol} \mathrm{Fr})$

Fuel Mass Burned - TotalHR/HOC - $75(\mathrm{~kg})$

$\mathrm{O}_{2}$ Drift During Test $=14$ (ppmv)

$\mathrm{O}_{2}$ Consumed $=170.38(\mathrm{~kg})$

CO Generated = $3.292(\mathrm{~kg})$

$\mathrm{CO}_{2}$ Generated $=218.78(\mathrm{~kg})$

Soot Generated $=0.838(\mathrm{~kg})$

Test Description:

Furniture flamability in $3.6 \mathrm{~m}$ room. Ignite throw pillow on sofa. BOB 360 in room. PFAS sample in doorway. HCN sample on roof duct.

\begin{tabular}{llll}
\hline Event Count & Time $(\mathrm{s})$ & System Time & Event Description \\
1 & 0 & $3 / 12 / 20209: 46: 09 \mathrm{AM}$ & Ignition \\
2 & 1255 & $3 / 12 / 202010: 07: 04 \mathrm{AM}$ & flashover \\
3 & 1825 & $3 / 12 / 202010: 16: 34 \mathrm{AM}$ & hon sample pumps stopped 1 minute post flashover \\
4 & 3007 & $3 / 12 / 202010: 36: 17 \mathrm{AM}$ & Suppression \\
5 & 3253 & $3 / 12 / 202010: 40: 24 \mathrm{AM}$ & Fire Out \\
6 & 3264 & $3 / 12 / 202010: 40: 33 \mathrm{AM}$ & room clear
\end{tabular}

Fig. 35. Test 2 - Summary report file generated by the NFRL calorimetry system. 


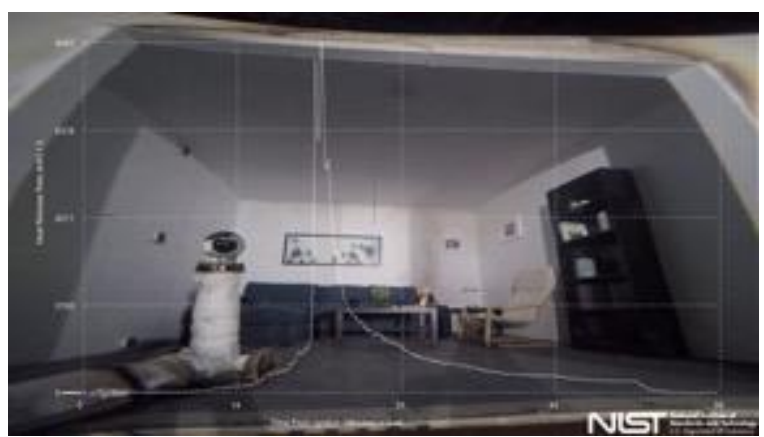

(a)

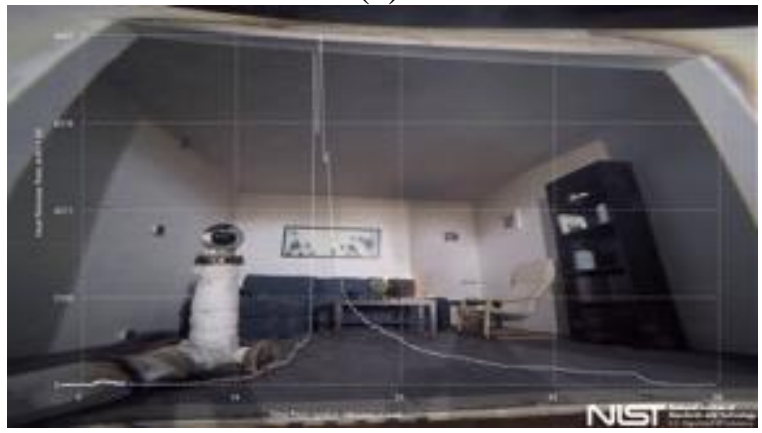

(c)

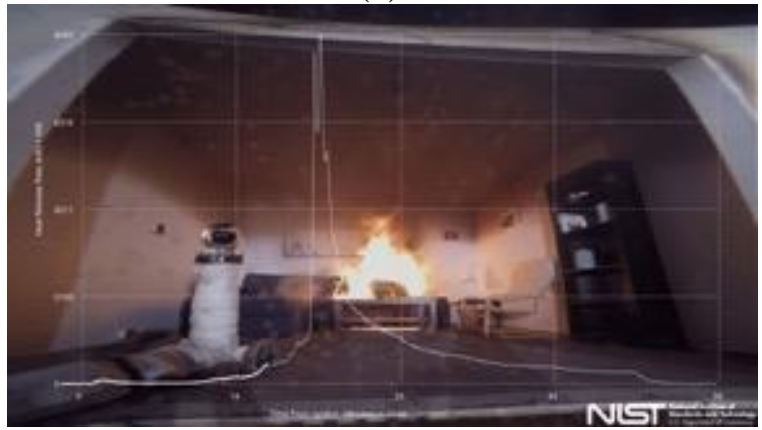

(e)

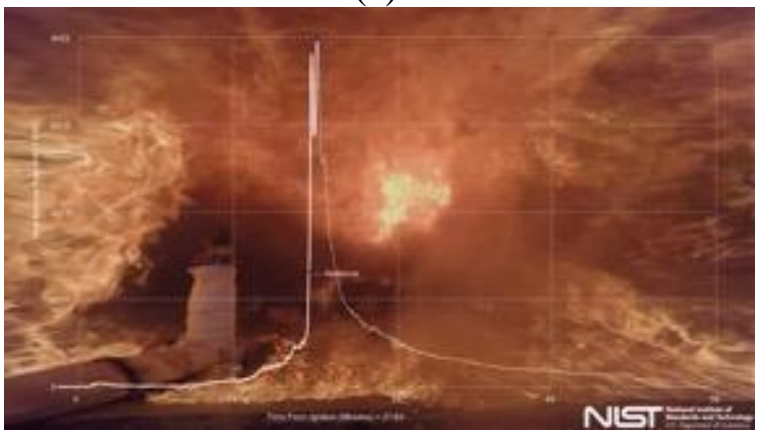

(g)

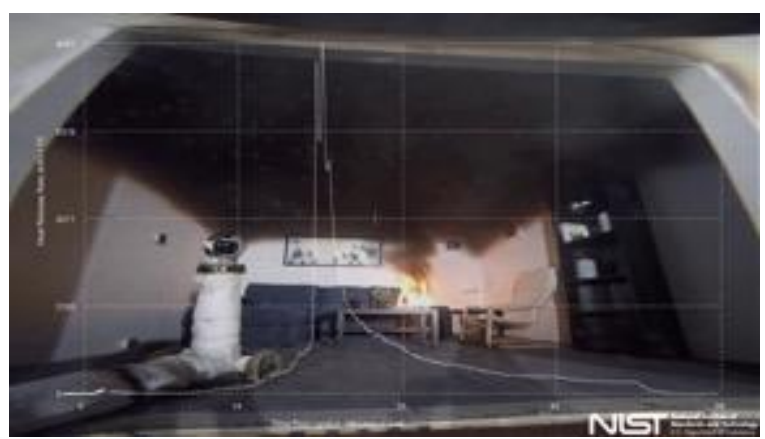

(b)

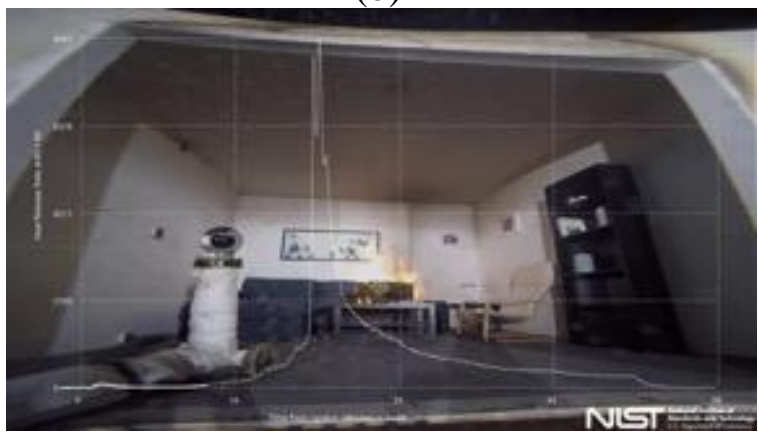

(d)

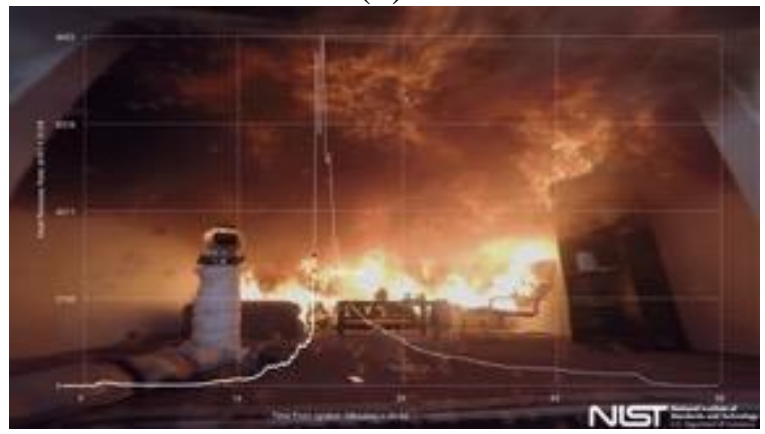

(f)

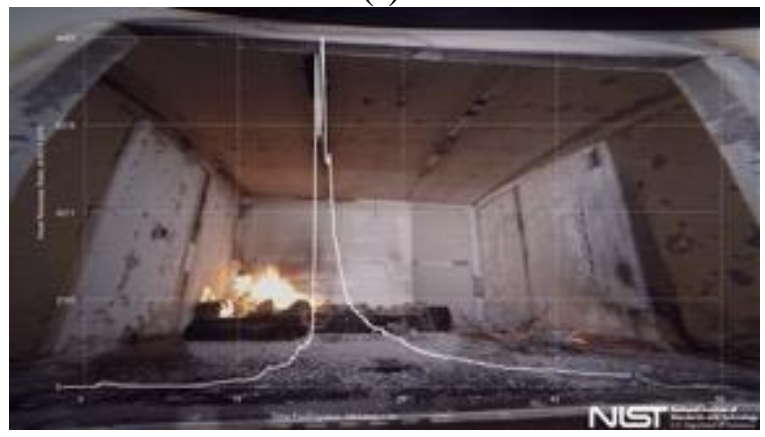

(h)

Fig. 36. Test 2 - Video snapshots with heat release rate curve overlaid. Times are relative to fire ignition: (a) just after ignition; (b) $2.02 \mathrm{~min}$; (c) $4.02 \mathrm{~min}$; (d) $11.68 \mathrm{~min}$; (e) $17.05 \mathrm{~min}$; (f) $20.92 \mathrm{~min}$ (near flashover); (g) $21.63 \mathrm{~min}$ (near peak HRR); (h) $50 \mathrm{~min}$ (just prior to fire suppression). 


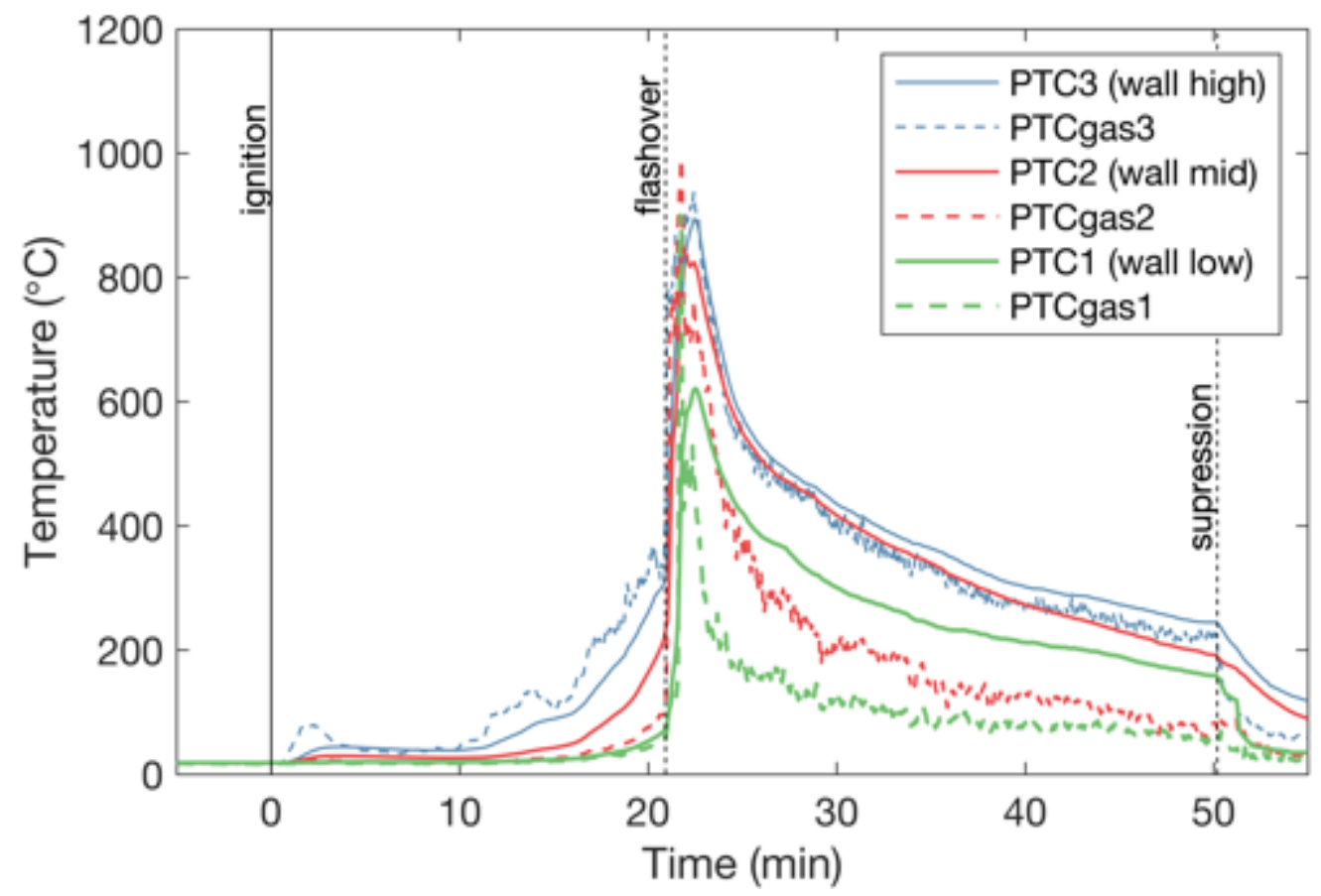

Fig. 37. Test 2 - Temperature measured by the plate thermocouples (PTC) and co-located bare bead thermocouples (PTCgas) on the compartment wall.

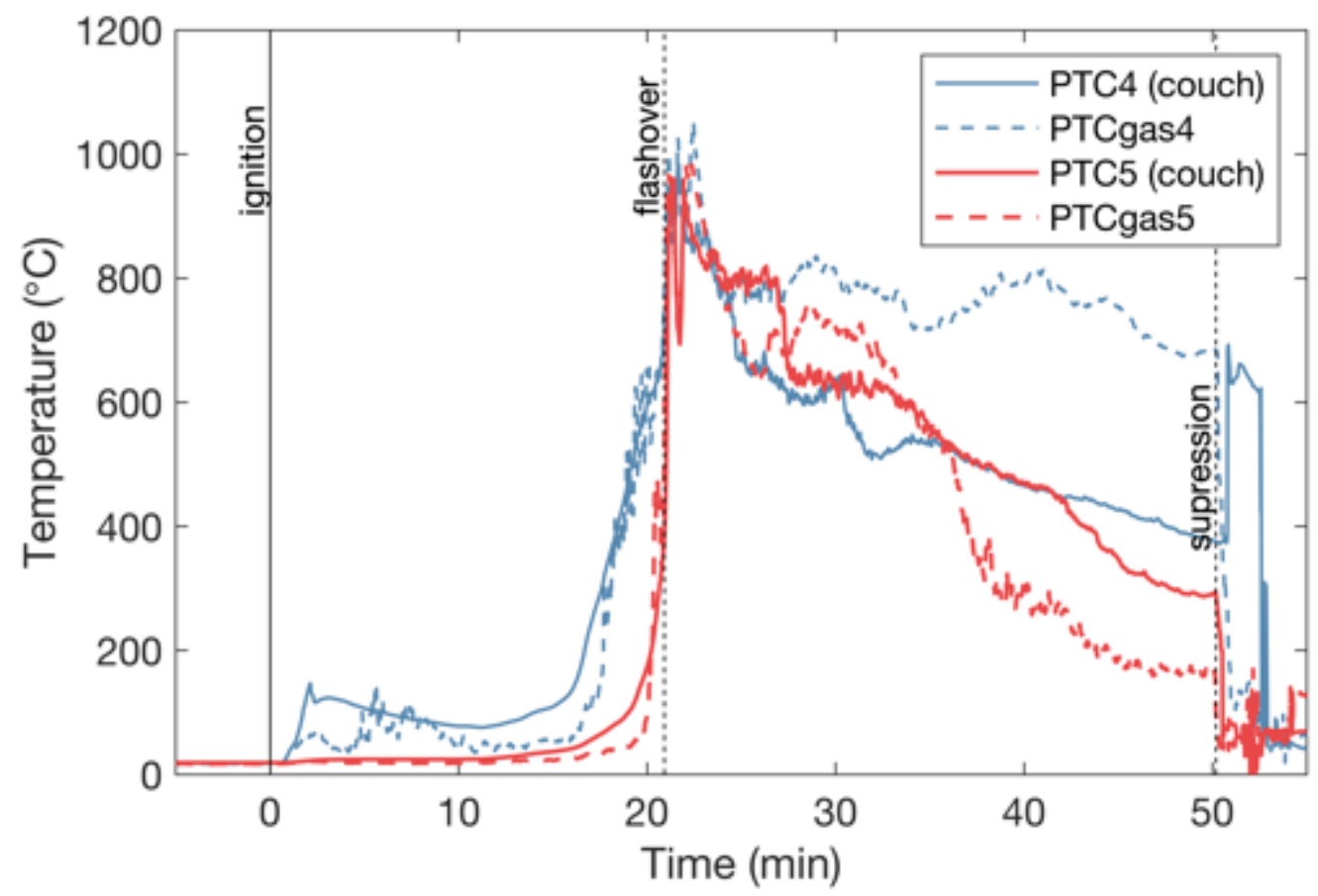

Fig. 38. Test 2 - Temperature measured by the plate thermocouples (PTC) and co-located bare bead thermocouples (PTCgas) on the couch. 


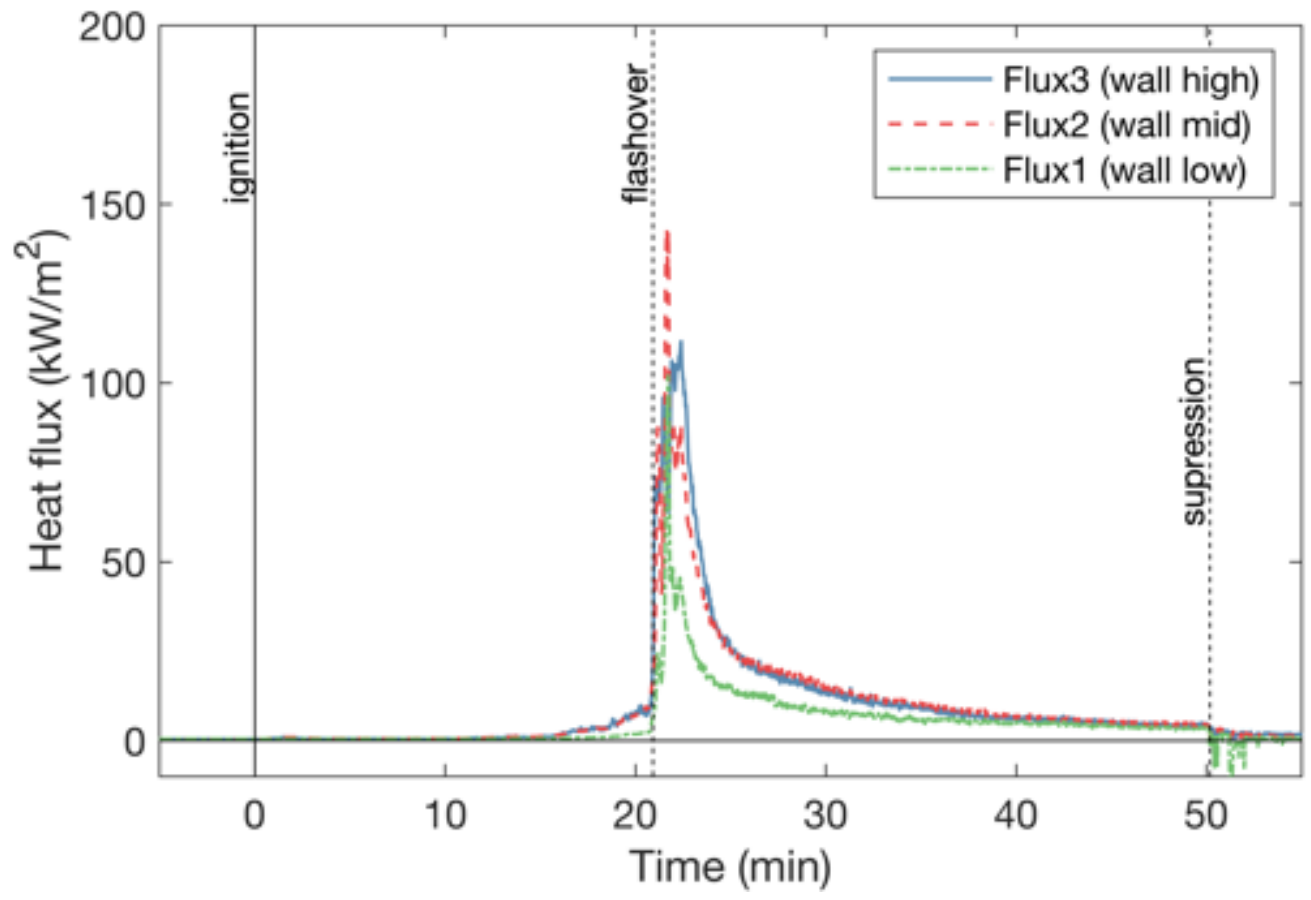

Fig. 39. Test 2 - Heat flux calculated for the plate thermocouples on the compartment wall.

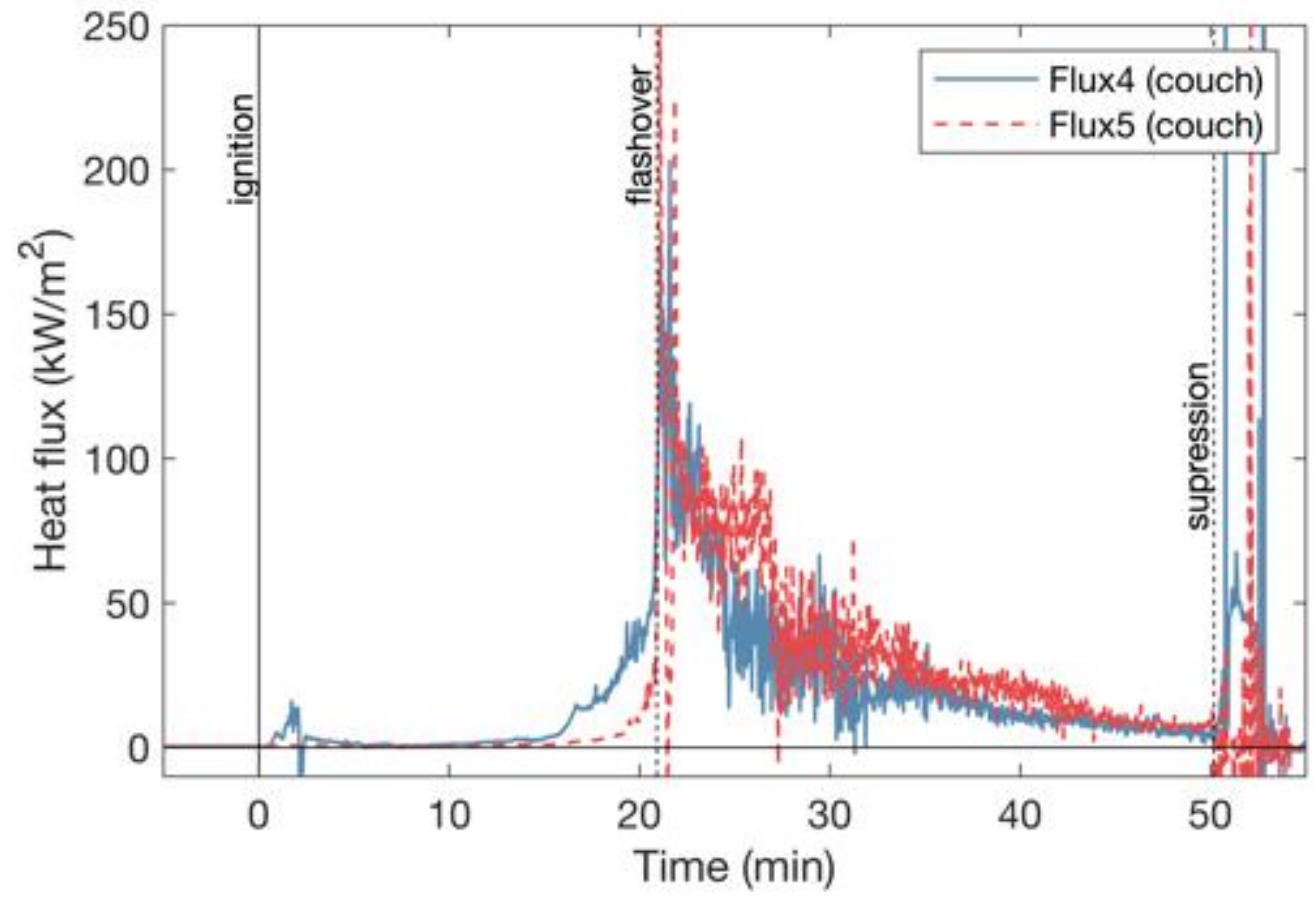

Fig. 40. Test 2 - Heat flux calculated for the plate thermocouples on the couch. 


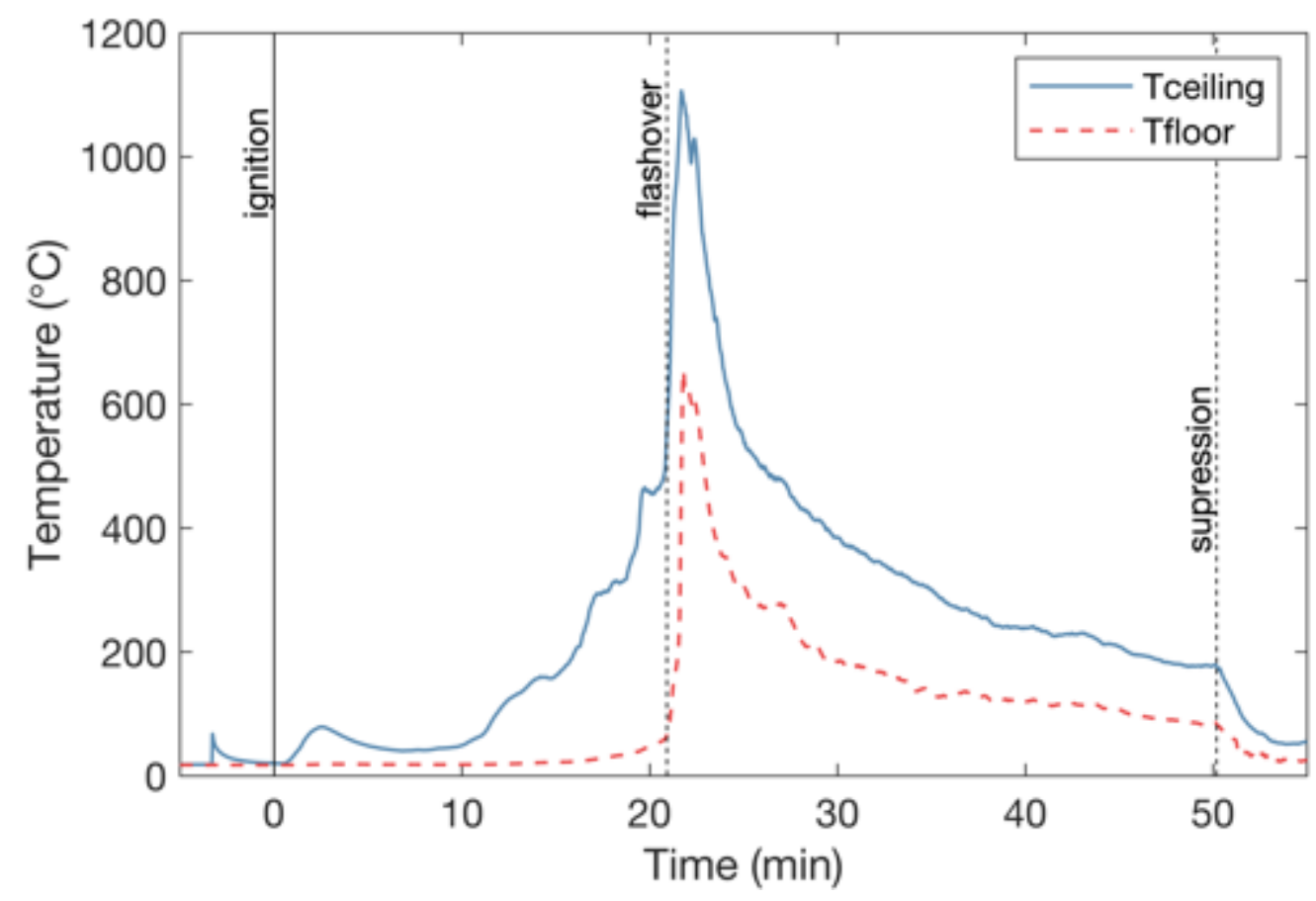

Fig. 41. Test 2 - Temperatures measured using shielded thermocouples near the ceiling and floor of the compartment.

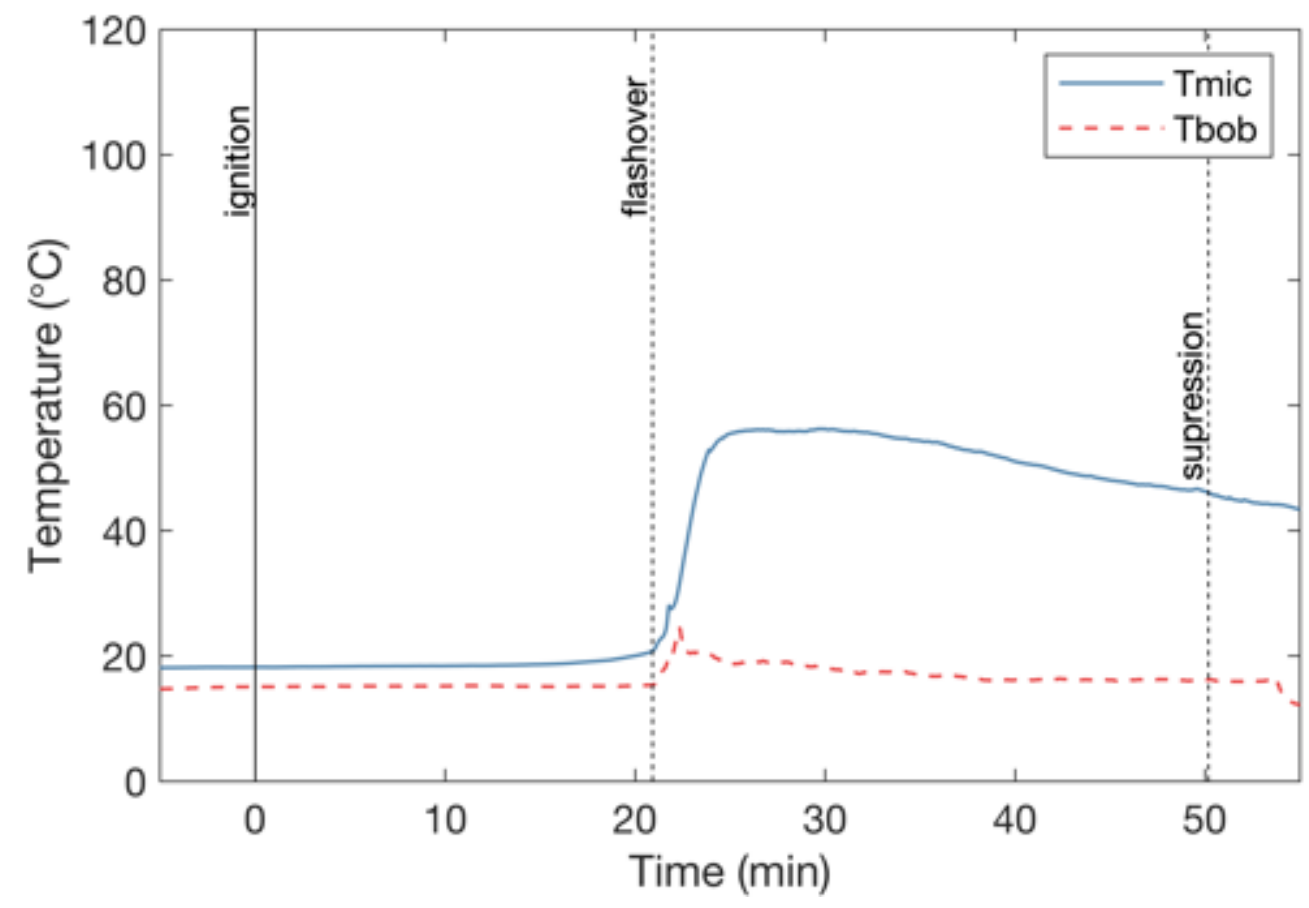

Fig. 42. Test 2 - Temperatures measured using thermocouples at the audio microphone embedded in the compartment wall and in the outflow of the cooling water for the Burn Observation Bubble. 


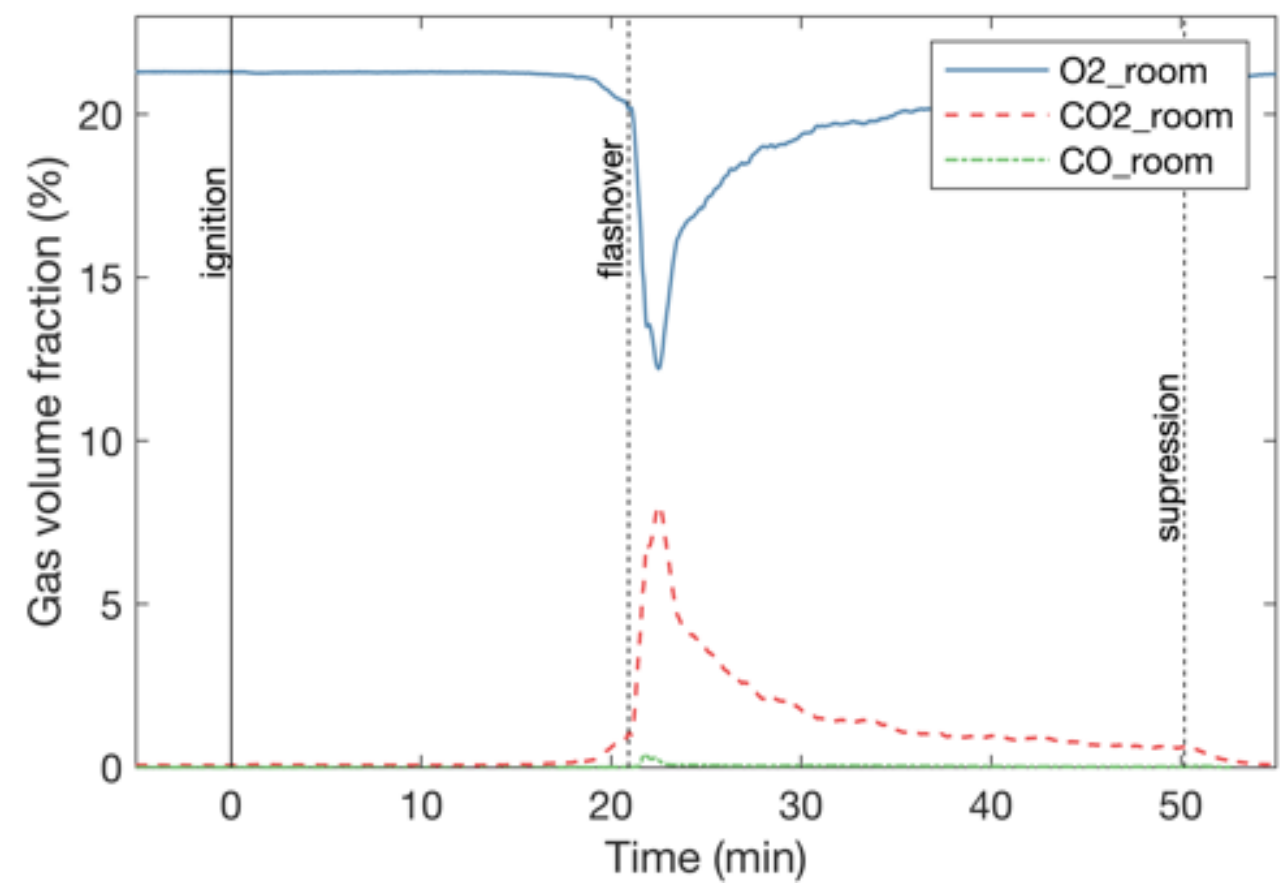

Fig. 43. Test $2-\mathrm{O}_{2}, \mathrm{CO}_{2}$ and $\mathrm{CO}$ concentrations in the upper gas layer inside the compartment. 


\section{Appendix D: Data for Test 3}

Remarks:

- Used one layer of $25 \mathrm{~mm}$ thick thermal ceramic fiber blanket and one layer of $10 \mathrm{~mm}$ thick silica coated aramid fabric (lower density) in an attempt to lower the peak temperature of the audio microphone embedded in the compartment wall without attenuating too much sound.

- Peak in ceiling temperature (Tceiling) in Fig. 50 just prior to ignition is caused by momentary heating with a propane touch as a visual marker for synchronizing the 360 degree video and measured data.

- The borosilicate glass dome on the Burn Observation Bubble (BOB) shattered shortly after compartment flashover presumably due to too high thermal strain gradients. 


\section{3-16-2020-NFRLHRR-RoomTest3}

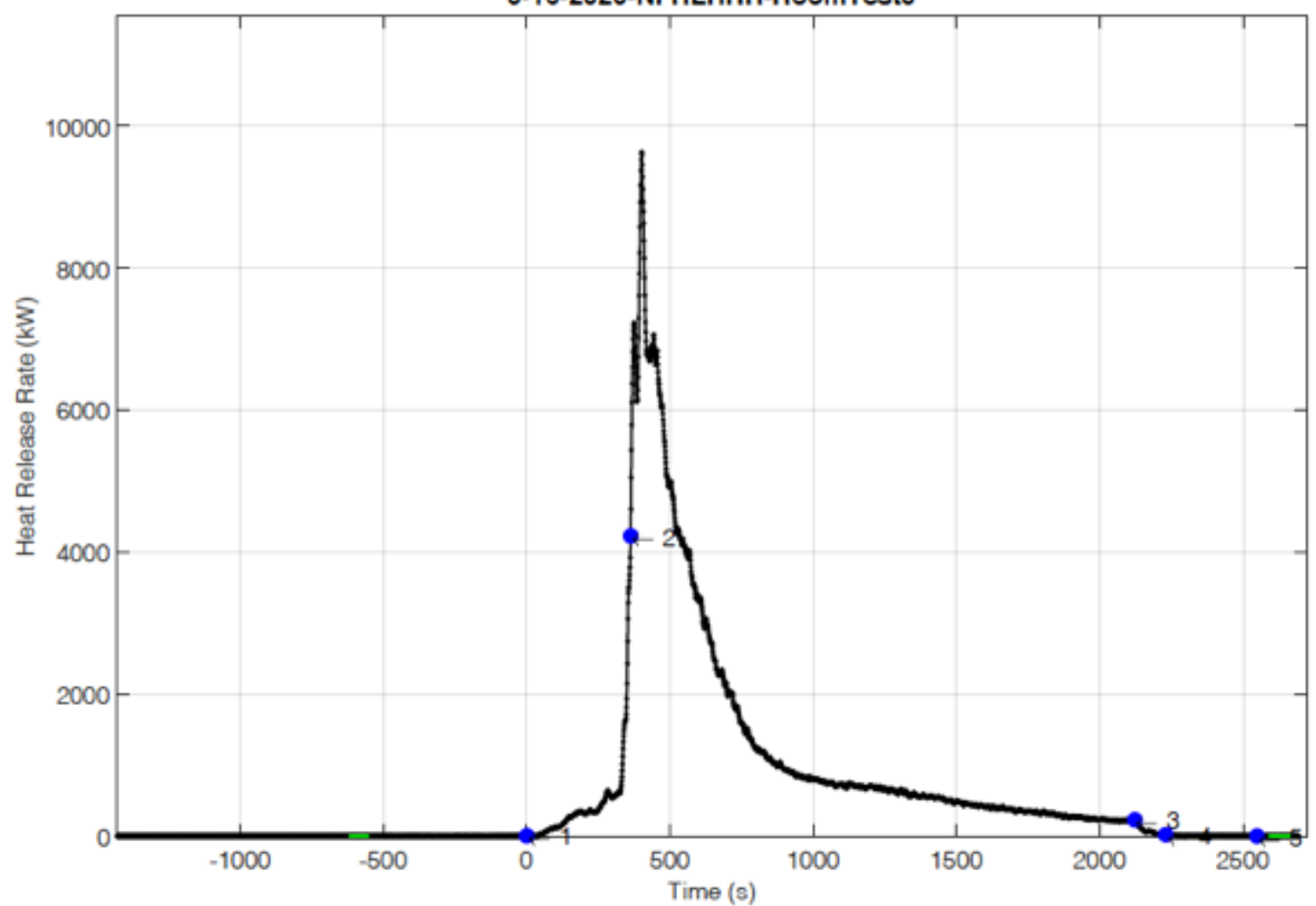

Hood Size $=9(\mathrm{~m})$, Ef $=13.1\left(\mathrm{~kJ} / \mathrm{g} \mathrm{O}_{2}\right) \quad, \mathrm{Cf}=1.055$

Fuel Type - Cellulose, Plastic, HOC = $30(\mathrm{MJ} / \mathrm{kg})$

Peak Heat Release Rate $=9639(\mathrm{~kW})$

Total Heat Release $=2636(\mathrm{MJ})$

NG Burner Peak HRR - 1 (kW)

NG Burner Total HR $=0$ (MJ)

Exhaust Flow $=47.4+1-0.48(\mathrm{~kg} / \mathrm{s})$

Total Burn Time $=0.619$ (Hrs)

$\mathrm{O}_{2}$ Baceline $=0.20938$ ( Vol Fr)

Fuel Mass Burned - TotalHR/HOC - $88(\mathrm{~kg})$

$\mathrm{O}_{2}$ Drift During Test $=11$ (ppmv)

$\mathrm{O}_{2}$ Consumed $=200.44(\mathrm{~kg})$

CO Generated = $3.913(\mathrm{~kg})$

$\mathrm{CO}_{2}$ Generated = $258.53(\mathrm{~kg})$

Soot Generated = $2.039(\mathrm{~kg})$

Test Description:

Furniture flamability in $3.6 \mathrm{~m}$ room. Ignite throw pillow on sofa. BOB 360 in room. PFAS sample in doorway. HCN sample on roof duct.

$\begin{array}{llll}\text { Event Count } & \text { Time }(s) & \text { System Time } & \text { Event Description } \\ 1 & 0 & 3 / 16 / 20202: 30: 28 \mathrm{PM} & \text { Ignition } \\ 2 & 363 & 3 / 16 / 20202: 36: 26 \mathrm{PM} & \text { flashover } \\ 3 & 2122 & 3 / 16 / 20203: 05: 51 \mathrm{PM} & \text { Suppression } \\ 4 & 2230 & 3 / 16 / 20203: 07: 38 \mathrm{PM} & \text { Fire Out } \\ 5 & 2548 & 3 / 16 / 20203: 12: 56 \mathrm{PM} & \text { room clear }\end{array}$

Fig. 44. Test 3 - Summary report file generated by the NFRL calorimetry system. 


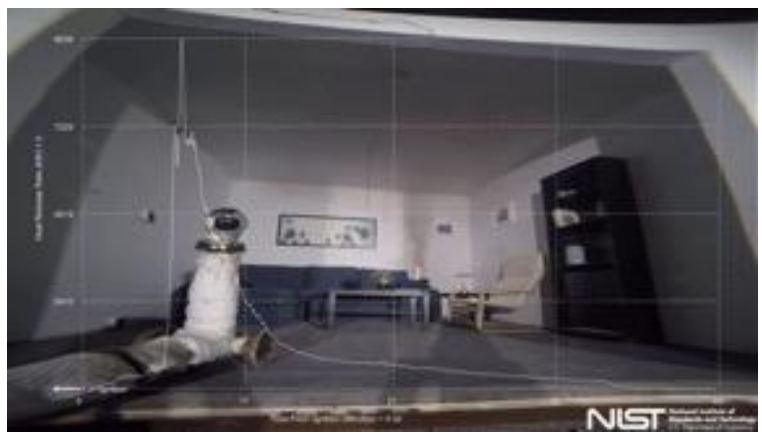

(a)

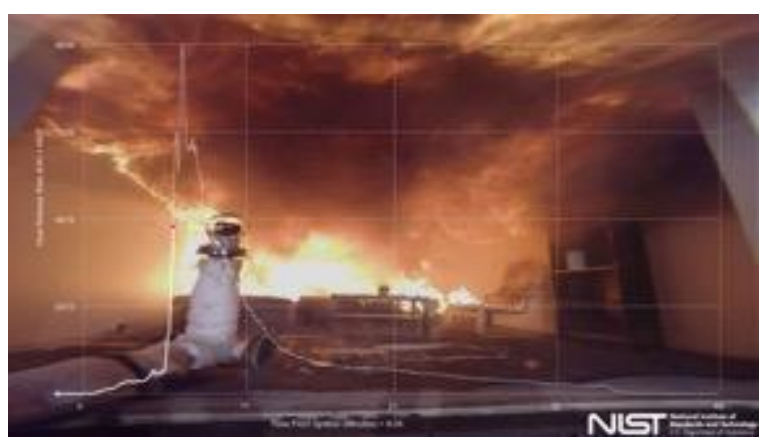

(c)

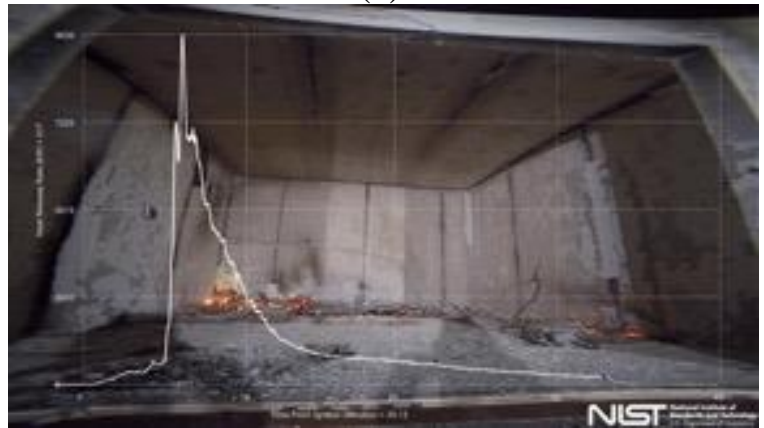

(e)

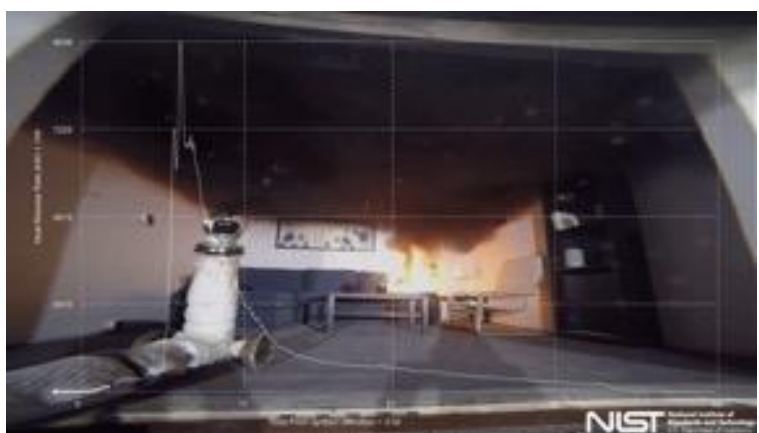

(b)

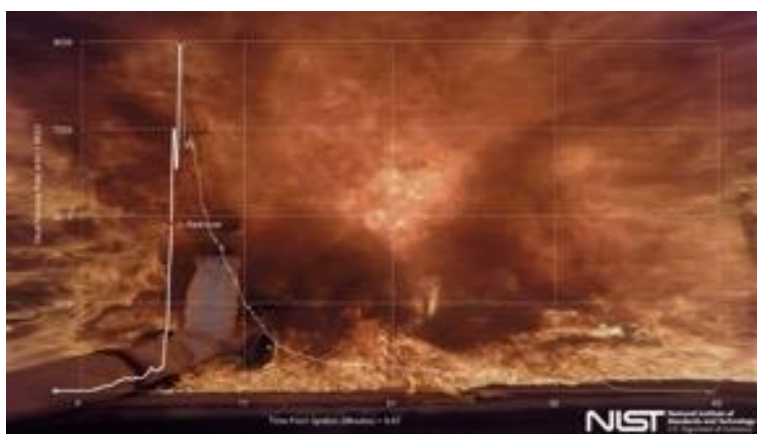

(d)

Fig. 45. Test 3 - Video snapshots with heat release rate curve overlaid. Times are relative to fire ignition: (a) just after ignition; (b) $2.02 \mathrm{~min}$; (c) 6.05 min (near flashover); (d) 6.67 min (near peak HRR); (e) 35.13 min (just prior to fire suppression). 


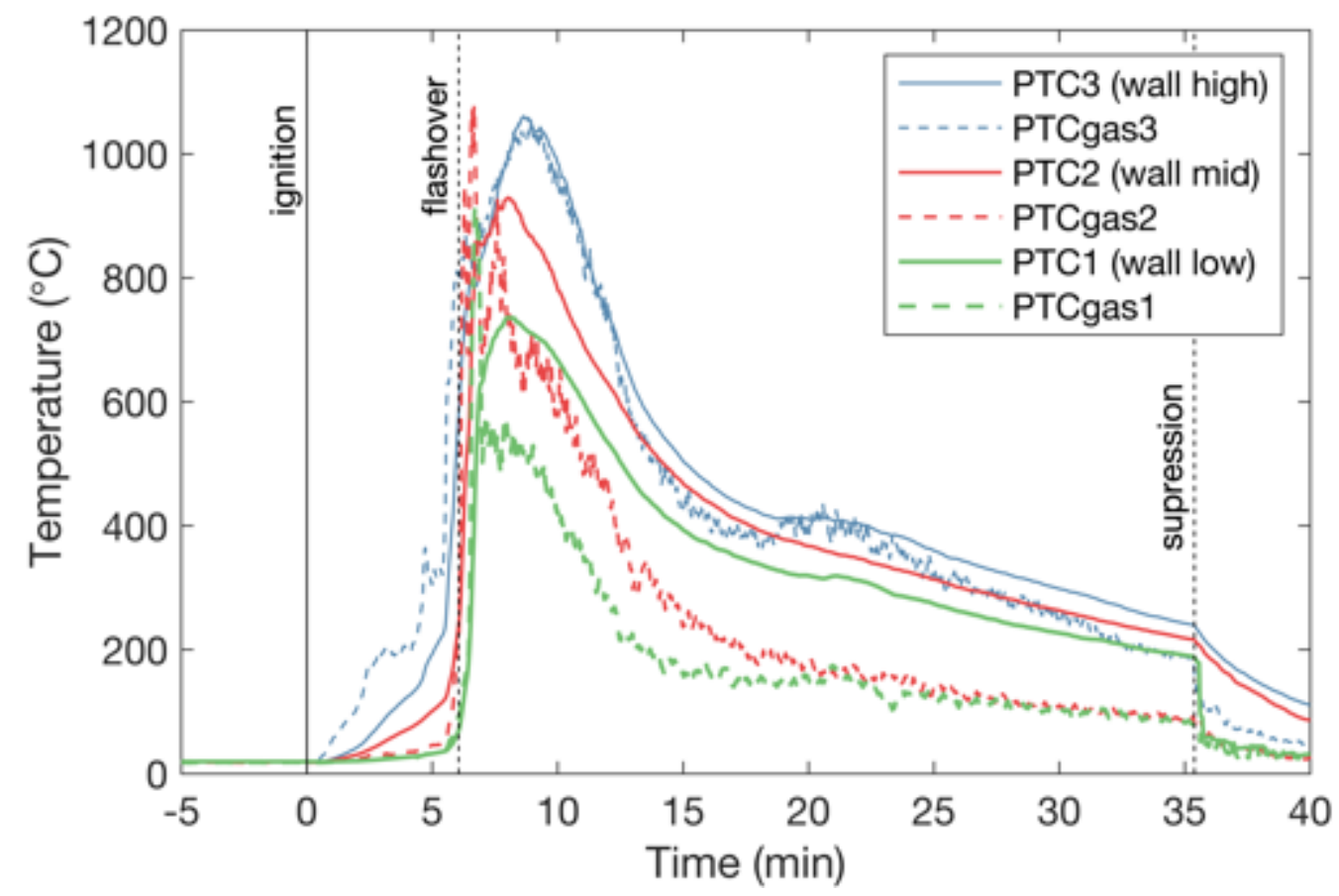

Fig. 46. Test 3 - Temperature measured by the plate thermocouples (PTC) and co-located bare bead thermocouples (PTCgas) on the compartment wall.

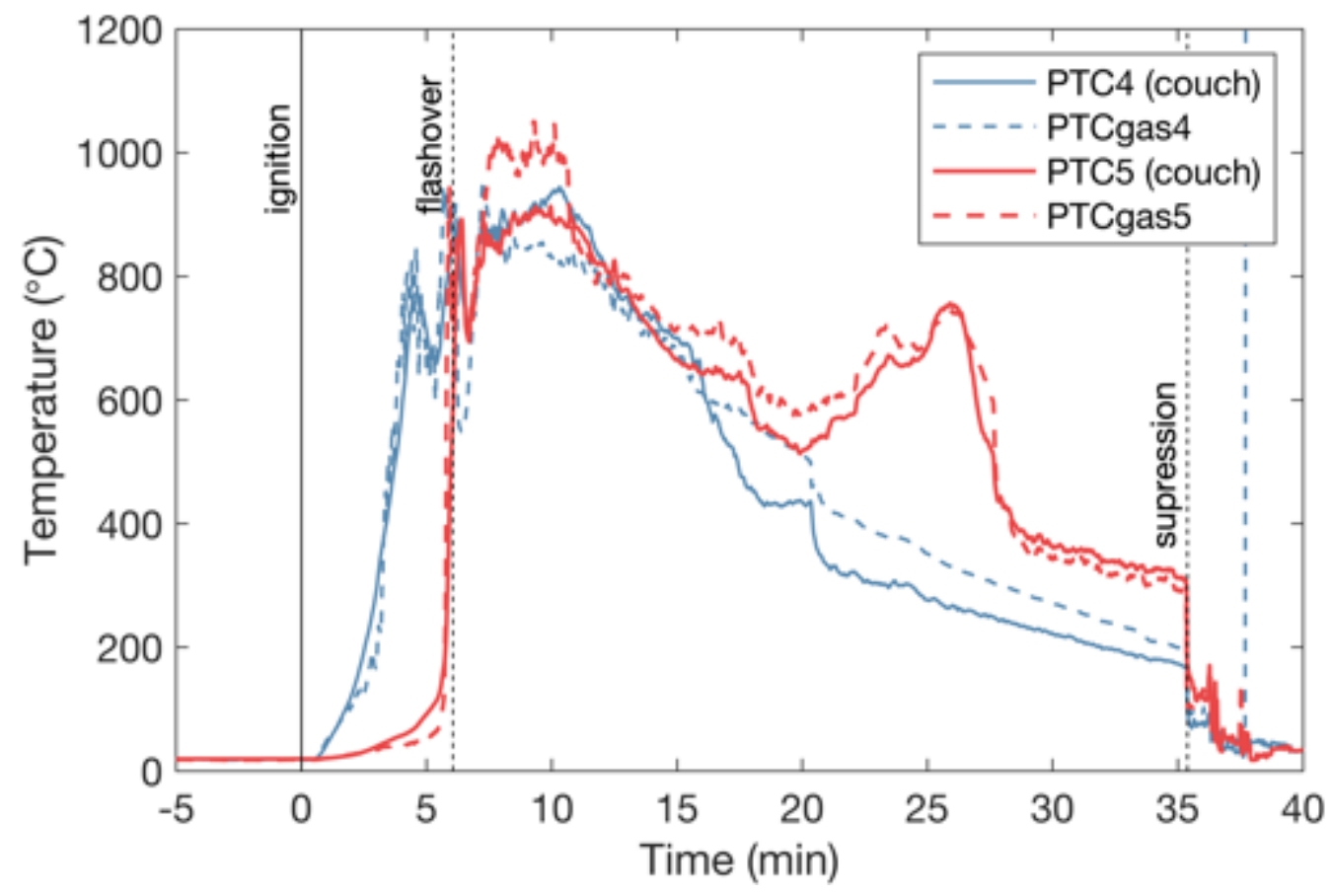

Fig. 47. Test 3 - Temperature measured by the plate thermocouples (PTC) and co-located bare bead thermocouples (PTCgas) on the couch. 


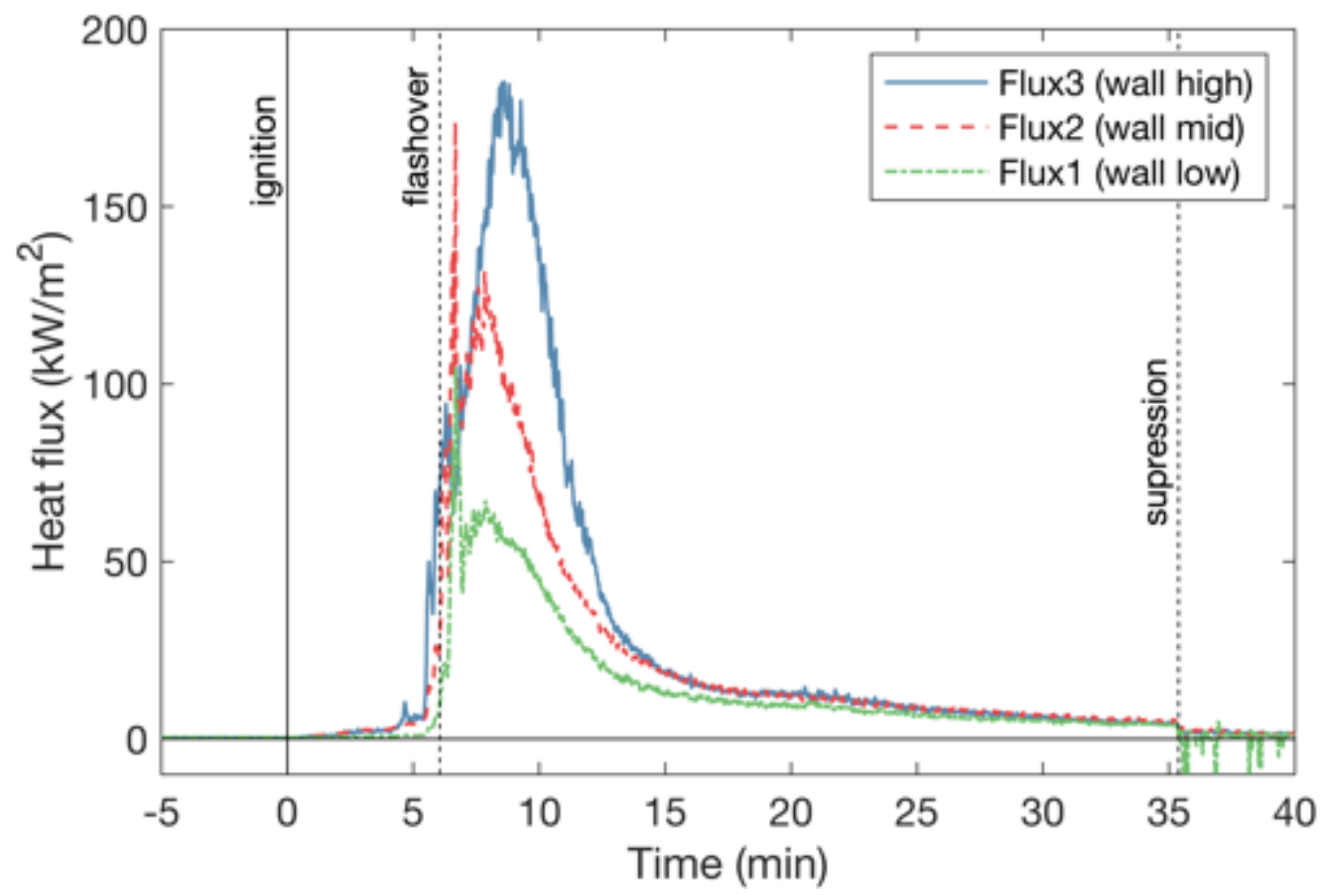

Fig. 48. Test 3 - Heat flux calculated for the plate thermocouples on the compartment wall.

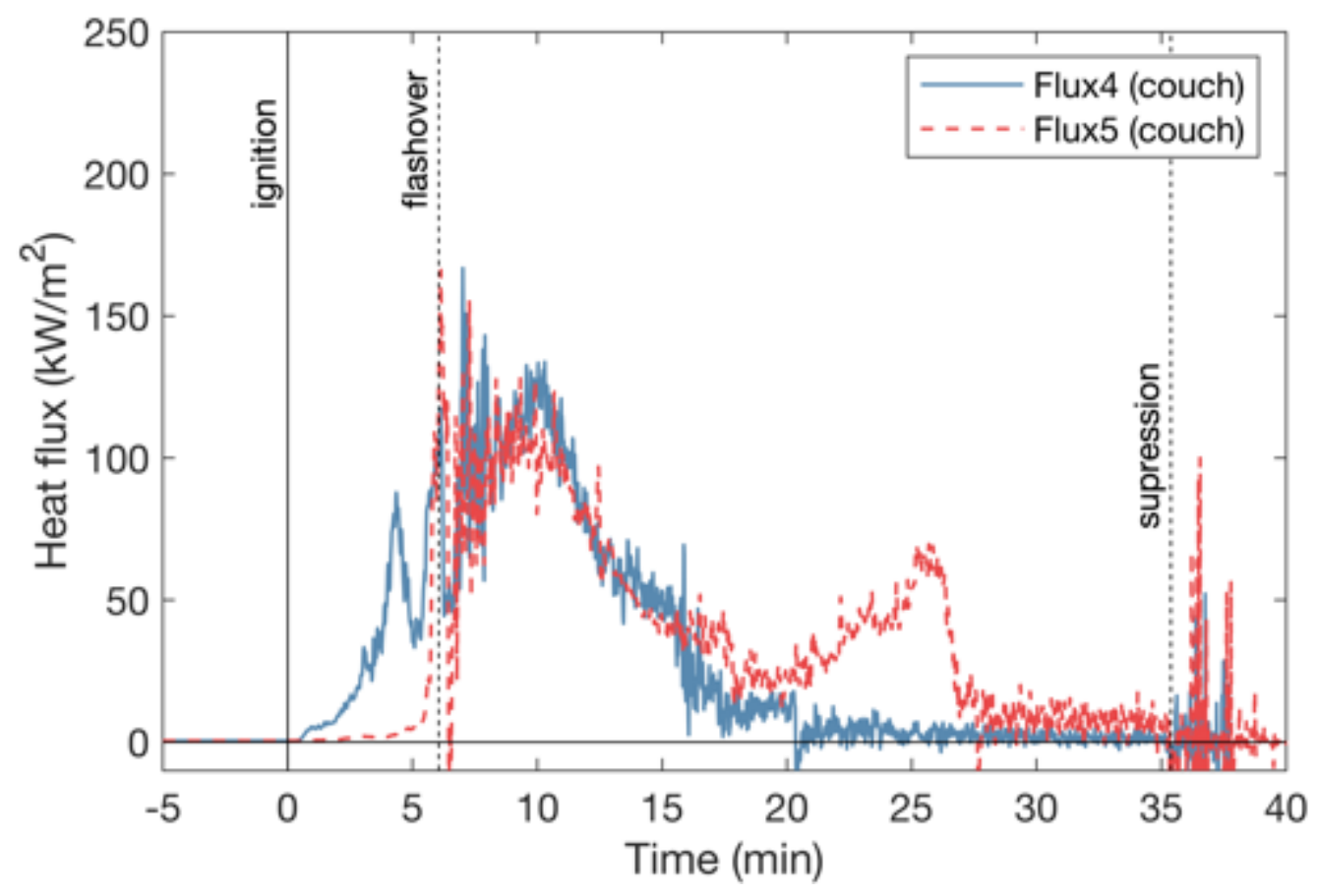

Fig. 49. Test 3 - Heat flux calculated for the plate thermocouples on the couch. 


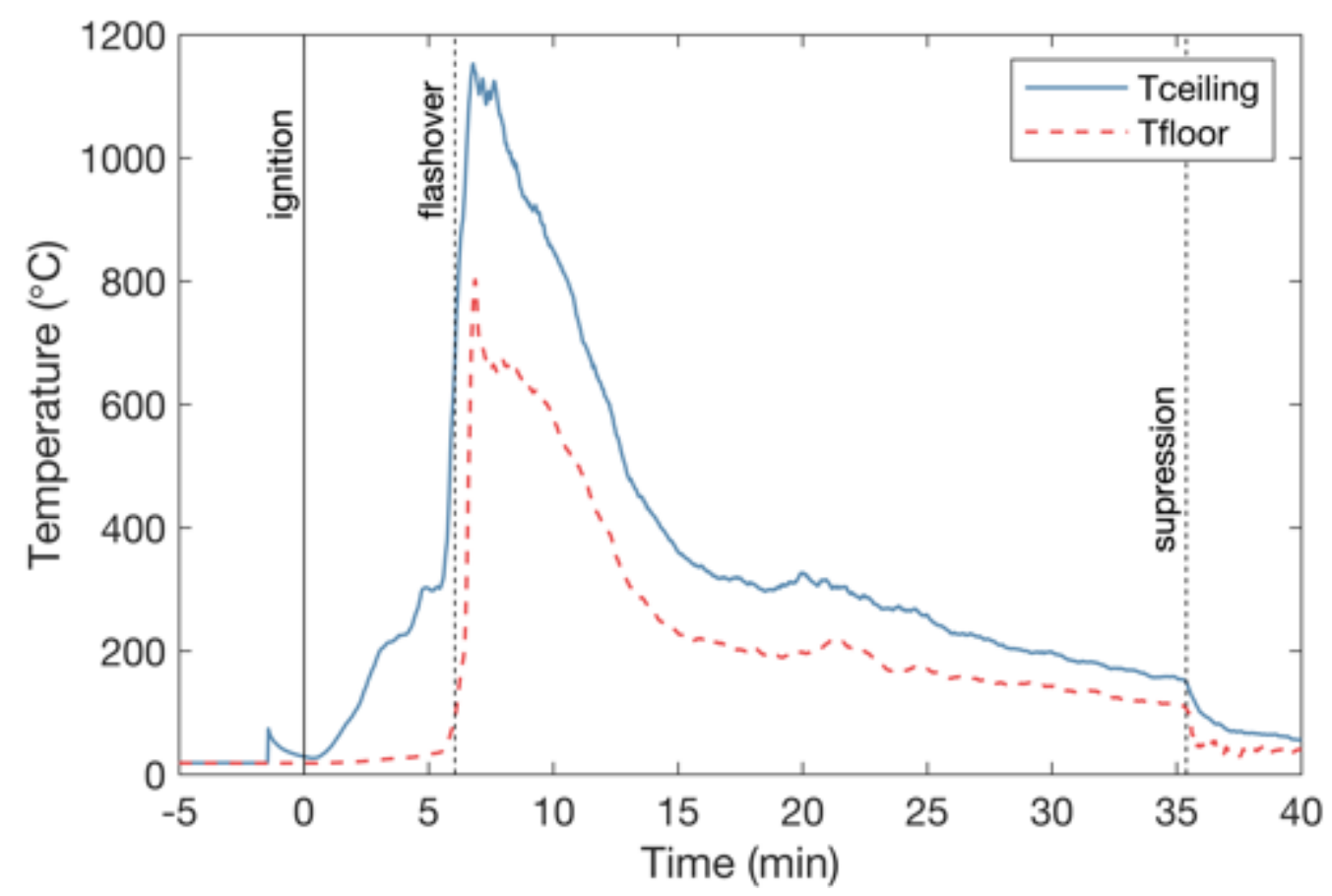

Fig. 50. Test 3 - Temperatures measured using shielded thermocouples near the ceiling and floor of the compartment.

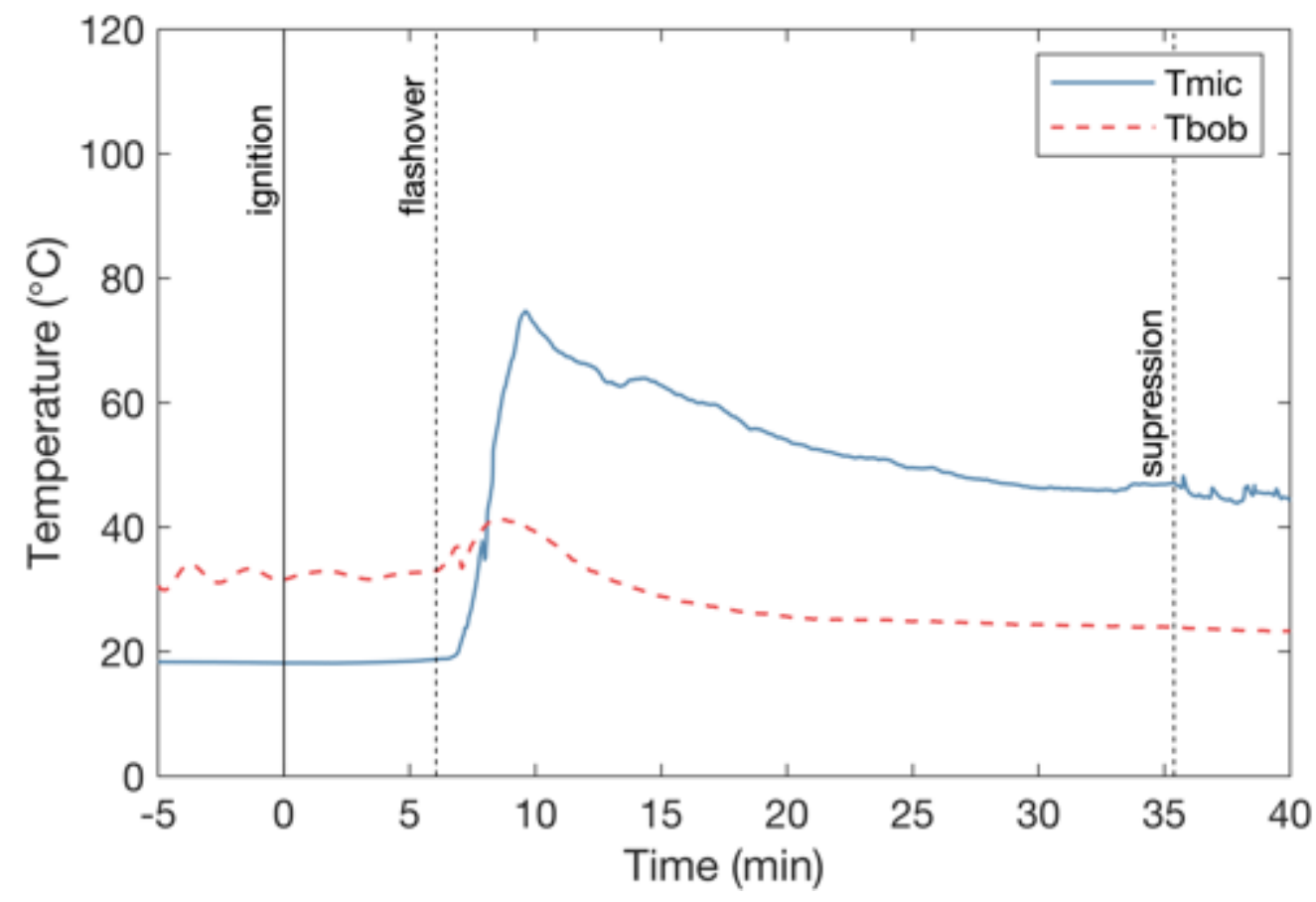

Fig. 51. Test 3 - Temperatures measured using thermocouples at the audio microphone embedded in the compartment wall and in the outflow of the cooling water for the Burn Observation Bubble. 


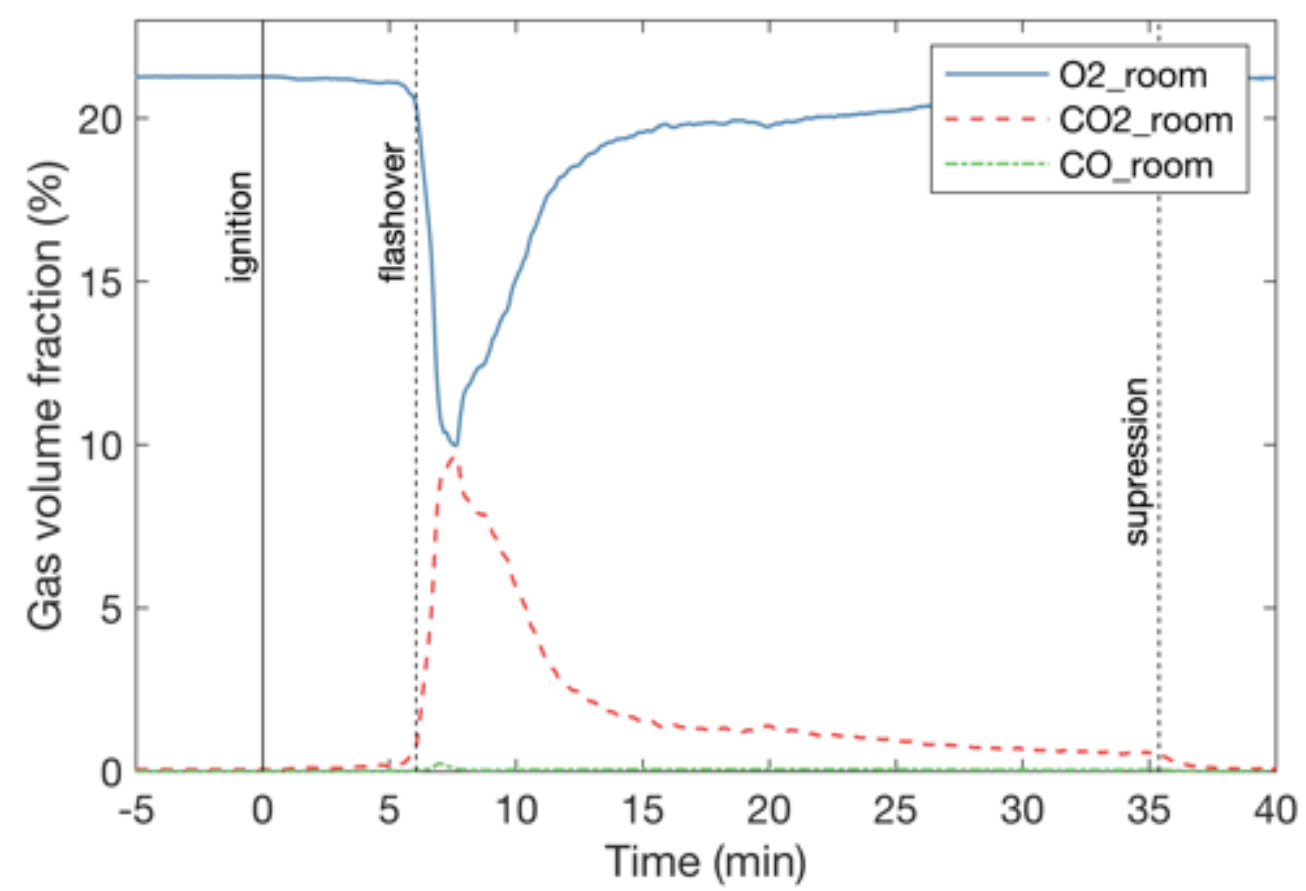

Fig. 52. Test $3-\mathrm{O}_{2}, \mathrm{CO}_{2}$ and $\mathrm{CO}$ concentrations in the upper gas layer inside the compartment. 